University of Louisville

ThinkIR: The University of Louisville's Institutional Repository

Electronic Theses and Dissertations

$12-2009$

\title{
The role of PKC-epsilon in models of alcohol- and toxin-induced liver disease.
}

J. Phillip Kaiser 1981-

University of Louisville

Follow this and additional works at: https://ir.library.louisville.edu/etd

\section{Recommended Citation}

Kaiser, J. Phillip 1981-, "The role of PKC-epsilon in models of alcohol- and toxin-induced liver disease." (2009). Electronic Theses and Dissertations. Paper 720.

https://doi.org/10.18297/etd/720

This Doctoral Dissertation is brought to you for free and open access by ThinkIR: The University of Louisville's Institutional Repository. It has been accepted for inclusion in Electronic Theses and Dissertations by an authorized administrator of ThinkIR: The University of Louisville's Institutional Repository. This title appears here courtesy of the author, who has retained all other copyrights. For more information, please contact thinkir@louisville.edu. 
THE ROLE OF PKC-EPSILON IN MODELS OF ALCOHOL- AND TOXIN-

INDUCED LIVER DISEASE

By

\author{
J. Phillip Kaiser \\ B.S., Texas A\&M, 2004 \\ M.S., University of Louisville, 2007
}

\begin{abstract}
A Dissertation
Submitted to the Faculty of the

Graduate School of the University of Louisville

In Partial Fulfillment of the Requirements

for the Degree of
\end{abstract}

Doctor of Philosophy

Department of Pharmacology and Toxicology

University of Louisville

Louisville, Kentucky

December 2009 
Copyright 2009 by J. Phillip Kaiser

All Rights Reserved 
THE ROLE OF PKC-EPSILON IN MODELS OF ALCOHOL- AND TOXIN-

INDUCED LIVER DISEASE

\author{
BY \\ J. Phillip Kaiser \\ B.S., Texas A\&M, 2004 \\ M.S., University of Louisville, 2007 \\ A Dissertation Approved on
}

September 30, 2009

By the following Dissertation Committee:

Dr. Gavin E. Arteel (Dissertation Mentor)

Dr. Jill Suttles

Dr. Aruni Bhatnagar

Dr. Craig J. McClain

Dr. William M. Pierce, Jr. 


\section{DEDICATION}

This dissertation is dedicated to my parents Darlene and Charlie Kaiser who have given me the best chances for educational growth; also to my wife Natalie Kaiser, for her support and patience throughout my graduate career. Furthermore, this dissertation is also dedicated to my brother Andrew Kaiser for supporting me over the years and for his comical relief during stressful times of my graduate career. Finally, further gratitude goes to all other friends, family, and loved ones who have supported me throughout this process. 


\section{ACKNOWLEDGEMENTS}

I would like to thank my dissertation advisor Dr. Gavin E. Arteel for his patience and for his sound advice on my journey to becoming an independent researcher. I would also like to thank my other committee members, Dr. Aruni Bhatnagar, Dr. Craig McClain, Dr.William M. Pierce Jr, and Dr. Jill Suttles for their assistance. Of these members, I would especially like to thank Dr.

Bhatnagar for supplying the PKCE knockout mice as a kind gift and for his sound advice for measuring hepatic DAG and fatty acid levels. I would also like to thank J. David Hoetker for the electron spray ionization/ mass spectrometry work and Dr. Jeff Lesgards for his assistance in measuring free fatty acids with gas chromatography. Special thanks go to my laboratory colleagues (past and present) and especially to Drs Juliane I. Beier and Luping Guo for their help and guidance over the years. I would also like to thank Isis Pharmaceuticals Inc. in particular Dr. Brett Monia for the generous use of the PKCE ASO. Further gratitude goes to Dr. Jun Zhang for graciously performing Western Blots for PKCE.

Much of this work was supported by a grant from the National Institute of Alcohol Abuse and Alcoholism (AA003624) and in part, by a predoctoral (F31) fellowship from the National Institute of Alcohol Abuse and Alcoholism (AA017346). 


\title{
ABSTRACT \\ THE ROLE OF PKC-EPSILON IN MODELS OF ALCOHOL- AND TOXIN- INDUCED LIVER DISEASE
}

\author{
J.Phillip Kaiser
}

December 17, 2009

Alcoholic liver disease (ALD) is a serious concern for the world's population. It is one of the leading causes of death and is also a huge economic burden. The biochemical mechanisms responsible for ALD are incompletely understood, therefore there is no FDA approved therapy to treat or reverse liver damage caused by alcohol exposure. Whereas the mechanisms behind ALD are poorly understood, the disease progression is well known. The first pathological step of ALD is steatosis followed by inflammation and necrosis; if the insult(s) responsible for the previous pathologies persists, fibrosis and cirrhosis can then develop. In previous experimental studies, preventing alcohol-induced steatosis can protect against further stages of liver damage; thus, understanding the mechanisms responsible for ethanol-induced steatosis may result in a therapy to treat ALD. Previous studies have shown that protein kinase-c epsilon (PKCE) contributes to steatosis owing to a non-alcoholic high fat diet. However, the role of PKC $\varepsilon$ in alcohol-induced fatty liver is not yet known. Therefore, the goal of this work was to investigate the role of PKC $\varepsilon$ in not only steatosis, but also in later stages of liver disease (i.e. steatohepatitis and fibrosis). It was determined in 
both acute and chronic mouse models of ethanol exposure that PKC $\varepsilon$ plays a causal role in steatosis owing to ethanol. Surprisingly, blocking steatosis had no apparent protective effect on inflammation and necrosis in the chronic model, which implies that these pathologies may have mechanistic distinctions. Lastly, it was shown that PKCE plays a pivotal role in the development of fibrosis caused by chronic exposure to carbon tetrachloride $\left(\mathrm{CCl}_{4}\right)$. In summary, it appears that PKC $\varepsilon$ plays a causal role in the early (steatosis) and late (fibrosis) stages of liver disease. The inhibition of $P K C \varepsilon$ could therefore result in a viable therapeutic means of preventing ALD. 


\section{TABLE OF CONTENTS}

PAGE

DEDICATION

ACKNOWLEDGEMENTS

\section{iii}

ABSTRACT

LIST OF FIGURES

\section{Chapter}

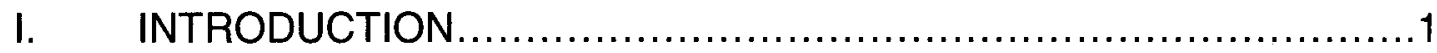

A. Background and Rationale for Study .............................

1. Why ALD is Bad.................................................

2. Current Clincal Treatment of ALD ..............................2

3. Mechanisms of ALD are Poorly Understood......................4

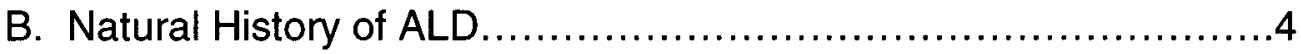

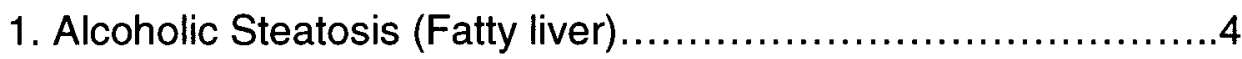

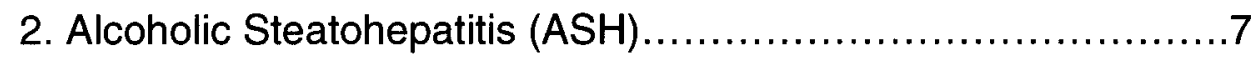

3. Fibrosis.....................................................

4. Cirrhosis and Hepatocellular Carcinoma.......................11

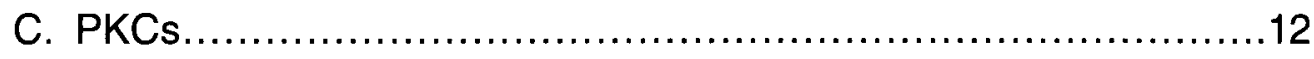

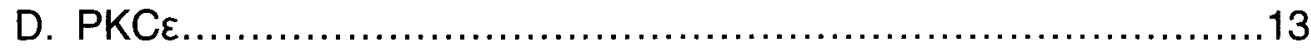

E. Experimental Models of ALD ..................................15

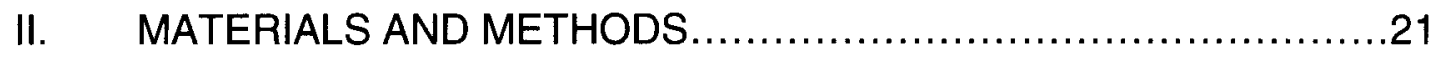



A. Animal Husbandry.
B. Acute Model of Ethanol Administration. .22
C. Immunoblotting for PKCE .23
D. Lipid Determinations .24
E. Quantification of DAG with Electrospray lonization Mass

Spectrometry. .24

F. RNA Isolation and real-time RT-PCR ............................25

G. Glucose-6-Phosphatase Activity............................26

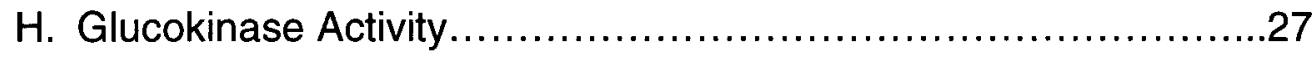

I. Tsukamoto-French Model of Chronic Alcohol Administration.....27

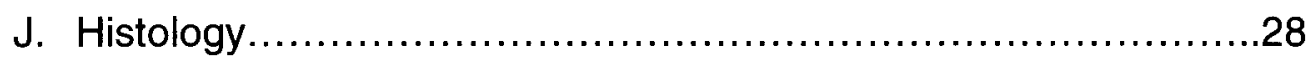

K. Detemination of individual fatty acid species by gas

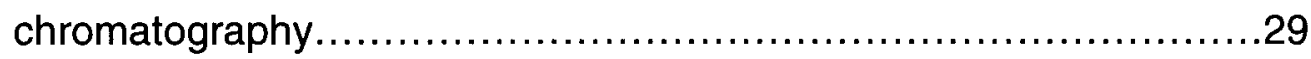

L. Clincal Chemistry............................................. 30

M. Chronic model of $\mathrm{CCl}_{4}$ Exposure ................................30

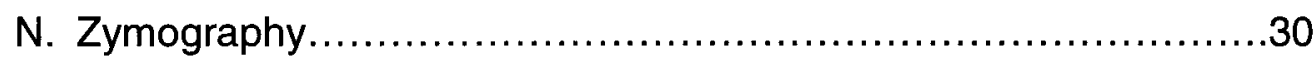

O. Immunofluorescent Detection of Fibrin Accumulation................31

III. PKC $\varepsilon$ PLAYS A CAUSAL ROLE IN ACUTE ETHANOL-INDUCED STEATOSIS

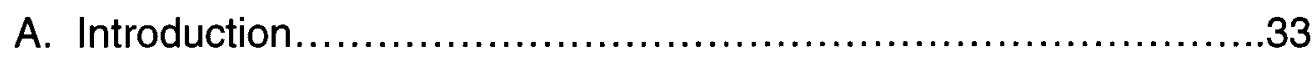

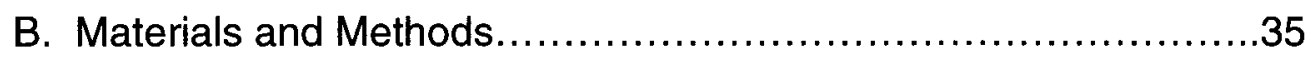

1. Animals and treatments........................................

2. Immunoblots.................................................... 
3. Lipid determinations..........................................35

4. RNA isolation and real-time RT-PCR .........................35

5. Glucose-6-Phosphatase activity ..............................35

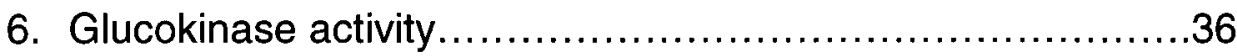

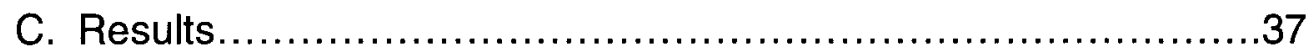

1. Ethanol increases hepatic lipids..............................36

2. Effect of ethanol on hepatic DAG levels and PKC $\varepsilon$ activation..36

3. Effect of ethanol on plasma insulin and glucose and expression of insulin responsive genes................................... 38

4. PKCE knockdown or knockout blunts ethanol-induced steatosis.....................................................

5. The effect of a PKCE ASO on ethanol-induced changes on insulin-responsive genes...................................40

D. Discussion..................................................... 40

IV. PKC $\varepsilon$ CONTRIBUTES TO CHRONIC ETHANOL-INDUCED

STEATOSIS BUT NOT TO INFLAMMATION AND NECROSIS.......60

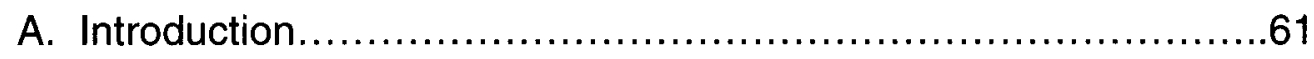

B. Materials and Methods.........................................62

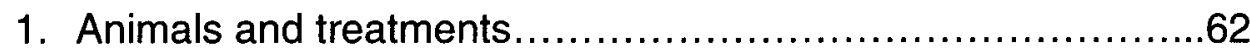

2. Histological anaylsis and clinical chemistry.................62

3. Clinical Chemistry ..........................................63

4. RNA isolation and real-time RT-PCR .......................63

5. Quantification of individual free fatty acid species..............63 
6. Immunoblotting................................................63

7. Lipid determinations.....................................63

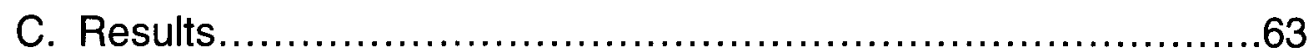

1. Body weight and urine ethanol concentrations................63

2. Effect of chronic ethanol exposure on plasma and histological indices of liver damage....................................64

3. Effect of ethanol on hepatic DAG...........................65

4. Chronic ethanol activates PKCE.............................65

5. Effect of knocking down PKCE on changes in hepatic lipids caused by ethanol.........................................66

6. Effect of ethanol on key genes............................67

7. Effect of chronic ethanol on aSMA and hepatic fibrin deposition..................................................

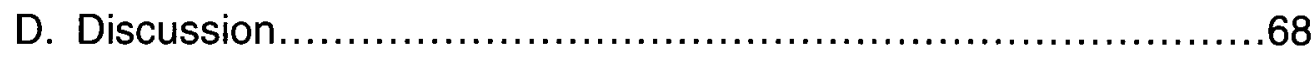

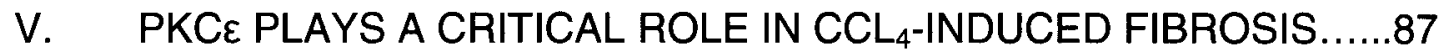

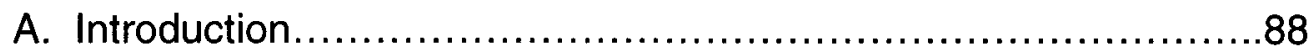

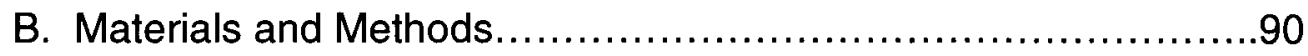

1. Animals and treatments......................................90

2. Immunoblotting.............................................. 90

3. Histological anaylsis.......................................... 90

4. Clincal Chemistry............................................ 90

5. RNA isolation and real-time RT-PCR .......................90

6. Zymography ............................................. 90 
C. Results

1. Effect of $\mathrm{CCl}_{4}$ on plasma and histological indices of liver damage and fibrosis

2. Chronic $\mathrm{CCl}_{4}$ decreases $\mathrm{PKC} \varepsilon$ activation.

3. Effect of $\mathrm{CCl}_{4}$ on profibrotic genes

4. $\mathrm{CCl}_{4}$ increases stellate cell activation and hepatic fibrin deposition .93

5. Effect of $\mathrm{CCl}_{4}$ on MMP-9 activity. 94

D. Discussion .94

VI. SUMMARY AND CONCLUSIONS. 110

A. Major Findings of this Dissertation

1. PKC $\varepsilon$ plays a causal role in ethanol-induced steatosis.

2. PKC $\varepsilon$ plays a critical role in chronic ethanol-induced steatosis but not inflammation or necrosis. 113

3. PKC $\varepsilon$ causes hepatic fibrosis. 115

B. Significance of this Study. 117

C. Strengths and Weaknesses of this Dissertation. .119

1. Strengths. 119

2. Weaknesses .121

D. Future Directions 124

1. Do other isoforms of PKC contribute to ALD. 124

2. Does $\mathrm{PKC} \varepsilon$ play a role in angiotensin II-induced fibrosis. .124 
3. Does PKC $\varepsilon$ play a critical role in LPS-induced hepatic inflammation................................................ 125

4. Are steatosis and inflammation mechanistically linked..........126

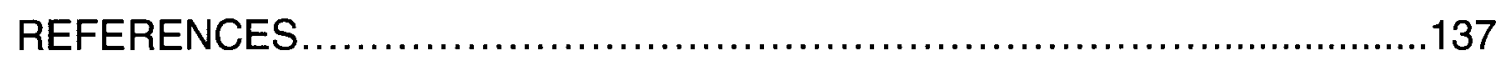

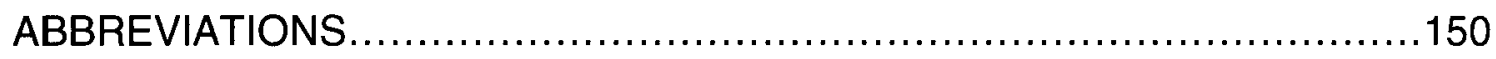

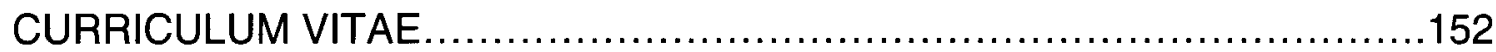




\section{LIST OF FIGURES}

FIGURE

PAGE

1.1: Mechanism by which $\mathrm{PKC} \varepsilon$ is causing hepatic insulin resistance. 19

3.1: Effect of acute ethanol on hepatic triglycerides and

NEFA.

3.2: Effect of acute ethanol on hepatic DAG levels .48

3.3: Effect of acute ethanol on specific DAG species. .50

3.4: Effect of acute ethanol on the activation of PKC $\varepsilon$ in mouse liver .52

3.5: Effect of acute ethanol on the plasma concentrations of insulin and glucose and on the expression/activity of insulin-responsive genes in mouse liver.... .54

3.6: Effect of PKCE ASO on ethanol-induced steatotis .56

3.7: The effect of the PKCE ASO on ethanol-induced changes on the expression of insulin responsive genes $1 \mathrm{~h}$ after ethanol exposure in mouse liver. .58

4.1: Effect of PKCE deficiency on chronic ethanol-induced liver damage.........73

4.2: Effect of chronic ethanol on hepatic DAG levels ............................75

4.3: Effect of chronic ethanol on the activation of PKC $\varepsilon$ in mouse liver...........77

4.4: Effect of chronic ethanol on indices of hepatic lipid accumulation.............79

4.5: Effect of chronic ethanol on specific free fatty acid species.....................81

4.6: Effect of ethanol on pro-inflammatory cytokines..........................83

4.7: Effect of ethanol on fibrin deposition................................... 85

5.1: Effect of the PKCE ASO on $\mathrm{CCl}_{4}$-induced liver damage.....................99

5.2: Effect of $\mathrm{CCl}_{4}$ on PKC $\varepsilon$ activation........................................ 101

5.3: Effect of $\mathrm{CCl}_{4}$ on the expression of profibrotic genes.....................103

5.4: Effect of $\mathrm{CCl}_{4}$ on aSMA and fibrin deposition.............................105

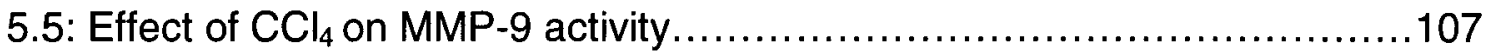

6.1: The involvement of other organs and cell types in causing ALD............129 
6.2: Working hypothesis by which PKC causes ethanol-induced steatosis.....131

6.3: The working hypothesis by which PKCE plays a critical role in hepatic steatosis but not inflammation or necrosis owing to chronic ethanol exposure.133

6.4: The proposed mechanism by which PKCE causes $\mathrm{CCl}_{4}$-induced hepatic

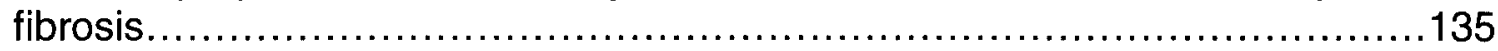


CHAPTER I

INTRODUCTION 


\section{A. Background and Rationale for Study}

\section{Why ALD is bad}

Alcoholic liver disease (ALD) is a serious medical concern for the world's population. Liver damage owing to alcohol is the most common form of liver disease. Furthermore, ALD is one of the leading causes of death in the world, ${ }^{1}$ affecting millions of people per year. For example, ALD is the fourth leading cause of death among urban males. ${ }^{2}$ ALD also poses a huge economic burden. From 1985 to 1992 , it is estimated that over $\$ 148$ billion was spent to treat people with ALD in the US alone. ${ }^{3}$ Despite the severity of ALD to the world's population, there is no FDA-approved therapy to treat or reverse the disease due to the mechanisms behind ALD being poorly understood.

\section{Current clinical treatment of ALD}

Currently, the clinical treatment of ALD focuses on abstinaining from drinking alcohol, treating decompensation, or transplanting the damaged liver. Abstinence from alcohol is the most obvious treatment in preventing ALD. In fact, numerous studies have shown the effectiveness of abstinence. ${ }^{4}$ Specifically, in patients with alcoholic cirrhosis, abstinence improved the survival rate by almost $50 \% .^{5}$ However, there is a very high rate of recidivism among alcoholic patients, thus making abstinence a rather unrealistic approach in treating ALD. Another means of combating ALD is treating the decompensation associated with the disease. There are many side effects of ALD, such as ascites, portal hypertension, and hepatorenal syndrome. It is these secondary 
effects of ALD that usually lead to the death of patients with ALD. ${ }^{4}$ Treating these secondary effects can prolong the life of ALD patients, but is only palliative. One of the most effective ways to treat ALD is liver transplantation. However, there are many barriers to this treatment, such as organ shortage, costs, and the ethical issue that people who have damaged their liver by abusing alcohol do not deserve a transplanted one. ${ }^{4}$ Furthermore, in order to be considered for a liver transplant, most clinics require alcoholics to abstain from drinking for six months, a task that proves to be impossible for most. Therefore, the finding of an appropriate therapy is critical to prevent alcohol-induced liver damage.

There are many emerging drug therapies to treat ALD. These drugs potentially treat ALD by preventing the immune response and proinflammatory cytokine release caused by alcohol. ${ }^{4}$ Some examples of these drugs are corticosteroids, pentoxifylline, and infliximab. These drugs have had some success in the clinics however they are not without drawbacks. For example, corticosteroids can only be used in the later stages of ALD, such as cirrhosis. ${ }^{4}$ Furthermore, corticosteroids have been shown to increase the risk of infections which could lead to death in some cases. ${ }^{4}$ Unfortunately, most drugs currently employed to treat alcoholics with liver disease, have similar drawbacks (e.g. increased risk of infection) thus increasing the urgency to develop better therapies that not only have fewer devastating side effects but can be used before later stages of ALD ensue. 


\section{Mechanisms of ALD are poorly understood}

The therapies discussed previously (Chapter I, section A2) are only partially effective. Therefore, there is more focus on understanding the biochemical mechanisms behind the development and progression of ALD. Whereas the mechanisms behind ALD are poorly understood, the disease progression is well understood. The first pathological change associated with ALD is steatosis, also known as fatty liver. If the abuse of alcohol continues, steatohepatitis (necrosis and inflammation) can occur followed by fibrosis and cirrhosis. Once the mechanisms behind these various pathologies are better understood, it is more likely that a viable therapeutic target to treat ALD will be identified. This Introduction will focus on the early pathologies of ALD that are known to be readily reversible and the histology associated with each, as well as the mechanisms hypothesized to be responsible for each respective one.

\section{B. Natural History of Alcoholic Liver Disease}

\section{Alcoholic Steatosis (Fatty Liver)}

The first pathological change associated with ALD is steatosis. Steatosis is a very common result of drinking alcohol, occurring in nearly $90 \%$ of people that consume alcohol and is rapidly (a few days) reversible with even the most extreme cases of fatty liver disappearing after three weeks of abstaining from alcohol. ${ }^{6,7}$ Steatosis is characterized by fat infiltration in the liver that can be classified as either macrovesicular or microvesicular. Macrovesicular steatosis is defined as having one large fat droplet per hepatocyte and lateral displacement of the nucleus whereas microvesicular is classified as many small fat droplets per 
hepatocyte. $^{8}$ Whereas steatosis was once thought to an inert pathology of ALD, more recent evidence has indicated that blunting or blocking steatosis could help prevent the progression of ALD., 10,11 As the liver accumulates fat, metabolic changes occur that sensitize the liver to further injury. Furthermore, the higher the degree of hepatic steatosis, the more suspectible a liver is to further stages of liver damage. ${ }^{9}$ Therefore, understanding the biochemical mechanisms by which alcohol is causing steatosis may be important in finding a means to prevent the later stages of ALD.

It has long been established that the metabolism of alcohol directly contributes to hepatic fat accumulation caused by this drug. Specifically, the metabolism of alcohol increases the ratio of NADH:NAD+ within the cell, which subsequently inhibits $\beta$-oxidation of fatty acids in the liver. Alcohol metabolism also increases the rate of esterification of fatty acids. ${ }^{12}$ These changes in fatty acid flux caused by ethanol metabolism subsequently lead to an accumulation of hepatic lipids. However, previous studies suggest that alcohol metabolism may not be the only causal factor for steatosis caused by ethanol. Specifically, many pharmacologic agents and genetic manipulations (e.g. knockouts) have been shown to block hepatic steatosis in rodent models of enteral alcohol exposure. For example, mice deficient in prooxidant-producing enzymes (e.g., NADPH oxidase and iNOS) ${ }^{13,14}$ or LPS binding/signaling molecules (e.g., CD14, TLR4, and LBP), all have less steatosis in response to alcohol compared with wildtypes. ${ }^{15-17}$ However, these pharmacologic/genetic changes that protected against steatosis had no apparent effect on alcohol metabolism, which implies 
that the shift in the NADH redox state still occurs. It is therefore likely alcohol metabolism is not the sole causal factor in ethanol-induced steatosis.

Impaired insulin signaling may also increase hepatic lipid accumulation caused by alcohol exposure. Insulin is a hormone with the main function of maintaining glucose homeostasis by causing organs (e.g. liver, muscle, etc.) to take up glucose from the blood. Once inside the cells of an organ, the glucose is metabolized (i.e. glycolysis) to provide the cell with energy. Insulin resistance refers to the situation where due to impairment of insulin signaling (see Chapter 1 , section $4 \mathrm{C}$ for more detail), normal amounts of insulin are no longer sufficient to cause transportation of glucose into a cell. This loss of insulin sensitivity can lead to hyperglycemia, bacterial infection, and impaired lipid metabolism. ${ }^{18}$

It is known that chronic and acute ethanol exposure cause hepatic insulin resistance in animal models. ${ }^{19}$ Furthermore, insulin resistance is a known risk factor for the development of ALD in humans. ${ }^{20}$ The effect of impaired insulin signaling on hepatic lipid accumulation is well-documented, especially in nonalcoholic fatty liver disease (NAFLD; see ${ }^{18}$ for review). Whereas less wellcharacterized, it is likely that insulin resistance similarly affects lipid metabolism in alcohol-induced liver disease. Indeed, recent work from this group has shown that the insulin-sensitizing drug, metformin, blocks fatty liver caused by ethanol exposure, supporting a causal link between insulin resistance and hepatic steatosis after ethanol exposure. ${ }^{21}$ 


\section{Alcoholic Steatohepatitis (ASH)}

The next stage of ALD is steatohepatitis, which like steatosis is also reversible upon abstinence from drinking alcohol. However, the reversion of steatohepatitis requires several weeks to months unlike steatosis which usually only requires days to revert to normal. ${ }^{22}$ The histological characteristics of steatohepatitis are macro- and microvesicular steatosis along with a robust infiltration of neutrophils as well as hepatocyte degeneration, ballooning, and oncotic necrosis, as well as hepatocyte apoptosis. ${ }^{23}$ While steatohepatitis is reversible, this stage of ALD is considered to be a rate-limiting step in the development of cirrhosis, as liver-related morbidity and death can occur in people with steatohepatitis. ${ }^{24,25}$

One of the prevailing hypotheses in the field of hepatology research is the "two-hit" hypothesis also known as "sensitization", which suggests that hepatic steatosis is not an inert pathology and may actually sensitize the liver to a second insult. ${ }^{9}$ For example, a previous study determined that a steatotic liver is more susceptible to endotoxtin- or cytokine-induced liver damage. ${ }^{26,27}$ One possible explanation could be that upon the development of steatosis, the liver undergoes cellular changes which sensitize the hepatocytes to further damage. ${ }^{28}$ One such cellular change responsible for the sensitization effect could be the decrease in peroxisome proliferators-activated receptors associated with liver inury. ${ }^{29-31}$ 
Alcohol can not only sensitize the liver to further injury by causing steatosis, but can also directly sensitize liver cells to inflammatory stimuli. For example, previous studies have determined that alcohol administration switches the function of TNFa from proproliferative to proapoptotic and that hepatocytes over expressing CYP2E1 become more sensitive to TNFa-induced cell death after alcohol exposure. ${ }^{26,32,33}$ The "two-hit" or "sensitization" hypothesis is just one mechanistic example by which alcohol may be causing inflammation.

Another mechanism thought to play a causal role in inflammation is a concept referred to as 'priming'. In a previous study by Deaciuc et al., it was determined that chronic low-dose LPS can only cause an inflammatory response in the presence of alcohol. ${ }^{34}$ In that model, alcohol exposure "primes" inflammatory cells to be activated by LPS. In support of this hypothesis, higher levels of the proinflammatory mediator TNFa are produced from monocytes isolated from patients with alcoholic hepatitis than in monocytes from drinkers without liver disease..$^{35}$ Alcohol exposure also increases the production of many proinflammatory cytokines/chemokines besides TNFa, such as IL-6, IL-8, and MCP-1, while at the same time, decreasing anti-inflammatory cytokines. ${ }^{36-38}$ The increase in cytokines/chemokines along with other mediators of inflammation (e.g. cytokine receptors) not only cause liver damage but also the systemic effects of ALD as well. ${ }^{35,39}$

The role of primed inflammatory cells by ethanol has also been well investigated. For example, one specific type of liver cell that produces proinflammatory cytokines are Kupffer cells, the resident macrophages of the 
liver. In a study completed by Dr. Thurman's group using a chronic model of ethanol exposure, mice were treated with gadolinium chloride $\left(\mathrm{GdCl}_{3}\right)$, a chemical that is directly toxic to Kupffer cells. $\mathrm{GdCl}_{3}$ prevented liver injury owing to chronic ethanol most likely due to the inability of Kupffer cells to produce mediators of inflammation. ${ }^{40}$

Priming and sensitization are both valid hypotheses by which ethanol can cause inflammation. These two scenarios, priming and sensitization, can be considered a series of events that occur during the progression of alcoholinduced liver injury. Specifically, alcohol primes inflammatory cells (e.g. Kupffer cells) to release mediators of inflammation (TNFa, IL-6, etc) that cause hepatoxicity in liver cells that have been sensitized by ethanol. Many studies support this concept, and the role of inflammatory cytokines in hepatic inflammation has been extensively researched. For example, TNFR1 knockout mice are protected against chronic ethanol-induced inflammation. ${ }^{41}$ Therefore, a suitable therapy in preventing ethanol-induced inflammation may need to target both priming and sensitization owing to alcohol exposure.

\section{Fibrosis}

Fibrosis is considered to be a wound healing process characterized by not only the previously mentioned pathologies (i.e. steatosis, inflammation, and necrosis); but also by accumulation of extracellar matrix proteins (ECM) (collagen, fibrin, etc) in the extracellular space of the liver, which then scars the liver. ${ }^{42}$ Although not as readily reversible as steatosis and steatohepatitis 
requiring much more time (months to years), fibrosis has been shown to revert to a normal liver if the underlying cause (e.g. hepatitis virus $C$ inftecion) is effectively treated. ${ }^{43}$

One possible mechanism of hepatic fibrosis is an increase in production of ECM (e.g. collagen, fibrin, laminin, etc.) increasing accumulation of ECM. When a liver transitions to a profibrotic state, hepatic stellate cells become activated, usually by profibrotic cytokines (e.g. TGF $\beta$-1) or transcription factors like Foxf1 and JunD. ${ }^{42}$ Upon activation, stellate cells transform to myofibroblats which synthesize and secrete ECM. In support of the role for stellate cell activation in causing fibrosis, inhibiting transcription factors that activate stellate cells, protected against fibrosis in various models. For example in a mouse model of $\mathrm{CCl}_{4}$-induced fibrosis, JunD knockout mice had fewer activated stellate cells and less fibrosis compared to wild-type mice. ${ }^{44}$

Another mechanism responsible for fibrosis is a decrease in the degradation of ECM that are secreted by stellate cells. A key determinant in the development of fibrosis is the balance between collaganeses (e.g. MMPs) that degrade ECM and their inhibitors (e.g. TIMPs).$^{45}$ In support of this balance, the inhibition of TIMPs has been shown to partially protect against $\mathrm{CCl}_{4}$-induced fibrosis. ${ }^{46}$ Furthermore, mechanisms that induce the degradation of ECM have also been shown to play a role in preventing fibrosis; one such mechanism is the plasminogen activating system. The activation of plasminogen by uPA/tPA to plasmin is a crucial step in preventing fibrosis as plasmin has been shown to directly degrade ECM-type proteins such as fibrin and laminin and indirectly 
activate MMPs. ${ }^{47-50}$ Therefore, inhibitors of the plasminogen activating system may play a causal role in hepatic fibrosis. One such inhibitor PAl-1, prevents the conversion of plasminogen to plasmin by inhibiting the activity of UPA and IPA and has been shown to play a causal role in bile duct ligation-induced hepatic fibrosis by impairing matrix degradation. ${ }^{51}$

\section{Cirrhosis and Hepatocellular Carcinoma}

If the insult(s) responsible for liver disease continue beyond fibrosis, cirrhosis can develop. Cirrhosis is considered to be an advanced stage of fibrosis; unlike fibrosis, cirrhosis is not reversible. Cirrhosis is characterized by more extensive scarring than fibrosis as well as altered liver parenchyma with septae and nodule formation, as well as distorted hepatic blood flow. ${ }^{42,52}$ Once cirrhosis develops, the result will most likely be mortality without a liver transplant. ${ }^{52}$ Death of the patient is not due to the actual cirrhosis but due to the secondary complications of the disease, such as hepatorenal syndrome and/or portal hypertension. ${ }^{4}$ Some patients are able to maintain compensated cirrhosis (i.e. stable cirrhotics), but the risk for the development of hepatocellular carcinoma increases $\sim 20$-fold due to preexistence of cirrhosis. ${ }^{53}$ The survival rate for a person inflicted with hepatocellular carcinoma is essentially nil. ${ }^{54}$ This high mortality rate of cirrhosis further emphasizes the need for a therapy that can prevent the progression of ALD before cirrhosis develops. 


\section{PKCs}

Protein Kinases C (PKC) comprises 11 isozymes of a family of serine/threonine kinases that a play a role in a variety of cellular signaling pathways. ${ }^{55}$ The PKC superfamily is comprised of three subfamilies (classical, conventional, and atypical) classified by their requirements for activation. The classical subfamily (e.g. PKCs $\alpha$ and $\beta 1$ ) is activated by calcium, diacylglycerol (DAG) and phospholipids. The novel family (PKCs $\eta$ and $\varepsilon$ ) is not regulated by calcium but is activated by DAG and fatty acids instead. Finally, the last class is the atypical class, which require neither DAG nor calcium to become activated. ${ }^{56}$ Although the subfamilies differ in their needs for activation, the general response once activated is quite similar. Upon binding of a cofactor (e.g. DAG, calcium, etc.) to the regulatory domain of the enzyme, the protein migrates to the membrane. Prior to this membrane interaction, there is a pseudosubstrate that is present in the catalytic region of the enzyme, maintaining the inactivity of the PKC. Once the enzyme is recruited to the membrane, the pseudosubstrate is released from the catalytic site and the PKC is then activated. ${ }^{55}$

The PKC family plays various biological roles, such as desensitizing receptors, regulating cell growth, and mediating immune responses. Whereas most PKC isozymes are expressed in various tissues and have multiple roles, some may be distributed in certain tissues and have unique roles in their respective tissue location. ${ }^{57}$ For example, $\mathrm{PKCy}$ is located primarily in the brain and plays a role in regulating the membrane structure of the central nervous system. However, isozymes like $\alpha$ and $\beta 1$ are expressed in multiple tissues (e.g. 
liver, muscles, etc) and play a role in numerous physiological processes. ${ }^{57}$

One pathway that almost all PKCs regulate is the insulin signaling. ${ }^{58}$ Whereas some isotypes of PKC (e.g. $\delta$ ) have a positive effect on the insulin signaling cascade, most PKCs impair insulin signaling. The binding of insulin to its receptor actives an intrinsic tyrosine kinase that phosphorylates the insulin receptor substrates (IRS). Upon tyrosine phosphorylation, signaling molecules like $\mathrm{PI} 3 \mathrm{~K}$ are recruited and become activated and through a series of downstream signaling events induce the physiological actions (e.g. cellular uptake of glucose, glucose metabolism, etc.) of insulin to maintain glucose homeostatis. ${ }^{58}$ PKCs disrupt insulin signaling by phosphorylating serine residues on IRS proteins, which then increases gluconeogenesis and the subsequent insulin resistance. ${ }^{59}$

\section{PKCE}

One example of a PKC that induces insulin resistance is PKCE. PKC $\varepsilon$ is a novel isotype, found in many organs, including the liver, and plays a diverse role in many cellular processes. Interestingly, many of the roles of PKC $\varepsilon$ coincide with mechanisms thought to play a part in the different pathologies (steatosis, steatohepatitis, and fibrosis) of ALD. For example, PKC $\varepsilon$ induces hepatic and muscular insulin resistance by increasing the serine phosphorylation of IRS-2, causing a decrease in tyrosine phosphorylation leading to impaired glycogen production and an increase in glucose production (see Figure 1.1 for detailed mechanism). ${ }^{18}$ Given this role of PKCE in insulin resistance, a known risk factor 
of steatosis, it is therefore possible that this kinase could also plays a role in ethanol-induced steatosis.

One of the major mechanisms by which chronic ethanol is hypothesized to cause inflammation is by priming macrophages (e.g. Kupffer cells) to release mediators that contribute to hepatic inflammation (see Chapter 1, section B2 for detailed mechanism). The killing of Kupffer cells via $\mathrm{GdCl}_{3}$ partially prevents alcohol-induced liver injury, further supporting the role of macrophages in inflammation owing to ethanol. ${ }^{40}$ PKC $\varepsilon$ has also been shown to play a critical role in the priming of proinflammatory cells as macrophages from PKC $\varepsilon$ knockout mice have an impaired response to LPS, characterized by a decrease in the amount of proinflammatory cytokines that are released. ${ }^{60}$ Therefore as PKC $\varepsilon$ is known to prime macrophages, it may be possible that PKCE plays a casual role in inflammation owing to chronic ethanol via the activation of Kupffer cells and the subsequent secretion of proinflammatoy mediators like TNFa., that are directly toxic to hepatocytes.

The next pathological step of ALD proceeding steatohepatitis is fibrosis, the last reversible phase of liver disease preceding cirrhosis. Whereas fibrosis or "remodeling" happens in many tissues besides the liver, such as bloods vessels (i.e. atherosclerosis) and kidneys (i.e. glomuleronephritis), the mechanisms behind fibrosis are potentially similar from organ to organ. For example, a major determinant in the transition of any organ to a profibrotic state is the activation and conversion of a cell type (e.g stellate cells in liver) to a myofibroblast, which then secrete ECM. Although the role of PKCE in regulating myofibroblast 
conversion and ECM secretion has not been directly tested in the liver, there is literature support for PKCE-dependent control of these parameters in other organs. For example, the knockdown of PKC $\varepsilon$ blunted lung fibrosis in patients with systemic sclerosis by decreasing the number of myofibroblasts. ${ }^{61}$

\section{E. Experimental Models of ALD}

To investigate the role of PKCE in various stages of $A L D$, a number of different animal models must be used to produce the pathological features observed in the human disease. There are many types of animal models of ALD, such as rodents, pigs, and nonhuman primates. For example, nonhuman primate models of ALD are good paradigms, due to physiological similarities to humans, to provide validation of a therapy that has been shown to be effective in treating ALD in rodent or other small animal models. However, the downside of using nonhuman primates to model ALD is the large expansive costs of their employment and the significant amount of time (months to years) these models need to cause a pathology of interest. Rodent models are advantageous due to the relatively inexpensive costs and the short length of time required to produce gross morphological changes observed in ALD. Mice are particularly useful because of the ability to genetically-alter them (knockout mice) to study a mechanism of interest.

The first animal model used in this dissertation was a mouse model of acute ethanol exposure which consists of a single bolus dose of ethanol. This model is advantageous as it is relativity quick compared to other models and 
serves as a screening tool for mechanisms of early ethanol-induced steatosis. Furthermore, the respective mechanisms responsible for acute and chronic ethanol damage have been shown to be similar (see Thurman et $\mathrm{al}^{62}$ for review); therefore mechanistic information yielded from the acute model of ethanol exposure may be applicable to liver injury owing to chronic ethanol. However, the acute model is not without its drawbacks. Whereas there is a robust steatotic response associated with a single bolus dose of ethanol, there is little or no inflammatory or necrotic component observed with this model. To determine the role of PKCE in hepatic inflammation, a chronic model of ethanol administration must be employed.

One model of alcohol exposure known to cause steatohepatitis in rodents is the intragastric feeding model, also known as the Tsukamoto-French intragastric feeding model. In this model, mice receive ethanol liquid diet via a permanent indwelling intragastric catheter. This model features not only steatosis ( 1 week of enteral ethanol feeding) but inflammation ( 2 weeks) and necrosis (4 weeks) as well. ${ }^{63}$ The chronic intragastric ethanol feeding model is useful in that it produces all of the aforementioned pathologies (steatosis, inflammation, etc) and allows for the controlled delivery of high doses of ethanol that result in blood alcohol levels adequate to cause pathological changes. The controlled delivery of ethanol is important because rodents have a natural aversion to alcohol and as a result, ad libitum ethanol feeding models rarely cause elevated blood ethanol levels nor produce the severe pathological changes seen in the Tsukamoto-French chronic ethanol model. ${ }^{64}$ However, such 
high doses of ethanol requiring a consistent monitoring of intoxication, requiring extensive animal husbandry required from this model. Furthermore, the need for surgical manipulation to implant the intragastric cannula, the relatively expansive cost of the model, coupled with the fact that little or no fibrosis is caused by this intragastric feeding model, signify the drawbacks of this approach. To study the role of PKCE in liver fibrosis, one must employ a severe model of liver damage that is capable of producing a profibrotic state in mice.

Whereas chronic ethanol exposure to rodent results in robust hepatic inflammation, there is only moderate fibrosis at best. Whereas there is still no optimal rodent model of experimental fibrosis, there are toxins that are capable of eliciting a fibrotic response in mice, one such chemical being $\mathrm{CCl}_{4}{ }^{65}$ Compared to another common model of fibrosis (i.e. bile duct ligation), $\mathrm{CCl}_{4}$ causes a more fibrotic response in the liver especially compared to chronic ethanol exposure. However, $\mathrm{CCl}_{4}$ models increase transaminases to high values $(\sim 8000 \mathrm{IU} / \mathrm{L})$ that are considered to be supramaximal to those found in humans with fibrosis. However, the $\mathrm{CCl}_{4}$ model produces pathology similar to the human disease, is well characterized, and has a rapid onset. Furthermore, should a therapy protect against fibrosis in this severe model, it is assumed that less robust fibrogeneses (i.e. human liver disease) will also be blunted.

Taken together, to properly investigate the mechanisms behind the various stages of ALD, one must employ a variety of different models depending on the pathological endpoint that is being researched. The goal of this dissertation was to investigate the role of PKC $\varepsilon$ in alcohol-induced hepatic 
steatosis, steatohepatitis, and fibrosis and the proper models to investigate these pathologies were employed. Chapter III focuses on the role of PKCE in early steatosis (acute ethanol). Chapter IV investigates the role of PKC $\varepsilon$ in steatohepatitis (chronic intragastric feeding) and finally Chapter V demonstrates the ability of PKCE to contribute to hepatic fibrosis $\left(\mathrm{CCl}_{4}\right)$. 
Figure 1.1: Mechanism by which PKC $\varepsilon$ is causing hepatic insulin resistance DAG activates $P K C \varepsilon$, which then increases the serine phosphorylation of of IRS-2, thus decreasing the tyrosine phoshosphorylation of the substrate. PI3K is indirectly deactivated leading to impaired glycogen production and increased gluconeogenesis. This figure was taken from a review by Petersen and Shulman. ${ }^{18}$ 


\section{How PKC $\varepsilon$ causes insulin resistance}

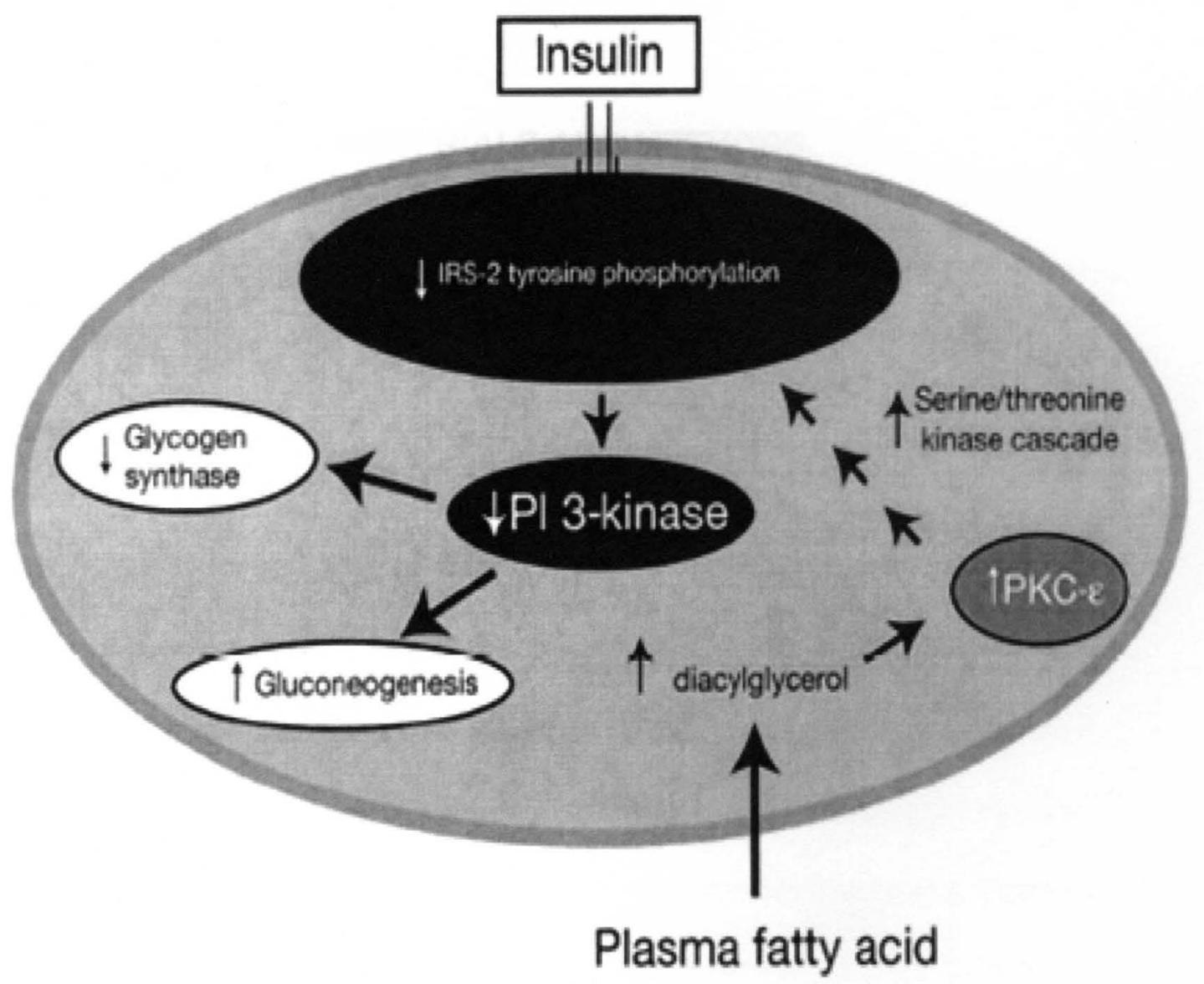

Petersen and Shulman. (2006) Am J Med 119: 10S-16S. 
CHAPTER II

MATERIALS AND METHODS 


\section{A. Animal Husbandry}

Mice were housed in a pathogen-free barrier facility accredited by the Association for Assessment and Accreditation of Laboratory Animal Care and procedures were approved by the local Institutional Animal Care and Use Committee. Six week old C57BL/6J mice were obtained from Jackson Laboratory (Bar Harbor, ME). PKC $\varepsilon$ knockout mice were a generous gift from the laboratory of Dr. Aruni Bhatnagar (University of Louisville). All knockout mice used in this study were generated by intercrossing 129SvJaexC57BL/6 hybrid $\mathrm{PKC} \varepsilon^{+/-}$mice as described previously. ${ }^{66}$ Food and tap water were allowed ad libitum prior to experimentation.

\section{B. Acute Model of Ethanol Exposure}

Mice were gavaged with a bolus dose of ethanol $(6 \mathrm{~g} / \mathrm{kg})$ as a $20 \%$ solution in saline. ${ }^{21}$ Isocaloric/isovolumetric maltose-dextrin was given as a control. With this dosage, blood ethanol levels reached $\sim 250-300 \mathrm{mg} / \mathrm{dL}$; whereas animals were ataxic, they did not lose consciousness and there were no deaths owing to alcohol overdose. Some mice received a PKC $\varepsilon$ antisense oligonucleotide (ASO). The PKCE ASO (sequence: 5'-

CTCGCAGATTTTGATCTTAA-3') was a kind gift from Dr. Brett Monia (Isis Pharmaceuticals Inc). The method of injection for the ASO was similar to the protocol described in Samuel et al ${ }^{67}$ but with slight modifications to account for the use of mice. Specifically, mice received the PKCE ASO or vehicle saline at a dose of $25 \mathrm{mg} / \mathrm{kg}$ (i.p.) twice a week for four weeks. Mice were sacrificed 0-12 hours after ethanol gavage. Animals were anesthetized with ketamine/xylazine 
(100/15 mg/kg, i.m.) and blood collected from the vena cava just prior to sacrifice. Citrated plasma was stored at $-80^{\circ} \mathrm{C}$ until further analysis. Portions of liver tissue were frozen immediately in liquid nitrogen, while others were frozenfixed in OCT mounting media (Tissue Tek, Hatfield, PA) for subsequent sectioning and mounting on microscope slides.

\section{Immunoblotting for PKC $\varepsilon$}

Western Blotting for PKCE was performed by Dr. Jun Zhang as described previously. ${ }^{68}$ Specifically, total hepatic protein was isolated from snap-frozen liver samples using isolation buffer [50 mM Tris- $\mathrm{HCl}(\mathrm{pH}$ 7.5), $10 \mathrm{mM}$ EGTA, and $50 \mathrm{mM}$ ß-mercaptoethanol] containing protease inhibitors (Roche, Penzberg, Germany). The homogenates were centrifuged at $100 \times \mathrm{G}$ to remove the unbroken cells. The supernatant was then centrifuged at $100,000 \times \mathrm{G}$ for $1 \mathrm{~h}$ at $4^{\circ} \mathrm{C}$. The resulting supernatant represented the cytosolic fraction. To solubilize the pellet, the pellet was resuspended into the isolation buffer with $0.1 \% \mathrm{NP}-40$, and incubated $30 \mathrm{~min}$ on ice followed by brief sonication. All buffers used for protein extraction contained protease, tyrosine phosphatase, and serine/threonine phosphatase inhibitor cocktails (Sigma, St. Louis, MO). Respective lysates (100 $\mu \mathrm{g}$ protein/well) were separated on $10 \%$ SDSpolyacrylamide gel. Proteins were then transferred to polyvinylidene difluoride membranes using a semidry electroblotter (Amersham, Piscataway, NJ). The resulting blots were probed with antibodies against PKCE (BD Transduction Laboratories, San Jose, CA) and bands visualized with the ECL plus kit 
(Amersham Biosciences, Piscataway, NJ). To ensure equal loading, all blots were stained with Ponceau red.

\section{Lipid Determinations}

Mouse livers were homogenized in $2 \times$ phosphate buffered saline. Tissue lipids were extracted with methanol:chloroform (1:2), dried in an evaporating centrifuge, and resuspended in $5 \%$ fat-free bovine serum albumin. Colorimetric assessments of hepatic triglycerides or non-esterified fatty acids (NEFA) were carried out using standard kits (Thermotrace, Melbourne, Australia and Roche, Penzberg, Germany). Values were normalized to protein in homogenate prior to extraction as determined by the Bradford assay (Bio-Rad Laboratories, Hercules, $\mathrm{CA})$.

\section{E. Quantification of DAG with electrospsray ionization/ mass spectrometry}

For the determination of hepatic DAG levels, hepatic lipids were extracted by an aqueous solution of chloroform and methanol as described by Bligh and Dyer ${ }^{69}$. Quantification of DAG was performed as described in Callender et al ${ }^{70}$. Specifically, DAG was separated from phospholipids by silica gel column chromatography with $65: 35: 0.7 \mathrm{CHCl}_{3}: \mathrm{CH}_{3} \mathrm{OH}: \mathrm{H}_{2} \mathrm{O}$ as the elution buffer. Before use, each column was plugged with glass wool and packed with $6 \mathrm{~cm}$ of silica gel and equilibrated with $10 \mathrm{ml}$ of the eluent. To recover DAG, the first $2 \mathrm{ml}$ of eluent were collected and dried in a vacuum and then resuspended in $120 \mu \mathrm{l}$ of 9:1

$\mathrm{CH}_{3} \mathrm{OH}: \mathrm{CHCl}_{3}$ with $5 \mu \mathrm{l}$ of $100 \mathrm{mM} \mathrm{CH}_{3} \mathrm{COONa}$. To evaluate the recovery of DAG during separation, all liver extracts were spiked with 100 pmoles of a known 
DAG standard (DAG 28:0). Samples were then analyzed by J. David Hoetker via electrospray ionization mass spectrometry on a Micromass ZMD equipped with a Harvard Apparatus syringe pump at an infusion rate of $10 \mu \mathrm{l} / \mathrm{min}$ in a positive ionization mode at a range of $\mathrm{m} / \mathrm{z} 20$ to $2,000 . \mathrm{Na}^{+}$adducts were used for the detection of individual DAG species. Select peaks were quantified by comparing to previously determined standards and then identified by fragmentation via ESI/MS/MS.

\section{F. RNA Isolation and Real-Time RT-PCR}

Message levels of select genes were detected by real-time reversetranscriptase PCR, which is routine by this group. ${ }^{14,71}$ Total RNA was isolated from liver tissue using RNA STAT 60 (Tel-Test, Friendswood, TX). Polymerase Chain Reaction primers and fluorogenic probes were designed using Primer Express (Version 1.5, Applied Biosystems, Foster City, CA). Primers were designed to cross introns, to ensure only cDNA and not genomic DNA is amplified (see Table I). The fluorogenic MGB probe was labeled with the reporter dye FAM (6-carboxyfluorescein). TaqMan Universal PCR Master Mix (Applied Biosystems) was used to prepare the PCR mix. The $2 \mathrm{X}$ mixture is optimized for TaqMan reactions and contains AmpliTaq gold DNA polymerase, AmpErase, dNTPs with UTP and a passive reference. Primers and probe were added to a final concentration of $300 \mathrm{nM}$ and 100nM respectively. CDNA was made from $1 \mu \mathrm{g}$ of total RNA using the Advantage for RT for PCR kit (BD Biosciences, Palo Alto, CA) following manufacture's instruction. The amplification reactions were carried out in the ABI Prism 7700 sequence 
detection system (Applied Biosystems) with initial hold steps $\left(50^{\circ} \mathrm{C}\right.$ for $2 \mathrm{~min}$, followed by $95^{\circ} \mathrm{C}$ for $\left.10 \mathrm{~min}\right)$ and $40-50$ cycles of a two-step PCR $\left(92^{\circ} \mathrm{C}\right.$ for 15 $\mathrm{sec}, 60^{\circ} \mathrm{C}$ for $\left.1 \mathrm{~min}\right)$. The fluorescence intensity of each sample was measured at each temperature change to monitor amplification of the target gene cDNA. The fluorescence signal increased when the probe binds to the single stranded template DNA and is digested by the 5'-3'-exonuclease activity of the AmpliTaq Gold DNA polymerase. Digestion of the probe releases the fluorescent reporter dye (FAM) from the quencher. The comparative CT method was determined used to fold differences between samples. The comparative CT method determines the amount of target, normalized to an endogenous reference ( $\beta$ actin) and relative to a calibrator $\left(2^{-\Delta \Delta} \mathrm{Ct}\right)$. The purity of PCR products were verified by gel electrophoresis.

\section{G. Glucose-6-Phosphatase Activity}

The enzymatic activity of glucose-6-phosphatase was measured by the production of phosphate from glucose-6-phosphate as described by KaidanovichBeilin et $\mathrm{al}^{72}$ with minor modifications. Using a hand-held homogenizer, livers $(\sim 100 \mathrm{mg})$ were homogenized in $500 \mu \mathrm{l}$ of $250 \mathrm{mM}$ sucrose-HEPES buffer $(\mathrm{pH}$ 7.4). Homogenates were centrifuged for $10 \mathrm{~min}$ at $3000 \times \mathrm{G}\left(4^{\circ} \mathrm{C}\right)$. To $100 \mu \mathrm{l}$ of this supernatant, $25 \mu \mathrm{l}$ of taurocholic acid was added and incubated on ice for 30 min. After incubation, $175 \mu$ l of homogenization buffer was mixed with this solution. A $60 \mu \mathrm{l}$ aliquot was then mixed with $140 \mu$ l of reaction buffer $(25 \mu \mathrm{l}$ of $0.5 \mathrm{M}$ Tris $\mathrm{HCl}$ buffer, $\mathrm{pH} 6.5,20 \mu \mathrm{l}$ of $100 \mathrm{mg} / \mathrm{ml}$ bovine serum albumin, $40 \mu \mathrm{l}$ of 
$100 \mathrm{mM}$ glucose-6-phosphate, and $50 \mu \mathrm{l}$ of distilled water). This solution was then incubated at $37^{\circ} \mathrm{C}$ for 0 and $20 \mathrm{~min} .140 \mu \mathrm{l}$ of stop solution ( $15 \%$ ice cold trichloroacetic acid) was added to both solutions ( 0 and $20 \mathrm{~min}$ ). The samples were the centrifuged at $3000 \times \mathrm{G}$ for $10 \mathrm{~min}$ at $4^{\circ} \mathrm{C}$. To $140 \mu \mathrm{l}$ of supernatant, phosphate reagent ( $5 \%$ ammonium molybdate tetrahydrate in $4 \mathrm{~N} \mathrm{HCl}$ and $1 \%$ Iron (II) sulfate heptahydrate) was added. This solution was incubated at $37^{\circ} \mathrm{C}$ for $10 \mathrm{~min}$. The shift in absorbance caused by the reaction of phosphate and ammonium molybdate tetrahydrate was read for each sample at $650 \mathrm{~nm}$ and results normalized to protein content.

\section{H. Glucokinase Activity}

The activity of glucokinase was measured by monitoring the absorbance of $\mathrm{NADH}$ formed from glucose-6-phosphate dehydrogenase as described by Rossetti et al. ${ }^{73}$ Briefly, livers $(\sim 100 \mathrm{mg})$ were homogenized in $1 \mathrm{ml}$ of HEPES buffer ( $50 \mathrm{mM}, \mathrm{pH}$ 7.4) containing $100 \mathrm{mM} \mathrm{KCl,} 1 \mathrm{mM}$ EDTA, $5 \mathrm{mM} \mathrm{MgCl}_{2}$, and $2.5 \mathrm{mM}$ dithioerythritol. The homogenates were then centrifuged at $100,000 \times \mathrm{G}$ for $45 \mathrm{~min}$ at $4^{\circ} \mathrm{C}$. $50 \mu$ of supernatant was then mixed with an ATP reagent buffer $(100 \mathrm{mM} \mathrm{KCl}, 7.5 \mathrm{mM} \mathrm{MgCl} 2,2.5 \mathrm{mM}$ dithioerythritol, $10 \mathrm{mg} / \mathrm{ml}$ bovine serum albumin, $100 \mathrm{mM}$ glucose, $.5 \mathrm{mM} \mathrm{NAD+,} 4$ units/ml of glucose-6phosphate dehydrogenase in $50 \mathrm{mM}$ buffer, $\mathrm{pH}$ 7.4). The absorbance of $\mathrm{NADH}$ was read at $340 \mathrm{~nm}$ at $37^{\circ} \mathrm{C}$ for $20 \mathrm{~min}$ and results normalized to protein.

\section{Tsukamoto-French Model of Chronic Alcohol Administration}

All necessary surgeries for this model were completed by Dr. Luping Guo, a senior research associate. Surgical implantation of the intragastric cannula 
and enteral feeding was performed as described previously. ${ }^{14}$ Specifically, C57BL/6J mice were anesthetized with isoflourane and a gastric cannula was implanted into the forestomach. Cannulas were fixed to the abdominal wall and secured with an anchoring button. Ampicillin and gentamicin (antibiotics) were administered via the intraperitoneal cavity. Briefly, a liquid diet described by Thompson and Reitz ${ }^{74}$ supplemented with lipotropes as detailed in Morimoto et al. ${ }^{75}$ was prepared daily. Either ethanol-containing or isocaloric maltose-dextrin (control) diet was fed for 4 weeks as described elsewhere. The initial rate of ethanol delivery (16 $\mathrm{g} / \mathrm{kg} /$ day) was increased in a step-wise manner $1 \mathrm{~g} / \mathrm{kg} /$ every 2 days until the end of the first week and then $1 \mathrm{~g} / \mathrm{kg} / 4$ days until the end of the experiment.

\section{J. Histology}

Liver pathology was scored as described by Nanji et al. ${ }^{76}$ : steatosis < $25 \%, 1 ; 25-50 \%, 2 ; 50-75 \%, 3 ;>75 \%, 4 ; 1$ or 2 for 1 or more inflammatory, necrotic, or fibrotic foci. Neutrophil accumulation in the livers was assessed by staining tissue sections for chloracetate esterase, a specific marker for neutrophils, using the napthol AS-D chloracetate esterase kit (Sigma, St. Louis MO). ${ }^{71,77}$ Extracellular matrix accumulation in liver sections was determined by staining with Sirius red-fast green. ${ }^{78}$

Sirius red staining was quantified by image analysis. Specifically, a Universal Imaging Corp. Image-1/AT image acquisition and analysis system (Chester, PA) incorporating an Axioskop 50 microscope (Carl Zeiss, Inc., Thornwood, NY) was used to capture and analyze 5 non-overlapping fields per 
section at $100 \times$ final magnification. Image analysis was performed using modifications of techniques described previously. ${ }^{79}$ Detection thresholds were set for the red color based on an intensely labeled point and a default color threshold. The degree of labeling in each section was determined from the area within the color range divided by the total area.

\section{K. Determination of individual free fatty acid species by gas}

\section{chromatography}

Biological samples were processed as described by Lepage and Roy. ${ }^{80}$ Briefly, $30 \mathrm{mg}$ of liver homogenate was weighed in glass tubes. While stirring, $200 \mu$ of acetyl chloride was slowly added. Tridecanoic acid (13:0) was used as internal standard. The tubes were tightly closed with Teflon-lined caps and subjected to methanolysis at $100^{\circ} \mathrm{C}$ for $1 \mathrm{hr}$. After adding $5 \mathrm{ml}$ of $6 \% \mathrm{~K}_{2} \mathrm{CO}_{3}$, the fatty acid esters were extracted twice with hexane and an aliquot of the hexane upper phase was injected into the chromatograph. FFA were chromatographed as methyl esters on an Agilent $6890 \mathrm{~N}$ GC equipped with an HP-5 capillary column ( $50 \mathrm{~m} \times 0.2 \mathrm{~mm}$ i.d. $\times 0.5 \mu \mathrm{m}$ phase thickness) coupled to a 5973 detector for mass spectrometry analysis. Helium was used as carrier gas. The split ratio was 20:I. The injection port temperature was $280^{\circ} \mathrm{C}$ and the detector was $250^{\circ} \mathrm{C}$. The $\mathrm{GC}$ column temperature was set at $150^{\circ} \mathrm{C}$ for $3 \mathrm{~min}$, increased by $5^{\circ} \mathrm{C} / \mathrm{min}$ until $260^{\circ} \mathrm{C}$ and then by $20^{\circ} \mathrm{C} / \mathrm{min}$ until $300^{\circ} \mathrm{C}$ and kept at this temperature for $4 \mathrm{~min}$. 


\section{Clinical Chemistry}

Serum indices of hepatic injury (AST, ALT) were measured using kits (Sigma) and spectrophotometric techniques routine in this laboratory. ${ }^{81}$ Urine alcohol was measured using standard spectrophotometric techniques ${ }^{82}$ also routine in this laboratory ${ }^{81}$

\section{Chronic Model of $\mathrm{CCl}_{4}$ Exposure}

Mice were exposed with $\mathrm{CCl}_{4}$ as described previously. ${ }^{83}$ Mice were administered $\mathrm{CCl}_{4}(1 \mathrm{ml} / \mathrm{kg}$ i.p.; diluted 1:4 in olive oil; Sigma-Aldrich, St. Louis, MO) $2 x /$ wk for 4 wk. Twenty-four $\mathrm{h}$ after the last $\mathrm{CCl}_{4}$ administration, mice were anesthetized by injection of a ketamine $\mathrm{HCL} /$ xylazine solution $(100 / 15 \mathrm{mg} / \mathrm{kg}$ i.m.; Sigma-Aldrich, St. Louis, MO).

\section{N. Zymography}

To determine the hepatic activity of MMPs, total hepatic protein was extracted using a lysis buffer consisting of $10 \mathrm{mM}$ cacodylic acid $(\mathrm{pH} 5.0)$ containing $150 \mathrm{mM} \mathrm{NaCl}, 1 \mu \mathrm{M} \mathrm{ZnCl}, 15 \mathrm{mM} \mathrm{CaCl}_{2}, 1.5 \mathrm{mM} \mathrm{NaN}_{3}$, and $0.01 \%$ Triton X-100. Lysates were then diluted in $2 \times$ sample buffer and separated on $10 \%$ SDS-polyacrylamide gels containing $0.1 \%$ gelatin. Gels were incubated twice for $30 \mathrm{~min}$ in $2.5 \% \mathrm{v} / \mathrm{v}$ Triton-X-100 solution and washed three times $30 \mathrm{~min}$ in developing solution (50 mM Tris, $0.1 \mathrm{M}$ glycine, $0.1 \mathrm{M} \mathrm{NaCl}$, ph 8.0) followed by a $40 \mathrm{~h}$ incubation in developing buffer at $37^{\circ} \mathrm{C}$. The caseinolytic activity was detected by staining the gel $(0.1 \%$ amido black, $45 \%$ methanol, $10 \%$ acetic acid $)$ for $2 \mathrm{~h}$ and then destaining (45\% methanol, 10\% acetic acid) for $30 \mathrm{~min}$. 
Densitometric analysis was performed using Image Quant software (Amersham Biosciences Corp, Piscataway, NJ).

\section{O. Immunofluorescent Detection of Fibrin Accumulation}

For immunofluorescent detection of fibrin deposition, sections of frozen liver (6- $\mu \mathrm{m}$ thick) were fixed in $10 \%$ buffered formalin containing $2 \%$ acetic acid for $\mathbf{3 0 ~ m i n ~ a t ~ r o o m ~ t e m p e r a t u r e ; ~ t h i s ~ a c i d ~ s t e p ~ s o l u b i l i z e s ~ a l l ~ b u t ~ c r o s s - l i n k e d ~}$ fibrin. Sections were blocked with PBS containing 10\% horse serum (Pierce, Rockford, IL) for $30 \mathrm{~min}$, followed by incubation overnight at $4^{\circ} \mathrm{C}$ with affinity purified rabbit anti-human fibrinogen IgG (Dako North America, Inc., Carpinteria, CA) diluted in blocking solution. Sections were washed three times for $5 \mathrm{~min}$ each with PBS and incubated for $3 \mathrm{~h}$ with donkey anti-rabbit antibody conjugated to Alexa 488 (Invitrogen, Carlsbad, CA). Sections were washed with PBS and visualized using a confocal microscope (Zeiss Axiovert 100 LSM 510; Carl Zeiss Inc., Thornwood, NY) and LSM 510 software. No staining was observed in controls for which the primary or secondary antibody was excluded from the staining protocol. Liver sections from all treatment groups were stained at the same time. 


\section{CHAPTER III}

PKCE PLAYS A CAUSAL ROLE IN ACUTE ETHANOL-INDUCED STEATOSIS

The text of this chapter was published in Archives of Biochemistry and Biophysics, 482(1-2), 104-1 (2009). 


\section{A. Introduction}

Alcoholic liver disease is one of the leading causes of death in the world, ${ }^{1}$ affecting millions of people per year. From 1985 to 1992, it is estimated that over $\$ 148$ billion was spent to treat people with ALD in the US alone. ${ }^{3}$ However, due to poor understanding of the mechanisms underlying ALD, there is still no FDAapproved therapy to prevent or reverse the progression of this devastating disease. The molecular mechanisms responsible for ALD must be delineated in order to identify an effective therapy to halt or reverse the pathological changes associated with ALD.

The first histological change associated with ALD is hepatic steatosis. Whereas steatosis was once thought to be an inert pathology of ALD, more recent evidence has indicated that blunting or blocking steatosis could help prevent the progression of ALD., 28, 84 It has long been established that the metabolism of alcohol directly contributes to hepatic steatosis caused by this drug. ${ }^{85}$ Specifically, the metabolism of alcohol increases the ratio of NADH:NAD+, which subsequently inhibits $\beta$-oxidation of fatty acids by hepatocytes. Alcohol metabolism also increases the rate of esterification of fatty acids. ${ }^{12}$ These changes in fatty acid flux caused by ethanol metabolism subsequently cause hepatic triglycerides to accumulate. However, previous studies suggest that other factors may contribute to steatosis caused by ethanol. Specifically, many pharmacologic agents and genetic alterations (e.g. knockout mice) have been shown to block hepatic steatosis in rodent models of alcohol exposure; for example, mice deficient in prooxidant-producing enzymes (e.g., 
NADPH oxidase and iNOS) ${ }^{13,14}$ or LPS binding/signaling molecules (e.g., CD14, TLR4, and LBP), all have less steatosis in response to alcohol compared to wildtypes. ${ }^{15-17}$ However, these pharmacologic/genetic changes, which protected against steatosis in previous studies, had no apparent effect on alcohol metabolism. It is therefore likely alcohol metabolism is not the sole causal factor in ethanol-induced steatosis.

One alternate mechanism by which ethanol may cause steatosis is via inducing hepatic insulin resistance. It has been reported that both chronic and acute ethanol exposure cause hepatic insulin resistance in animal models. ${ }^{19}$ The effect of impaired insulin signaling on hepatic lipid accumulation is welldocumented, especially in non-alcoholic fatty liver disease (NAFLD; see ${ }^{18}$ for review). Whereas less well-characterized, it is likely that insulin resistance has a similar effect on lipid metabolism in alcohol-induced liver disease. Furthermore, insulin resistance is a known risk factor for the development of ALD in humans. ${ }^{20}$ Recent work from this group has shown that the insulin-sensitizing drug, metformin, blocks fatty liver caused by ethanol exposure, supporting a link between insulin resistance and hepatic steatosis after ethanol exposure. ${ }^{21}$

A possible mechanism by which ethanol is causing hepatic insulin resistance and the subsequent steatosis is via activating Protein Kinase C epsilon (PKCE).$^{18}$ It is proposed that PKC $\varepsilon$ inhibits the tyrosine phosphorylation of insulin receptor substrate-2 (IRS-2) and thereby impairs hepatic insulin signaling. ${ }^{18}$ It was recently shown that the activation of PKCE plays a causal role in hepatic insulin resistance in experimental NAFLD. ${ }^{86}$ Here, using an acute 
mouse model, the hypothesis that ethanol exposure activates PKC $\varepsilon$ and that PKCE contributes to hepatic steatosis was directly tested.

\section{B. Materials and Methods}

\section{Animals and Treatments}

Mice were treated with ethanol as described in Chapter II. Additionally, some mice were treated with a PKC $\varepsilon$ ASO to decrease the expression of PKC $\varepsilon$ to $20 \%$ of control mice.

\section{Immunoblots}

Immunoblotting to compare the membrane and cytosolic fractions of PKCE was performed as described in Chapter II.

\section{Lipid Determinations}

Frozen sections of liver were stained for hepatic lipids via oil red $\mathrm{O}$ staining. Determination of hepatics lipids (i.e. NEFA, triglycerides, and DAG) was performed as detailed in Chapter II.

\section{RNA isolation and real-time RT-PCR}

See detailed method in Chapter II.

\section{G6Pase Activity}

The activity of G6Pase was measured by a colorimetric assay as described in Chapter II. 


\section{GK Activity}

GK activity was determined spectrophotometrically as detailed in Chapter

II.

\section{Results}

\section{Ethanol increases hepatic lipids}

Figure 1 shows the effect of acute ethanol on hepatic triglycerides and non-esterified fatty acids (NEFA) in wild-type mice. The hepatic triglyceride content in isocaloric maltose-dextrin mice was similar to those for naïve animals.

As has been observed previously (e.g., ${ }^{21}$ ), ethanol caused a progressive increase in triglycerides during the course of the study; at the $12 \mathrm{~h}$ timepoint, values were $\sim 20$-fold higher than maltose-dextrin controls (Figure 1, open squares). Acute ethanol also increased hepatic NEFA content, but the temporal pattern differed from the response of hepatic triglycerides. Specifically, hepatic NEFA were significantly increased by ethanol $\sim 5$-fold $1 \mathrm{~h}$ after exposure, and then progressively returned to basal levels by the $12 \mathrm{~h}$ timepoint (Figure 1, closed circles).

\section{Effect of ethanol on hepatic DAG levels and PKC $\varepsilon$ activation}

As mentioned previously, DAG are major mediators of PKC $\varepsilon$ activation. ${ }^{14}$ Since de novo DAG synthesis requires NEFA, it was hypothesized that the increase in NEFA caused by alcohol may also increase DAG levels in the liver. Therefore, the effect of acute ethanol on hepatic DAG was determined (Figure 
3.2 and .33). Figure 3.2 shows representative chromatograms from control- and ethanol-treated mice, while Figure 3.3 shows summary data. Whereas long chained DAG were in general increased $2 \mathrm{~h}$ after ethanol exposure (Figure 3.2 and 3.3, upper panel, not all species responded equally. The effect of ethanol on four specific DAG species was determined in Figure 3.3. DAG $32: 1(\mathrm{~m} / \mathrm{z} 589)$, DAG 34:2 (m/z 615) and DAG 38:6 ( $\mathrm{m} / \mathrm{z} 663)$ were all significantly increased $(\sim 1.5$-fold $)$ due to acute ethanol. DAG $32: 0(\mathrm{~m} / \mathrm{z} 577)$ with an ether linkage at the Sn1 position showed an even more robust effect of ethanol with values $\sim 3$-fold higher than controls (Figure 3.3). Interestingly, only long chained DAG were affected, whereas short and medium chained DAG were not increased by ethanol.

Figure 3.4 shows the effect of ethanol on the ratio of membrane to cytosolic PKCE. An increase in this ratio is an index of increased activation of this enzyme. Maltose dextrin administration had no significant effect on the translocation of PKCE to the membrane compared with naïve mice. At $1 \mathrm{~h}$ after ethanol exposure, there was a significant increase ( $50 \%)$ in PKC $\varepsilon$ membrane localization. This effect diminished initially to basal levels, but then returned at 8 $h$ and progressively increased with values $\sim 3$-fold higher than controls $12 \mathrm{~h}$ after ethanol exposure (Figure 3.4). 


\section{Effect of ethanol on plasma insulin and glucose and expression of insulin-responsive genes}

As mentioned in the Introduction of this chapter, it is known that acute and chronic ethanol causes hepatic insulin resistance in rodents. For example, Onishi et al. ${ }^{19}$ showed that bolus ethanol caused insulin resistance within $2 \mathrm{~h}$ after administration, as determined by both hyperinsulinemic-euglycemic clamp, as well as by the phosphorylation status of IR and IRS-1 and -2. To corroborate these previous findings under the current conditions, the effect of ethanol on surrogate markers of insulin resistance and signaling were determined. Accordingly, the effect of ethanol on plasma insulin and glucose was determined (Figure 3.5, upper panel). $2 \mathrm{~h}$ after ethanol exposure, there was a significant increase ( 3-fold) in plasma insulin levels (Figure 3.5, upper panel, closed circles), which then progressively decreased to basal levels $\sim 12 \mathrm{~h}$ after ethanol exposure. Despite this increase in plasma insulin, the concentration of plasma glucose did not significantly decrease. Indeed, ethanol caused a significant increase $(\sim 50 \%)$ in plasma glucose concentrations, $4 \mathrm{~h}$ after ethanol exposure (Figure 3.5, upper panel, open squares).

In addition to determining plasma concentrations of insulin and glucose, the effect of ethanol on the expression and activity of insulin-responsive genes was also determined. Specifically, the effect of ethanol on mRNA and protein activity of 2 key genes regulated by insulin was determined (Figure 3.5). Messenger RNA levels of G6Pase, which is downregulated by insulin, was significantly upregulated by ethanol (Figure 3.5, middle panel, closed circles) with 
a maximal value ( 8-fold) $2 \mathrm{~h}$ after exposure. After the $2 \mathrm{~h}$ timepoint, expression progressively returned to basal with values $12 \mathrm{~h}$ after exposure not significantly different than controls. Bolus ethanol also caused a significant increase in hepatic G6Pase protein activity (Figure 3.5, middle panel, open squares), but the effect of ethanol on enzyme activity was not as robust as observed with mRNA expression. Messenger RNA levels of GK, a gene which is upregulated by insulin, was significantly decreased $\sim 5$-fold by ethanol (Figure 3.5 , lower panel, closed circles) and this effect was maintained throughout the course of the study. GK enzyme activity was also significantly decreased by ethanol (Figure 3.5, lower panel, open squares), but this effect on protein activity was again less robust than observed with mRNA expression, and had recovered by $\sim 4 \mathrm{~h}$ after ethanol exposure.

\section{PKC $\varepsilon$ knockdown or knockout blunts ethanol-induced steatosis}

As mentioned in the Introduction, $\mathrm{PKC} \varepsilon$ contributes to steatosis in models of NAFLD. ${ }^{86}$ Since PKCE was activated by ethanol in the current work (Figure 3.4), the effect of 'knocking-down' PKCE with ASOs or genetic ablation of the PKCE gene ('knockout') on ethanol-induced steatosis was determined by oil red O staining and by quantitation of hepatic triglycerides (Figure 3.6). Steady state levels of PKCE mRNA in ASO-exposed mice were significantly decreased to 23.3 $\pm 4.7 \%$ of levels found in ethanol-exposed mice (data not shown). Lipid staining from mice receiving maltose dextrin was minimal and similar to naïve chow-fed animals (Figure 3.6, upper left panel). Analogous to previous studies in this model, ${ }^{21}$ ethanol increased oil red O staining in the liver (Figure 3.6, upper right 
panel) with both macro- and micro-vesicular steatosis observable at the $12 \mathrm{~h}$ timepoint. This effect of ethanol on lipid accumulation was blunted in livers from PKCE ASO-treated mice; this protective effect in the ASO mice appeared to affect macrovesicular steatosis (large lipid droplets) more robustly than the microvesicular droplets (Figure 3.6, lower left panel). ASO administration also blunted the increase in triglycerides caused by ethanol by $50 \%$; a similar protective effect was observed in PKCE knockout mice (Figure 3.6, lower right).

\section{The effect of a PKC $\varepsilon$ ASO on ethanol-induced changes on insulin- responsive genes}

As mentioned in the Introduction, $\mathrm{PKC} \varepsilon$ activation and insulin resistance have been linked in experimental NAFLD. ${ }^{86}$ The effect of a knocking down PKC $\varepsilon$ on the ethanol-induced alterations in insulin-responsive genes (see Figure 3.5) caused by alcohol was therefore determined under these conditions (Figure 3.7). Pretreatment with the PKCE ASO significantly ( 2-fold) blunted the upregulation of G6Pase owing to ethanol (Figure 3.7, upper panel); however the downregulation of GK caused by ethanol was not significantly affected in PKCE ASO-treated mice (Figure 3.7, lower panel).

\section{Discussion}

Steatosis is a critical stage in the pathology of ALD, as it has been shown that the degree of steatosis can be predictive of future stages of ALD. ${ }^{84}$ Also, the prevention of steatosis could actually protect against more severe stages of ALD such as fibrosis and cirrhosis. ${ }^{9}$ Thus, studying the causes of lipid accumulation 
in this acute model is useful not only for screening new mechanisms of alcoholinduced steatosis, but it may also identify therapies to treat ALD. It was previously shown that $\mathrm{PKC} \varepsilon$ plays a causal role in hepatic steatosis in experimental NAFLD ${ }^{86}$ However, the role of PKC $\varepsilon$ in ethanol-induced steatosis has not been determined and was subsequently the focus of this study. Here, using an acute model of ethanol exposure, ${ }^{21}$ results were provided that support a causal relationship between PKC $\varepsilon$ activation and ethanol-induced steatosis. First, it was demonstrated that ethanol increases the activation of PKCE, concomitant with indices of insulin resistance. Next, it was determined that the inhibition of PKCE protects against insulin resistance as well as steatosis both owing to acute ethanol.

\section{How does PKC $\varepsilon$ cause fatty liver?}

One possible mechanism by which PKC $\mathrm{E}$ causes fatty liver is by impairing hepatic insulin signaling. ${ }^{18}$ In previous studies, it has been shown that both acute and chronic exposure to ethanol, causes hepatic insulin resistance in rodents (e.g., ${ }^{19}$ ). To verify this effect of ethanol under these conditions, plasma levels of insulin and glucose, as well as the expression of insulin responsive genes (GK and G6Pase) were investigated. An index of insulin resistance is hyperinsulinemia as a consequence of the body no longer responding to the normal levels of insulin. Acute ethanol significantly increased ( 3-fold) plasma concentrations of insulin (Figure 3.5, upper panel, closed circles), but had no effect on plasma glucose; this apparent inability of insulin to decrease plasma glucose under these conditions is in line with previous studies using euglycemic 
clamps. ${ }^{19}$ Ethanol also changed the expression profiles of the insulin responsive genes in a manner that is suggestive of insulin resistance (Figure 3.5, middle/lower panel). Specifically during times of unimpaired insulin signaling, GK expression is upregulated by insulin while G6Pase expression is downregulated. This effect of insulin contributes to the shift in the metabolism of the cell from glucose production to glucose utilization. However, Figure 3.5 illustrates that acute ethanol increases G6Pase expression while decreasing GK, which is a pattern opposite to that caused by insulin. Taken together, these data support the hypothesis that ethanol causes hepatic insulin resistance in vivo under the current conditions.

The effect of ethanol on insulin responsive genes was also determined in mice that received the PKCE ASO (Figure 3.7). Interestingly, whereas the upregulation of G6Pase caused by ethanol was almost completely blunted by the ASO, the downregulation in GK was not affected by the ASO. These data indicate that PKCE mediates some aspects of insulin resistance, but not others. This may not be surprising, given the fact that these two genes are regulated by insulin via different downstream signaling cascades. ${ }^{87,88}$ Therefore, PKC $\varepsilon$ could inhibit the cascade that downregulates G6Pase by insulin, but not be involved in the cascade that upregulates GK by insulin. These results suggest that PKCE may be a causal player in part, for the impaired hepatic insulin signaling caused by this model of acute ethanol exposure. 


\section{Potential mechanism by which ethanol activates PKC $\varepsilon$}

One of the well-known metabolic effects of ethanol metabolism is an increase in the NADH:NAD+ ratio; as mentioned in the Introduction of this chapter, this increased pyridine nucleotide redox ratio inhibits the $\beta$-oxidation of free fatty acids, which then causes NEFA to accumulate. ${ }^{85}$ The rapid and robust increase in hepatic NEFA observed here (Figure 3.1) are likely attributable to this mechanism. DAG can be produced by a number of different mechanisms, including de novo synthesis via the triacylglycerol pathway. In addition to increasing NEFA supply for DAG synthesis, the metabolic effect of ethanol metabolism is likely to increase other metabolites that are required DAG synthesis (e.g., dihydroxyacetone phosphate, a-glycerophosphate, etc.). ${ }^{89}$ For example, glyceraldehyde phosphate dehydrogenase is inhibited and glycerol-3phosphate dehydrogenase is activated by an increase in the NADH:NAD+ ratio ${ }^{90}$; such an effect will be expected to cause dihydroxyacetone phosphate and $\alpha-$ glycerophosphate to accumulate, which would further favor DAG formation from NEFA.

The blockade of expression of PKCE was only able to confer partial protection against fatty liver owing to acute ethanol exposure. This result suggests that other mechanisms independent of PKC $\varepsilon$ are also playing a role in steatosis caused by ethanol. For example, there are many isoforms of PKC besides $\varepsilon$ that have been shown to cause insulin resistance. ${ }^{58}$ Therefore, it is possible that one or more of these PKC isoforms could be collaborating with PKC $\varepsilon$ to cause ethanol-induced steatosis. Alternatively, agents that cause 
insulin resistance through mechanisms unrelated to the PKC family could also be contributing to fatty liver owing to ethanol. Finally, it may very well be possible that the redox inhibition of the $\beta$-oxidation of free fatty acids caused by the metabolism of alcohol is responsible for the remaining steatosis that is not blunted by the PKCE ASO. Clearly, all of these possible mechanisms could be working in tandem with PKCE to cause ethanol-induced fatty liver.

\section{Summary and Conclusions}

The main goal of this work was to identify and characterize the role of PKC $\varepsilon$ in early alcohol-induced liver disease. The experiments described here suggest a potential mechanism by which PKCE is activated as well as the means by which $\mathrm{PKC} \varepsilon$ contributes to ethanol-induced steatosis. Specifically, ethanol accumulates NEFA which then increases DAG synthesis. DAG allosterically activates $\mathrm{PKC} \varepsilon$, which then impairs insulin signaling and causes hepatic steatosis. Taken together, the results of this study support the hypothesis that PKC $\varepsilon$ plays a causal role in ethanol-induced steatosis. PKC $\varepsilon$ may therefore present a therapeutic target that could prevent and/or halt the progression of ALD. 
Figure 3.1: Effect of acute ethanol on hepatic triglycerides and NEFA.

Quantitation of triglycerides (open squares) and NEFA (closed circles) was determined via colormetric assays. Data represent means \pm SEM $(n=4-6)$ and are normalized to $\mathrm{mg}$ protein. ${ }^{\mathrm{a}}, \mathrm{p}<0.05$ compared to the absence of ethanol ( Time $=0 \mathrm{~h}$ ). 


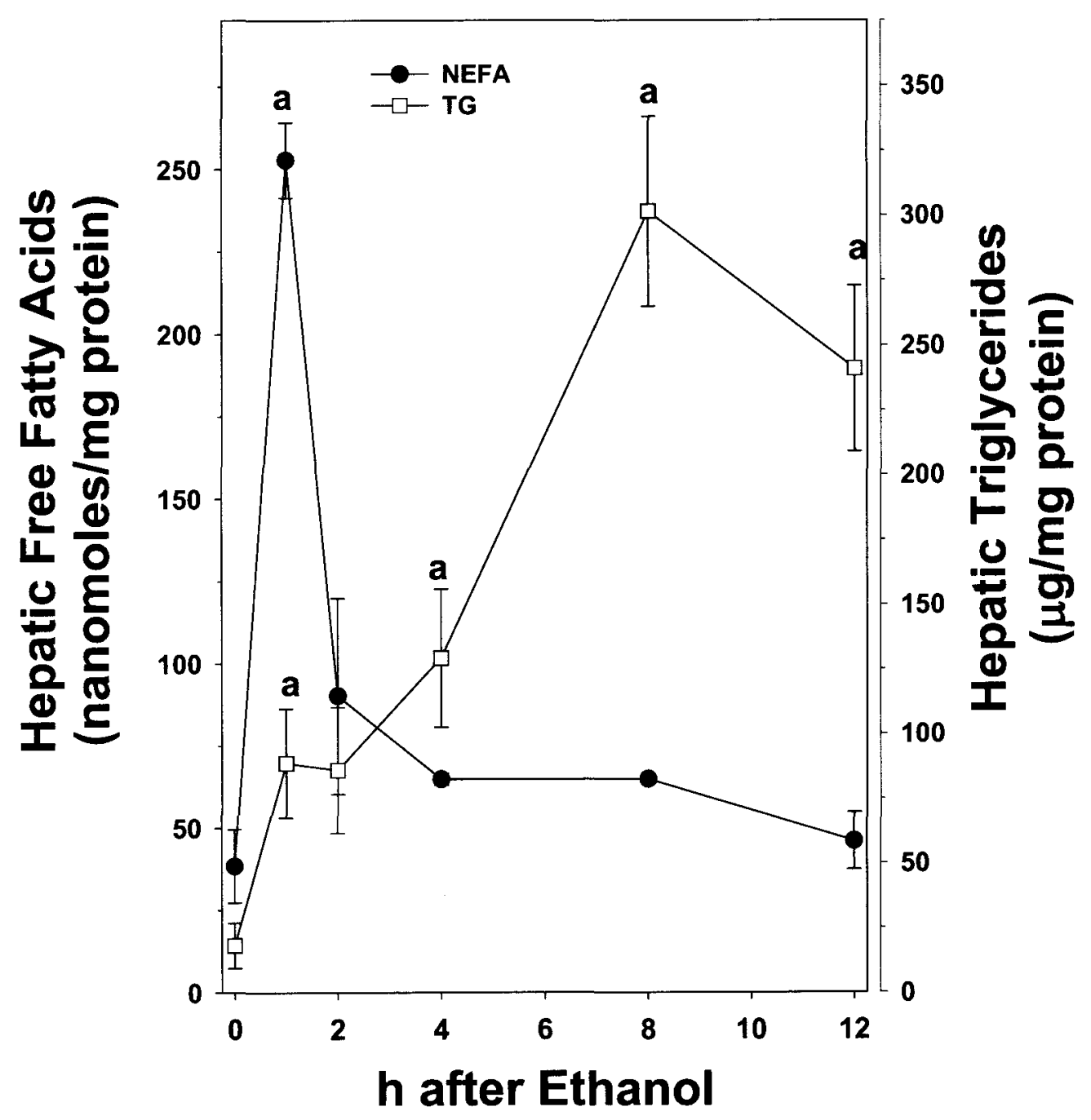


Figure 3.2: Effect of acute ethanol on hepatic DAG levels.

Positive electron spray ionization mass spectrums are shown from liver extracts after chromatographic separation on a silica gel column to remove polar phospholipids. $1.48 \mu \mathrm{g}$ phosphate of sample was loaded per column. Since $\mathrm{Na}^{+}$ adducts were used to detect DAG species, the $\mathrm{m} / \mathrm{z}$ value represents the molecular weight of the respective DAG plus the weight of a sodium molecule $\left(\mathrm{M}+\mathrm{Na}^{+}\right)$. Representative chromatograms of livers from control and ethanolexposed mice are shown with peaks identified by fragmentation to be a known DAG: DAG 32:1 with an ether linkage $\left(\mathrm{M}+\mathrm{Na}^{+}=575\right)$, DAG 32:0 with an ether linkage $\left(\mathrm{M}+\mathrm{Na}^{+}=577\right), \mathrm{DAG} 32: 1\left(\mathrm{M}+\mathrm{Na}^{+}=589\right), \mathrm{DAG} 34: 2\left(\mathrm{M}+\mathrm{Na}^{+}=615\right), \mathrm{DAG}$ 34:1 $\left(\mathrm{M}+\mathrm{Na}^{+}=617\right), \mathrm{DAG} 36: 4\left(\mathrm{M}+\mathrm{Na}^{+}=639\right)$ and DAG 38:6 $\left(\mathrm{M}+\mathrm{Na}^{+}=663\right)$. The series numbers indicate the total number of carbons in the acyl chains on the DAG molecule. The peak at $\mathrm{m} / \mathrm{z} 535$ corresponds to the internal standard (DAG 28:0). 

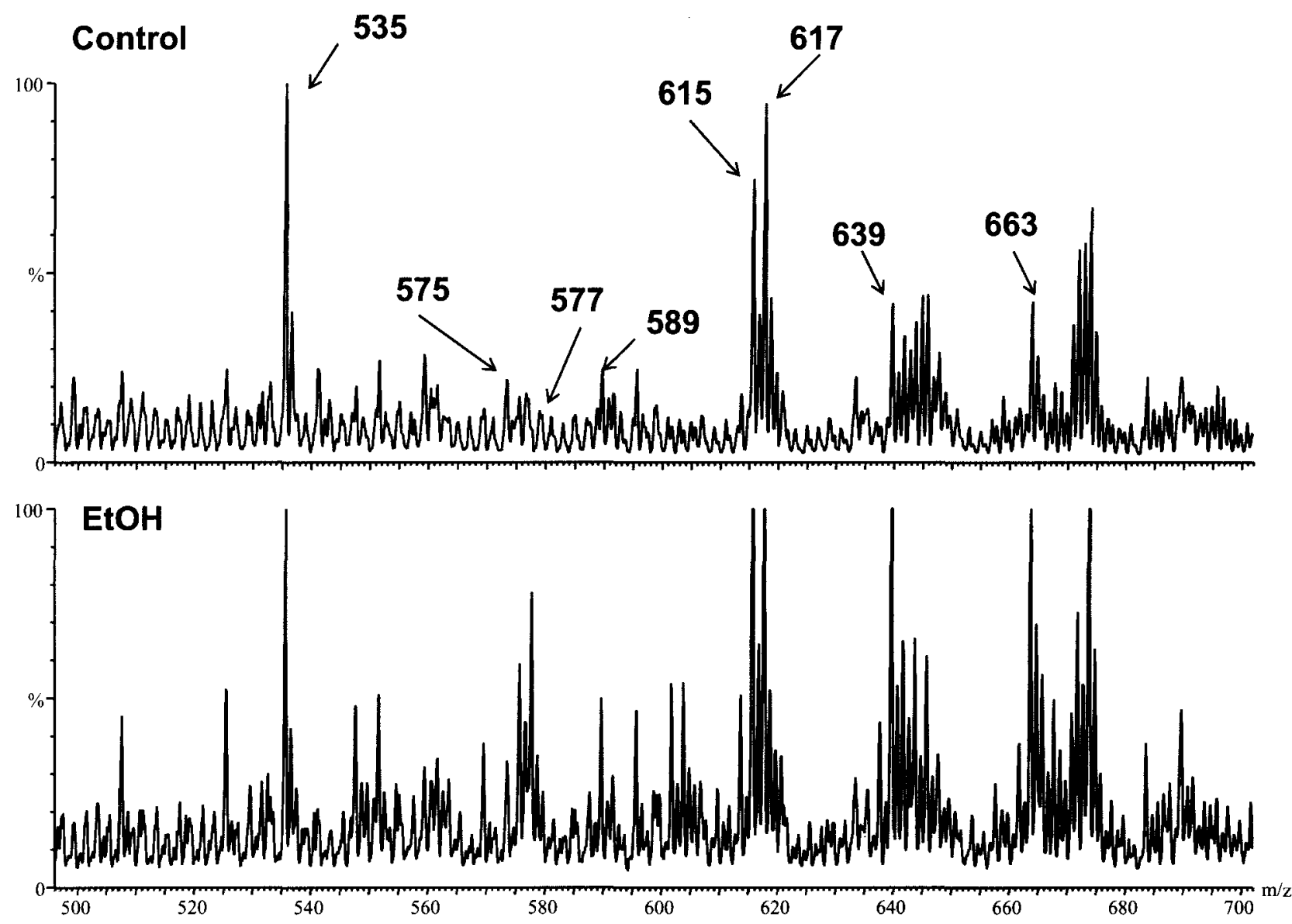
Figure 3.3: Effect of acute ethanol on specific DAG species.

Quantification of DAG was performed as described in Chapter II.

Summary data of mean results of control (red) and ethanol-exposed (green) mice are shown in the upper panel (see also Figure 3.2). The lower panel compares and summarizes the relative amounts of select DAG identified in the upper panel.

Data represent means \pm SEM $(n=4-6)$ and are normalized to $\mu$ g phosphate. ${ }^{a}$, $p<0.05$ compared to the absence of ethanol. 

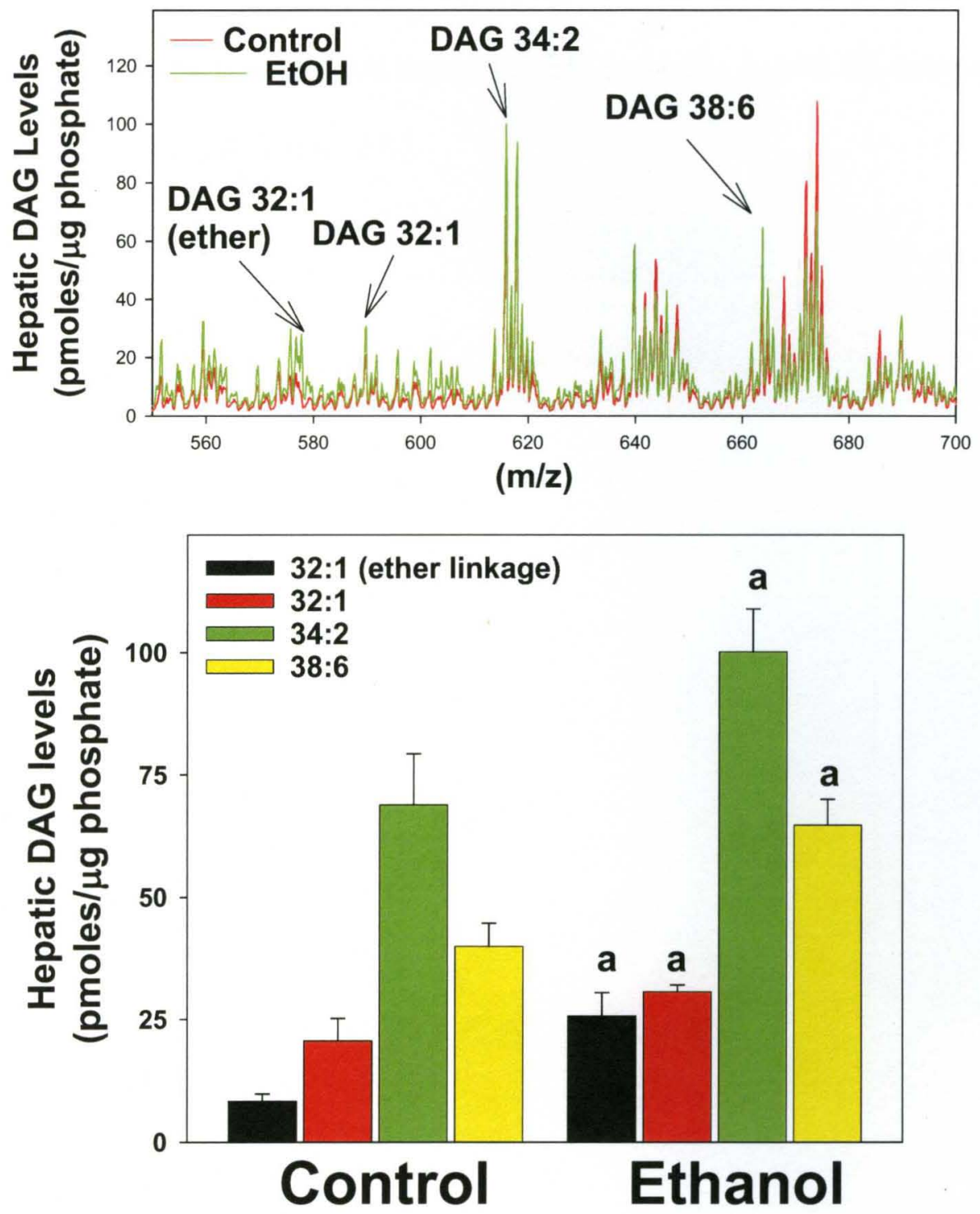
Figure 3.4: Effect of acute ethanol on the activation of PKC $\varepsilon$ in mouse liver.

Western blot of PKCE was performed as described in Chapter II.

Representative blots are shown depicting the membrane and cytosolic fractions of $P K C \varepsilon$. The data represent means \pm SEM $(n=4-6) .{ }^{a}, p<0.05$ compared to the absence of ethanol (Time $=0 \mathrm{~h})$. 


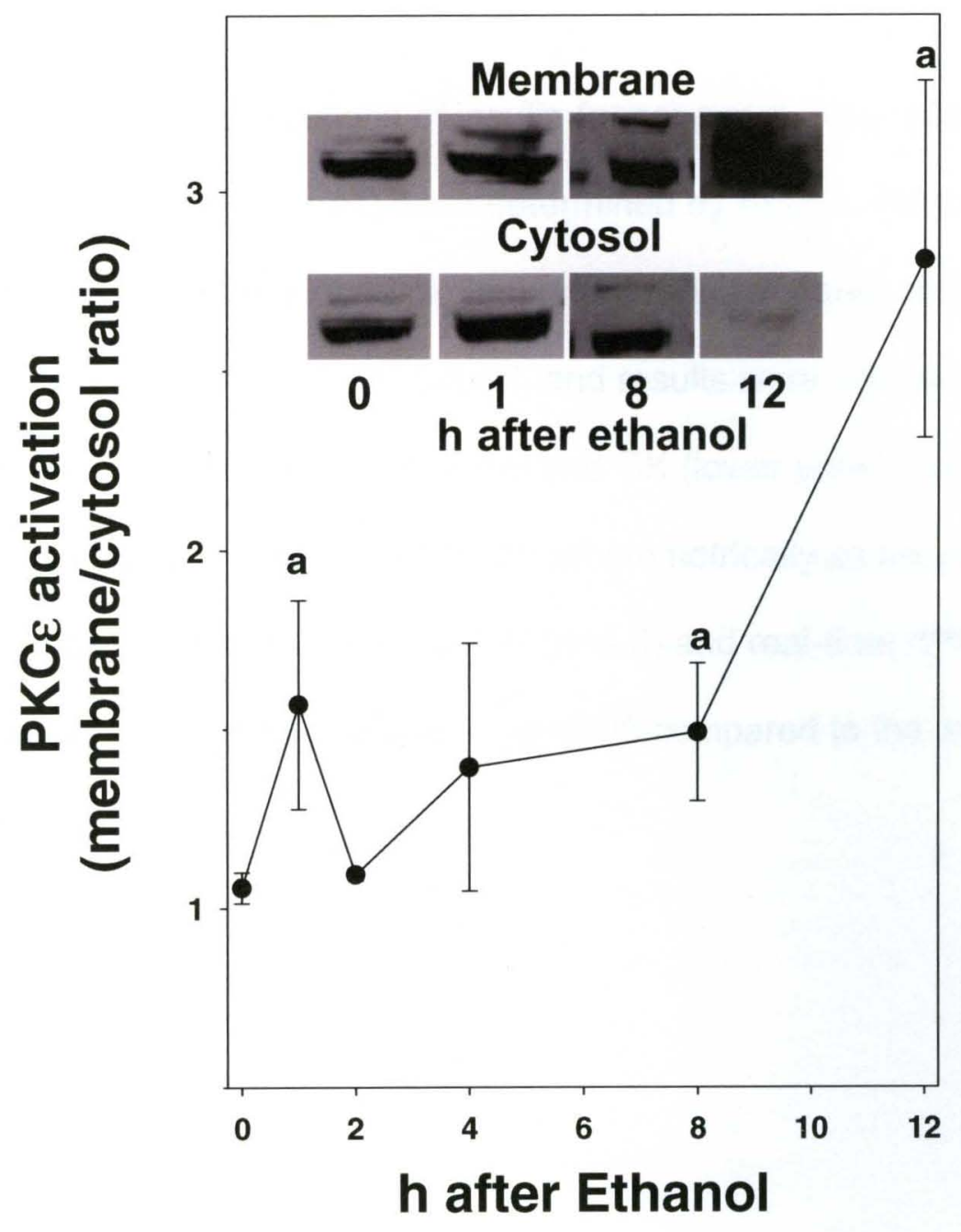


Figure 3.5: Effect of acute ethanol on the plasma concentrations of insulin and glucose and on the expression/activity of insulin-responsive genes in mouse liver.

Plasma concentrations of insulin (upper panel, closed circles) and glucose (upper panel, open squares) were determined by ELISA. Real-time rtPCR for G6Pase (upper panel, closed circles) and GK (lower panel, closed circles) was performed as described in Chapter II, and results were normalized to $\beta$-actin. G6Pase (upper panel, open squares) and GK (lower panel, open squares) protein activity was determined spectrophotometrically as described in Materials and Methods. Data are means \pm SEM ( $n=4-6)$ and real-time rtPCR data are reported as fold of control values. ${ }^{a}, p<0.05$ compared to the absence of ethanol ( Time=0 h). 

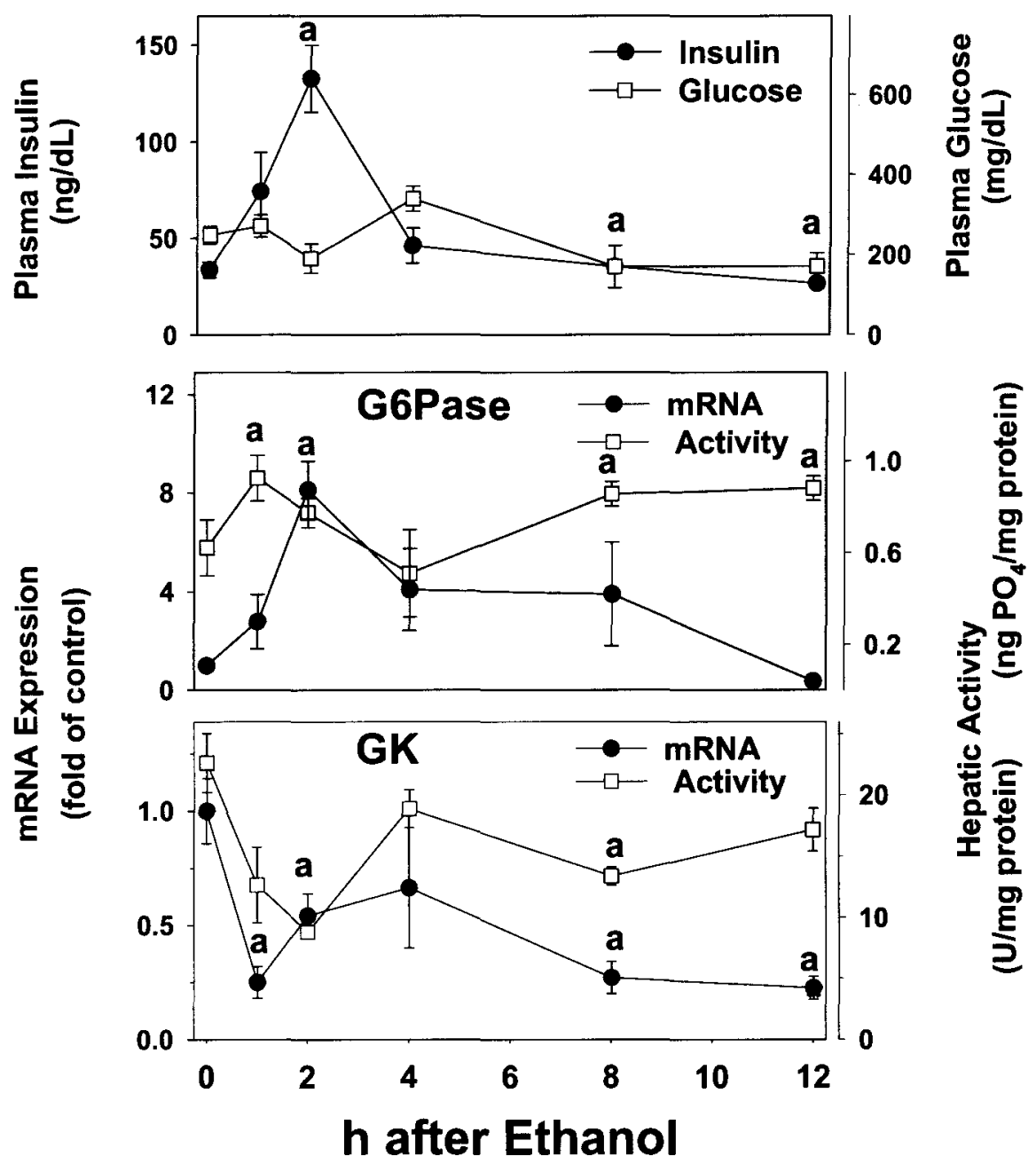
Figure 3.6: Effect of PKCE ASO on ethanol-induced steatosis.

Oil red O staining was performed as described in Chapter II.

Representative photomicrographs (200xmagnification) of saline-treated wild-type mice receiving maltose-dextrin (upper right panel) and ethanol (upper left panel), as well as PKCE ASO treated-mice receiving ethanol (lower left panel) are shown. Quantitation of triglycerides (lower right panel) was performed via a colorimetric assay as described in Chapter II. Data represent means \pm SEM $(n=4-6)$ and are normalized to mg protein. ${ }^{a}, p<0.05$ compared to the absence of ethanol; ${ }^{b}$, $p<0.05$ compared with wild-type or saline-treated mice exposed to ethanol. 


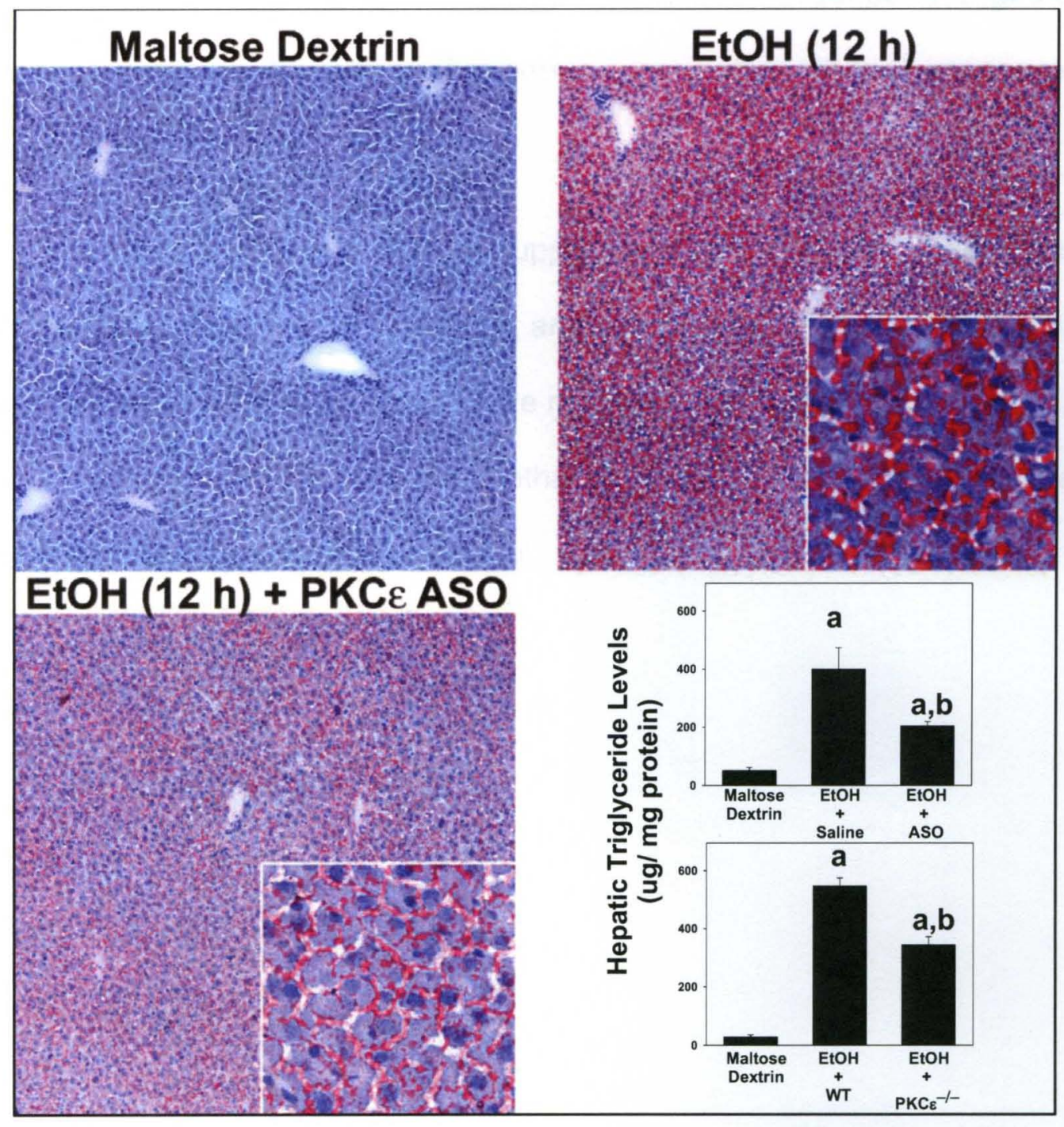


Figure 3.7: The effect of the PKCE ASO on ethanol-induced changes on the expression of insulin-responsive genes 1 hour after ethanol exposure in mouse liver.

Real-time rtPCR for G6Pase (upper panel) and GK (lower panel) was performed as described in Chapter II, and results were normalized to $\beta$-actin. Data are means \pm SEM $(n=4-6)$ and are reported as fold of control values. ${ }^{a}$, $p<0.05$ compared to the absence of ethanol as determined; ${ }^{b}, p<0.05$ compared with saline-treated exposed to ethanol. 


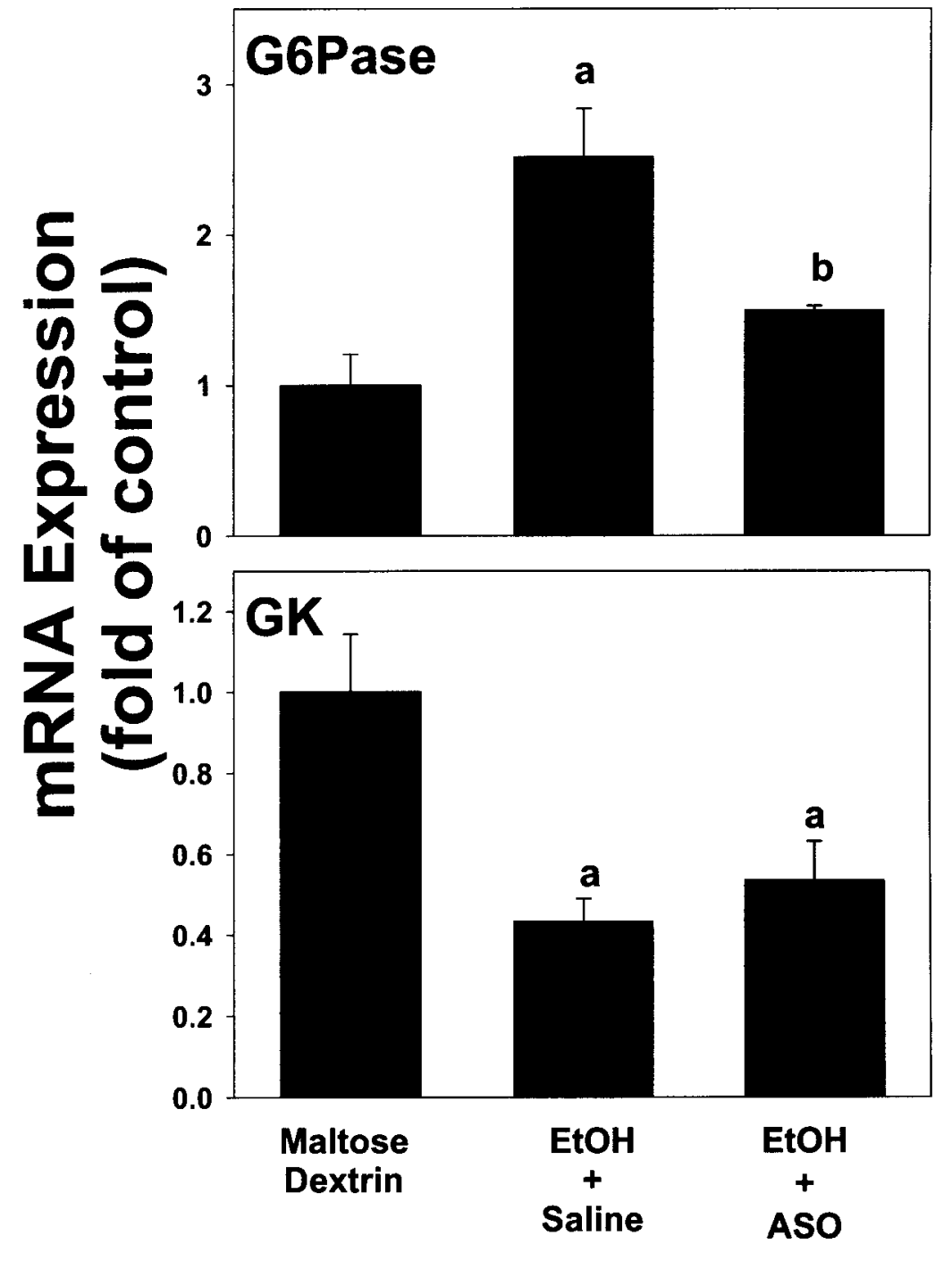




\section{CHAPTER IV}

PKC $\varepsilon$ contributes to chronic ethanol-induced steatosis in mice but not inflammation and necrosis 


\section{A. Introduction}

Alcoholic liver disease is a serious concern for the world's population, causing millions of deaths per year. ${ }^{1}$ The pathological steps of ALD are well understood: steatosis first develops, followed by inflammation and necrosis; if the insult(s) persists, fibrosis and cirrhosis can then develop. Whereas the disease progression is well understood, our knowledge of the mechanisms involved in causing the disease is lacking; as a result, there is no FDA-approved therapy to treat or reverse ALD. Steatosis is a critical stage in the pathology of alcoholic liver disease (ALD). Although steatosis was once thought to be an inert pathology of ALD, more recent evidence has indicated that blunting or blocking steatosis could help prevent the progression of ALD. ${ }^{9,28,84}$ Therefore, pharmacologically targeting the cause(s) of ethanol-induced steatosis is a promising potential therapy for ALD.

Recent evidence has suggested that protein kinases $c$, in particular protein kinase c-epsilon (PKCE), can contribute to steatosis in experimental nonalcoholic fatty liver disease (NAFLD). ${ }^{86}$ Specifically, PKC $\varepsilon$ impairs the tyrosine phosphorylation of the insulin receptor substrate-2 (IRS-2), which leads to hepatic insulin resistance, impaired lipid metabolism, and subsequent steatosis. ${ }^{86}$ Chapter III in this dissertation showed that PKCE also plays a causal role in acute ethanol-induced steatosis in mice. ${ }^{91}$ Results from that study support the working hypothesis that the inhibition of $\beta$-oxidation of fatty acids caused by ethanol metabolism increases the fatty acid supply for de novo diacylglycerol (DAG) synthesis. This increase in DAG allosterically activates PKCE, which then 
contributes to the increase in hepatic triglycerides caused by ethanol by inducing insulin resistance (Chapter III). ${ }^{91}$ Thus, PKC $\varepsilon$ activation may be a shared mechanism of hepatic steatosis in ALD and NAFLD.

Whereas acute bolus ethanol induces a robust steatotic response in the liver (Chapter III), ${ }^{91}$ there is little or no inflammation or necrosis caused by this dose regimen of ethanol in rodents. PKCE has been shown to contribute to inflammation in response to various insults (e.g. LPS), which suggests that PKC $\varepsilon$

may also contribute to more advanced stages of ALD (e.g. steatohepatitis). ${ }^{92}$ Furthermore, as mentioned above, blunting steatosis caused by alcohol may in and of itself prevent later phases of ALD. This potential role of PKCE in these later stages of experimental ALD has not yet been directly studied. Therefore, the purpose of this study was to determine the role of PKCE in chronic ethanolinduced liver damage. Specifically, the effect of knocking down PKCE on liver damage caused by chronic enteral alcohol exposure was determined in mice.

\section{B. Materials and Methods}

\section{Animals and Treatments}

Mice were exposed to ethanol via the Tsukamoto-French model described in Chapter II. Some animals received a PKCE ASO as mentioned in Chapter III.

\section{Histological analysis}

See detailed method in Chapter II. 


\section{Clinical Chemistry}

See detailed method in Chapter II.

\section{RNA isolation and Real-Time PCR}

See detailed method in Chapter II.

\section{Quantitation of individual free fatty acid species}

Specific free fatty acid species were quantitated by gas chromatography as described in Chapter II.

\section{Immunoblotting}

Western blotting of PKC $\varepsilon$ was performed as described in Chapter II.

\section{Lipid Determinations}

See detailed method in Chapter II.

\section{Results}

\section{Body weight and urine ethanol concentrations.}

Throughout the duration of this study, all mice gained $\sim 0.5 \mathrm{~g} /$ week, with no differences between dietary and treatment groups. Daily urine alcohol concentrations cycled between 0 and $500 \mathrm{mg} / \mathrm{dl}$ in ethanol-exposed mice, as observed previously. ${ }^{14} \mathrm{PKC} \varepsilon$ ASO- and vehicle-treated mice receiving ethanol had similar patterns of urine alcohol cycling, with mean alcohol levels not significantly different $(284 \pm 78 \mathrm{mg} / \mathrm{dl}$ versus $217 \pm 44 \mathrm{mg} / \mathrm{dl}$ for vehicle and ASO groups, respectively). In saline-treated mice fed control diet, liver weights (as 
percent of body weight) were $5.9 \pm 0.5 \mathrm{~g}$, whereas ethanol-fed mice had liver weights of $9.7 \pm 0.3 \mathrm{~g}$. This doubling in liver weight was not affected by knocking down PKC $\varepsilon$.

\section{Effect of chronic ethanol exposure on plasma and histological indices of liver damage}

Figure 4.1A shows representative photomicrographs depicting liver pathology ( $\mathrm{H}+\mathrm{E}$ stain, left column), fat accumulation (oil red $\mathrm{O}$ stain, middle column) and neutrophil infiltration (CAE stain, right column). Figure 4.1B summarizes quantitation of the staining, as well as plasma transaminase values. Administration of PKCE ASO to animals fed control diet had no effect on liver pathology or plasma transaminases (Figure 4.1B). Chronic exposure to ethanol diet for 4 weeks increased fat accumulation, inflammation, and cell death (Figure 4.1A, middle row, Figure 4.1B) as well as increases in plasma transaminases (ALT and AST) (Figure 4.1B, right panel). Coadministration of the PKCE ASO partially blunted the hepatic fat accumulation caused by ethanol (Figure 4.1A, bottom row, Figure 4.1B); specifically, the PKC $\varepsilon$ ASO blunted the increase in macrovesicular fat caused by ethanol, but did not significantly alter microvesicular fat accumulation. However, the PKC $\varepsilon$ ASO did not significantly attenuate the increases in indices of inflammation and liver damage caused by ethanol (Figure 4.1). Indeed, the increase in neutrophils caused by ethanol was significantly enhanced ( 2-fold) by ASO administration (Figure 4.1B, left panel). In line with these findings, the PKCE ASO did not prevent the increase in transaminases caused by ethanol (Figure 4.1B, right panel). 


\section{Effect of ethanol on hepatic DAG}

Some of the major activators of PKC $\varepsilon$ are diacylglycerols (DAG). ${ }^{18}$ Therefore, the effect of chronic ethanol on hepatic DAG content was determined (Figure 4.2). Figure 4.2 shows representative mass chromatograms from mice fed control- and ethanol-containing diet. In general, most DAG species were increased by ethanol. For example, chronic ethanol significantly increased hepatic content of DAG $36: 4$ from $129 \pm 26$ pmoles/mg wet weight to $346 \pm 66$ pmoles/mg wet weight. Likewise, ethanol exposure increased the amount of DAG $36: 3$ from $72 \pm 4$ pmoles $/ \mathrm{mg}$ wet weight to $289 \pm 63$ pmoles $/ \mathrm{mg}$ wet weight.

\section{Chronic ethanol activates PKCE}

Figure 4.3 shows the effect of chronic ethanol on protein and mRNA levels of PKCE. As stated previously, a recent study completed by this group demonstrated that acute ethanol increases the ratio of membrane to cytosolic PKC $\varepsilon$ (Chapter III), ${ }^{91}$ which is indicative of increased activation. Therefore, the effect of chronic ethanol on this index of PKCE activation was determined in Figure 4.3 (upper panel). Ethanol exposure significantly increased ( 5-fold) PKC $\varepsilon$ membrane localization compared to controls (Figure 4.3, lower left panel). As expected, administration of the PKCE ASO decreased protein levels in both compartments. Figure 4.3 (lower right panel) shows the effect of ethanol on mRNA levels of PKCE. Ethanol alone had no effect on PKCE mRNA expression compared to control mice that received vehicle. In line with the Western data, 
ASO treatment significantly decreased PKCE mRNA levels to about $20 \%$ of controls, irrespective of diet treatment (Figure 4.3, lower right panel).

\section{Effect of knocking down PKC $\varepsilon$ on changes in hepatic lipids caused by ethanol}

Histological indices of lipid accumulation (see Figure 4.1) indicated that ethanol-induced steatosis was blunted by the PKC $\varepsilon$ ASO. The effect of the PKC $\varepsilon$ ASO on the increases in specific hepatic lipid pools (triglycerides, FFA, cholesterol, and phospholipids) was therefore determined. Figure 4.4 shows various parameters of lipid accumulation caused by ethanol. Chronic ethanol caused significant increases in triglycerides, FFA, cholesterol, and phospholipids (Figure 4.4). The PKCE ASO partially increased cholesterol and phospholipids in control-fed mice (Figure 4.4C and D). Furthermore, ASO treatment partially prevented the ethanol-induced increases in triglycerides, FFA, and phospholipids (Figure 4.4). It has been shown that some species of fatty acid (i.e. palmitic acid) can mediate toxic effects in liver cells. ${ }^{93}$ Therefore, a change in total FFA (Figure 4) may not yield information about specific fatty acids of interest. The effect of ethanol and the PKCE ASO on the spectrum of fatty acids was therefore determined by gas chromatography/mass spectrometry (Figure 4.5). Ethanol caused robust increases in all species of fatty acids analyzed compared to control-fed animals. While not able to blunt the accumulation of all species, the PKC $\varepsilon$ ASO blunted ( $50 \%)$ the increases in palmitic (16:0) and oleic $(18: 1 n-9)$ (Figure 4.5). 


\section{Effect of ethanol on key genes}

One of the major genes responsible for de novo fatty acid synthesis is fatty acid synthase (FAS); this gene has also been shown to contribute to ethanol-induced lipid accumulation. ${ }^{94}$ To determine if FAS induction could be in part responsible for the observed effects of the PKCE ASO under these conditions (Figure 4.4B), FAS expression was determined by real-time rtPCR (Figure 4.6A). Chronic ethanol significantly increased ( 4-fold) FAS mRNA levels and this increase was completely attenuated by ASO treatment (Figure 4.6A). Previous studies have demonstrated a key role of TNFa in experimental ALD; for example, TNFR1 knockout mice are almost completely protected against chronic alcohol-induced liver damage. ${ }^{41}$ Furthermore, TNFa has been shown to increase FAS levels. ${ }^{95}$ Ethanol robustly increased ( 3-fold) TNFa expression, and this upregulation was almost completely attenuated by knocking down PKCE (Figure 4.6B). Recent studies have also identified a role of PAl-1 in experimental liver damage caused by chronic ethanol. ${ }^{21}$ Therefore, the effect of chronic ethanol on the expression of this gene was tested (Figure 4.6C). As has been observed previously, ${ }^{21}$ four weeks of enteral ethanol exposure significantly increased ( 4-fold) PAI-1 expression. In contrast to its effect on TNFa, coadminstration of the PKCE ASO had no effect on the increase in PAl-1 expression caused by ethanol (Figure 4.6C).

\section{Effect of chronic ethanol on hepatic fibrin deposition}

It was previously shown that PAI-1 contributes to inflammatory liver damage caused by chronic ethanol exposure. ${ }^{21}$ Previous work has also 
demonstrated that the inhibition of fibrin degradation by PAI-1 contributes to hepatic inflammation. 21, 96, 97 Since the induction of PAI-1 was not attenuated by the PKC $\varepsilon$ ASO (Figure 4.6C), the effect of chronic ethanol on hepatic fibrin deposition was determined. Figure 4.7 comprises representative confocal photomicrographs depicting immunofluorescent detection of fibrin deposition. Chronic enteral ethanol increased fibrin deposition in sinusoidal spaces of the liver lobule (Figure 4.7). In line with PAI-1 expression results (Figure 4.6C), PKC $\varepsilon$ ASO treatment did not affect this increase in fibrin deposition caused by ethanol (Figure 4.7).

\section{Discussion}

It was previously determined that $\mathrm{PKC} \varepsilon$ plays a critical role in acute ethanol-induced steatosis (Chapter III). ${ }^{91}$ However, chronic ALD is actually a series of pathologies (e.g. inflammation, necrosis, etc.) that may or may not be mechanistically related. Therefore, it is important to determine the role of PKCE, not only in steatosis, but also in later more severe stages of ALD. Therefore, the goal of this work was to investigate the role of PKCE in a model of chronic ALD.

The 'two-hit' hypothesis implies that preventing steatosis should blunt more advanced liver damage (e.g., inflammation and necrosis). ${ }^{27,98}$ Since the inhibition of PKC $\varepsilon$ prevented acute ethanol-induced steatosis (Chapter III), it was hypothesized a priori that this effect on steatosis would also protect against inflammation and necrosis caused by chronic ethanol exposure. Surprisingly, whereas PKCE ASO-treatment indeed blunted steatosis caused by chronic ethanol, it provided no protection against inflammation or necrosis (Figure 4.1). 
Ethanol exposure causes steatosis via increases in synthetic pathways of lipids as well as decreases in catabolic pathways. For example, ethanol induces FAS expression and activity (synthetic) and concomitantly inhibits the $\beta$-oxidation (catabolic) of fatty acids. ${ }^{85,94}$ Here, the increase in FAS expression caused by ethanol was almost completely attenuated in ASO-treated mice that received ethanol (Figure 4.6). This downregulation of FAS by the ASO correlated with a decrease in lipid (i.e. triglycerides, FFA, and phospholipids) accumulation caused by ethanol (Figure 4.4). Therefore, these data suggest that under these conditions, the increase in lipid accumulation caused by ethanol is mediated, in part, by the indirect upregulation of FAS via PKCE. Although, there is no evidence that PKCE directly influences FAS expression, it has been shown that TNFa increases FAS levels in rodent liver. ${ }^{95}$ Furthermore, previous studies have shown that PKC $\varepsilon$ mediates the upregulation of TNFa expression caused by LPS exposure in liver. ${ }^{99}$ Here, the increases in mRNA levels of TNFa caused by ethanol were significantly blunted by ASO treatment (Figure 4.6). Therefore, the PKC $\varepsilon$ ASO may be blunting FAS induction indirectly by preventing the induction of TNFa.

As mentioned in the Introduction of this chapter, steatosis is hypothesized to be a key step in ALD. ${ }^{9}$ Furthermore, conditions that blunt steatosis generally blunt later stages of experimental ALD. ${ }^{100}$ It was therefore somewhat surprising that even though the PKCE ASO was able to significantly attenuate fatty liver caused by alcohol, more severe liver injury was unaffected. Such a finding, however, is not without precedent. For example, Yamaguchi et al. ${ }^{101}$ showed 
that in a methionine-choline deficient mouse model, the inhibition of diacylglycerol acyltransferase 2 (DGAT2) prevented steatosis, but actually exacerbated inflammation and liver damage. The increase in liver injury in that study was attributed to the accumulation of toxic free fatty acids that no longer enter into triglyceride synthesis. Here, such an increase in fatty acids ${ }^{101}$ was not observed in the PKCE ASO group. Indeed, there was a general decrease in this lipid pool (Figure 4.4). Furthermore, the ethanol-induced increase in fatty acids known to be hepatotoxic (e.g. palmitic acid ${ }^{102}$ ) was actually blunted by the PKC $\varepsilon$ ASO (Figure 4.5). It is therefore unlikely that the effects observed here can be explained via the mechanisms identified in those previous studies. ${ }^{101,102}$

A previous study determined that a high fat diet with cholesterol can cause inflammation with little or no steatotic response. ${ }^{103}$ Specifically, it was determined that LDLR-deficient and apolipoprotein E2 overexpressing mice fed a high fat cholesterol diet did not have increased triglyceride content compared to control mice, but the diet did increase the number of inflammatory foci. In that study, the authors propose that a diet high in cholesterol increases plasma lowdensity lipoproteins, triggering a hepatic inflammatory response. ${ }^{103}$ Furthermore, previous studies have shown that accumulation of mitochondrial cholesterol can be hepatotoxic. ${ }^{104}$ These mechanisms could in principle provide an explanation for the results obtained here, as it was determined that chronic ethanol caused a significant elevation in cholesterol that was not attenuated by the PKCع ASO (Figure 4.4C). However, the increase in hepatic cholesterol associated with liver damage in that study ${ }^{103}$ was far more than the $\sim 2$-fold increase observed here 
(Figure 4.4C). Nevertheless, the potential role of cholesterol accumulation under these conditions cannot be dismissed.

In a recent study performed by this group, it was determined PAI-1 is involved in the sensitization of ethanol preexposure to LPS-induced inflammation and liver damage. ${ }^{97}$ PAI-1 has been shown in studies completed by this group and others to contribute to hepatic inflammation. ${ }^{21,51,97,105}$ One main function of PAl-1 is to impair fibrinolysis, which is hypothesized to mediate the inflammatory effects of PAI-1 upregulation. ${ }^{96}$ For example, it was shown that fibrin matrices are permissive to chemotaxis and activation of monocytes and leukocytes. ${ }^{106,107}$ In that study, ${ }^{97}$ PAl-1 inhibition blocked fibrin deposition, as well as the liver damage. These results suggest that the fibrin accumulation plays an important role in sensitizing the liver to LPS-induced damage. Under the current conditions, chronic ethanol upregulated PAI-1, which was unaffected by the PKCE ASO (Figure 4.6). Chronic ethanol also caused a robust accumulation of fibrin, which could not be attenuated by the PKCE ASO (Figure 4.7). The inability of the PKCE ASO to prevent fibrin accumulation could explain why the PKCE ASO blocked steatosis but had no effect against inflammation.

Taken together, the results of this work provide further support for the role of PKC $\varepsilon$ in ethanol-induced steatosis. Furthermore, this study determined that knocking down PKCE does not prevent inflammation, most likely by failing to prevent the induction of PAI-1 caused by ethanol. Therefore, this work gives further support to the proinflammatory role of PAl-1 in liver, potentially via its ability to block fibrin degradation. These data also suggest that therapies that 
block steatosis may be ineffective in preventing liver injury if they do not regulate inflammatory mediators, such as PAI-1. 
Figure 4.1: Effect of PKC $\varepsilon$ deficiency on chronic ethanol-induced liver damage

Panel A, representative photomicrographs of hematoxylin and eosin $[(H+E$, left panel, 100x) (inserts are 400x)], oil red $O$ [(middle panel, 100x (inserts are $400 \times)$ ] and chloroacetate esterase (CAE, right panel, 100x) staining are shown. Panel B summarizes quantitation of histological and plasma indices of liver damage. 

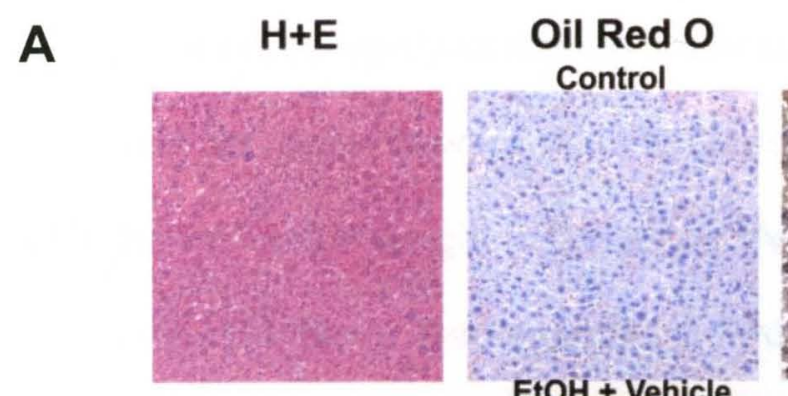

CAE
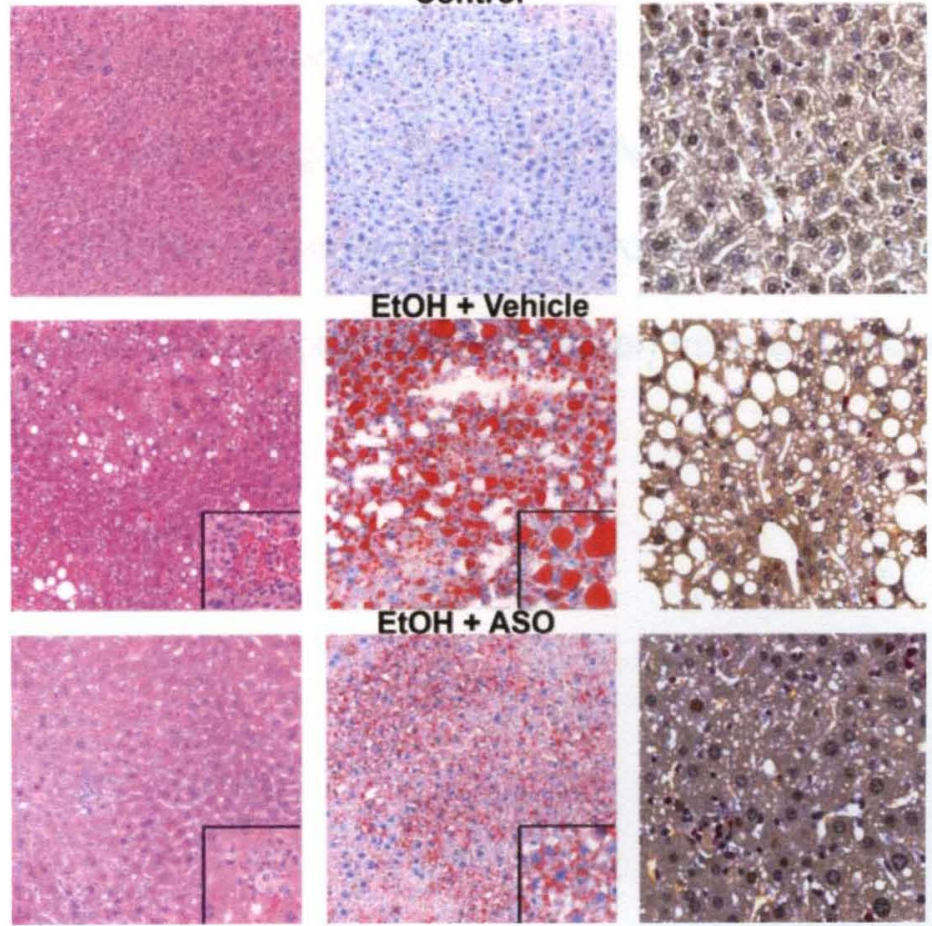

B
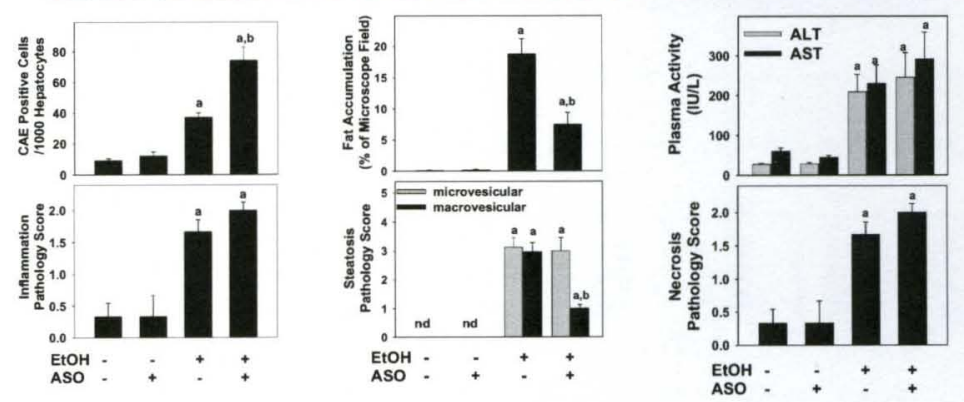
Figure 4.2: Effect of acute ethanol on hepatic DAG and levels

Positive electron spray ionization mass spectrums are shown from liver extracts. Since $\mathrm{Na}^{+}$adducts were used to detect DAG species, the $\mathrm{m} / \mathrm{z}$ value represents the molecular weight of the respective DAG plus the weight of a sodium molecule $\left(\mathrm{M}+\mathrm{Na}^{+}\right)$. Representative chromatograms of livers from control (upper panel) and ethanol-exposed (lower panel) mice are shown. 


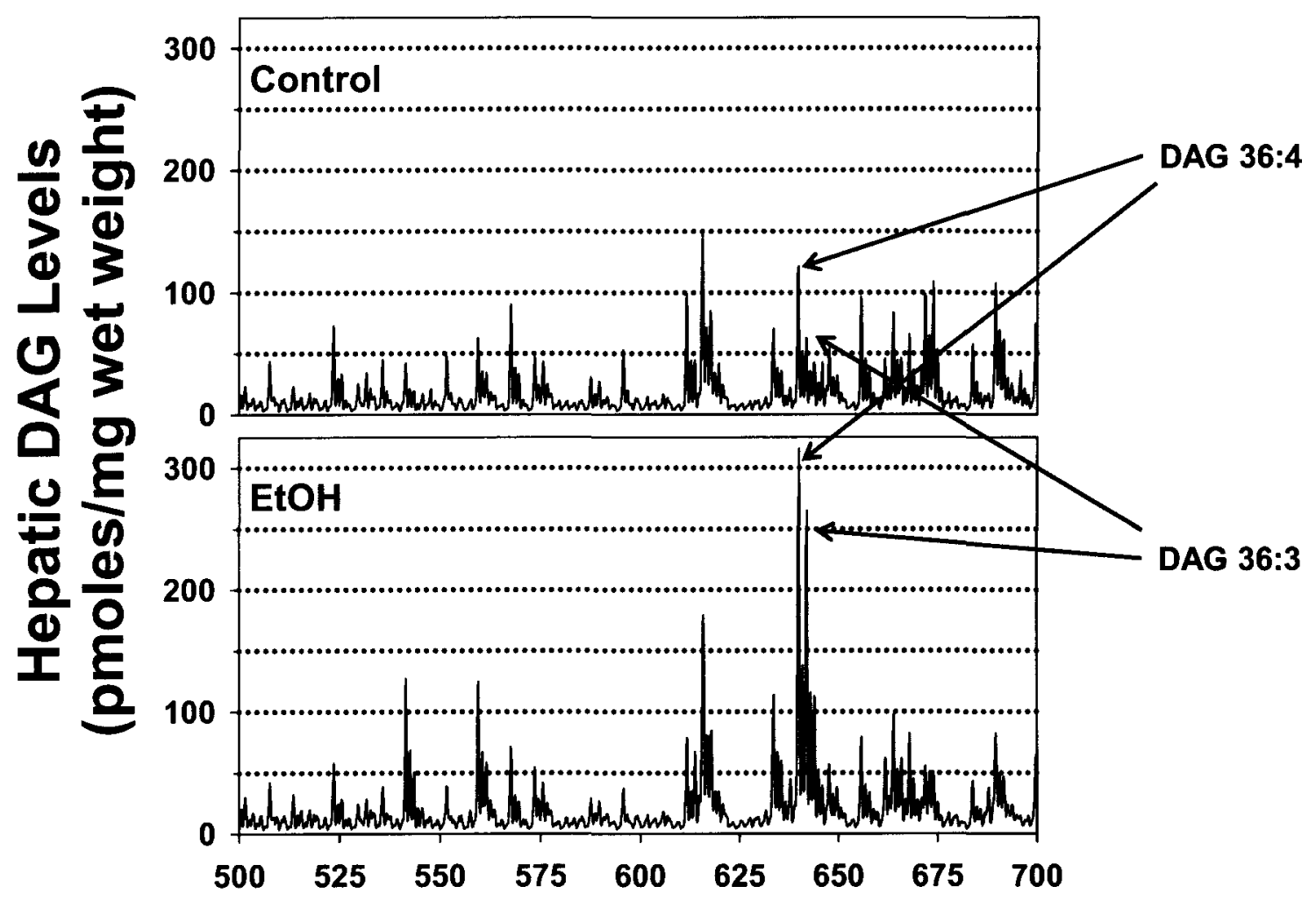


Figure 4.3: Effect of chronic ethanol on the activation of PKC $\varepsilon$ in mouse liver

Representative Western blots (upper panel) are shown depicting the membrane and cytosolic fractions of PKC $\varepsilon$ and quantitated by image-analysis (lower left panel). Real-time rtPCR results (lower right panel) were normalized to $\beta$-actin. 

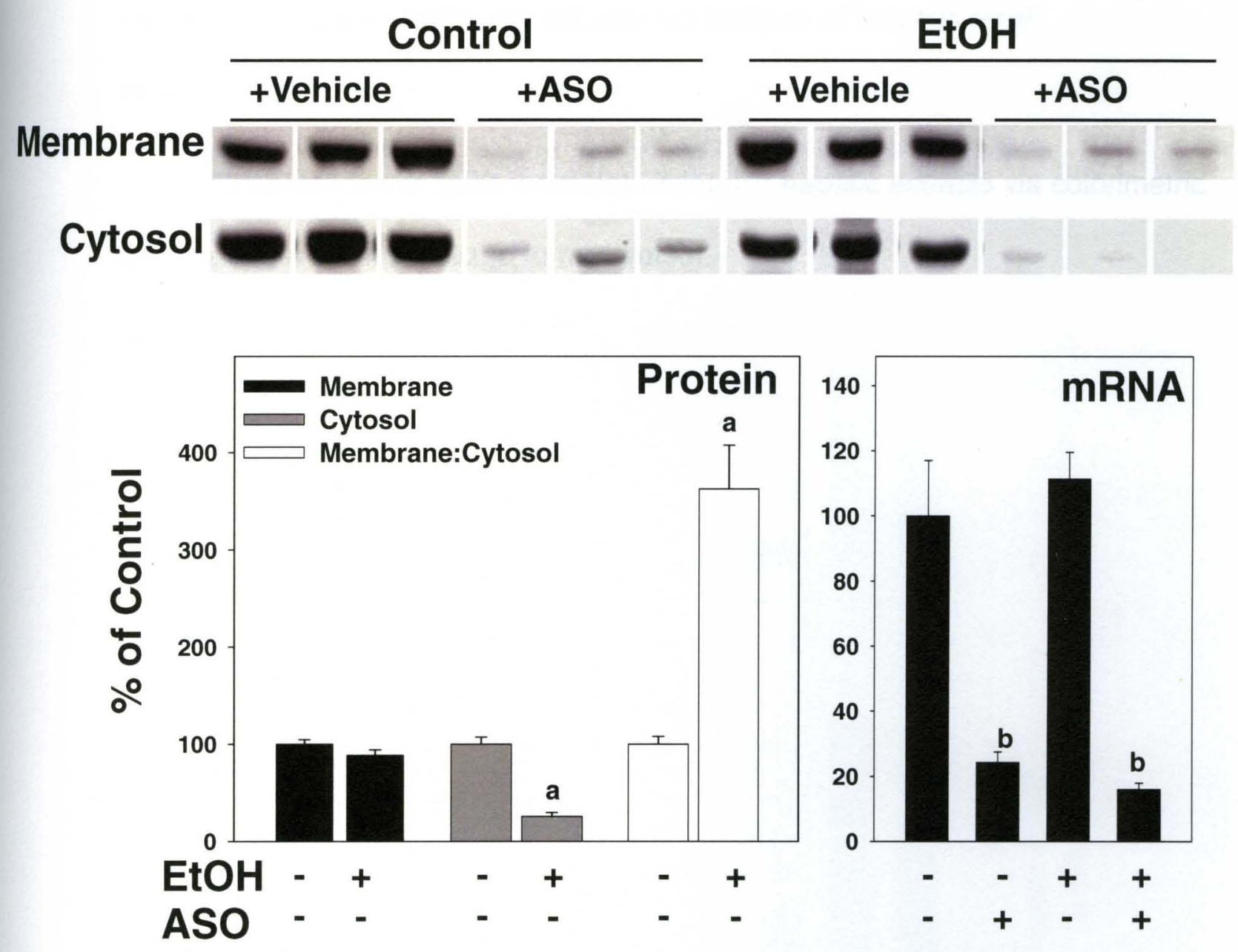
Figure 4.4: Effect of chronic ethanol on indices of hepatic lipid accumulation

Quantitations of lipids were determined in hepatic extracts via colorimetric assays. Data are normalized to $\mathrm{mg}$ protein. 
A

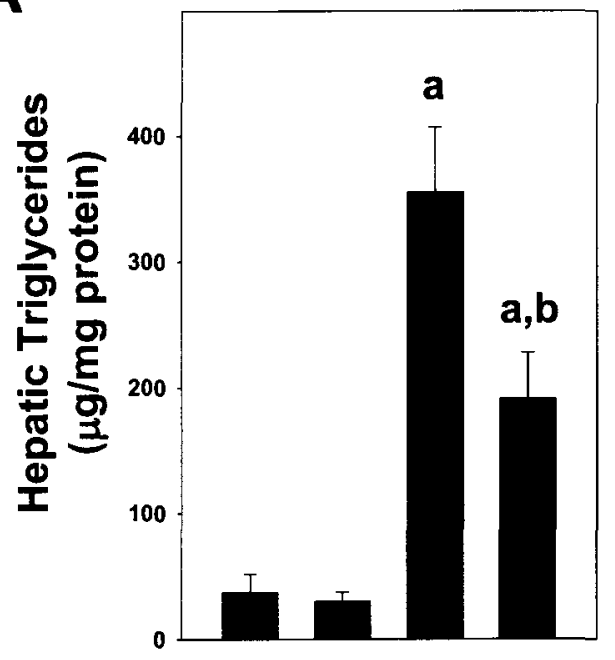

C

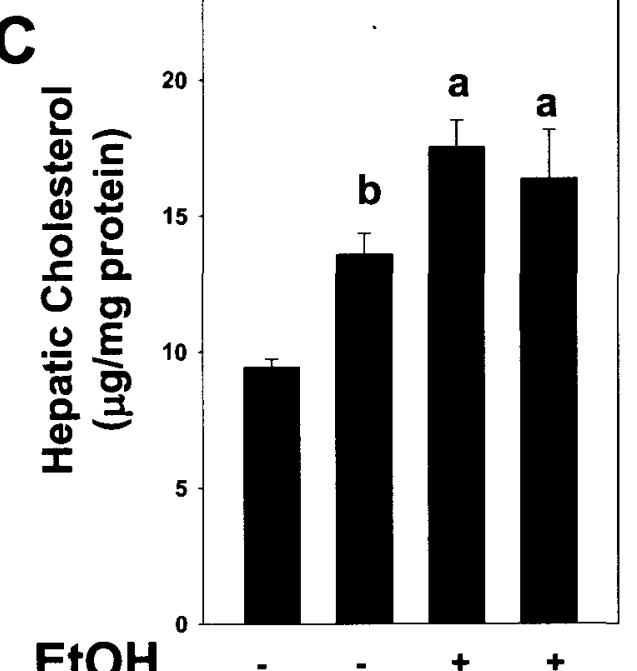

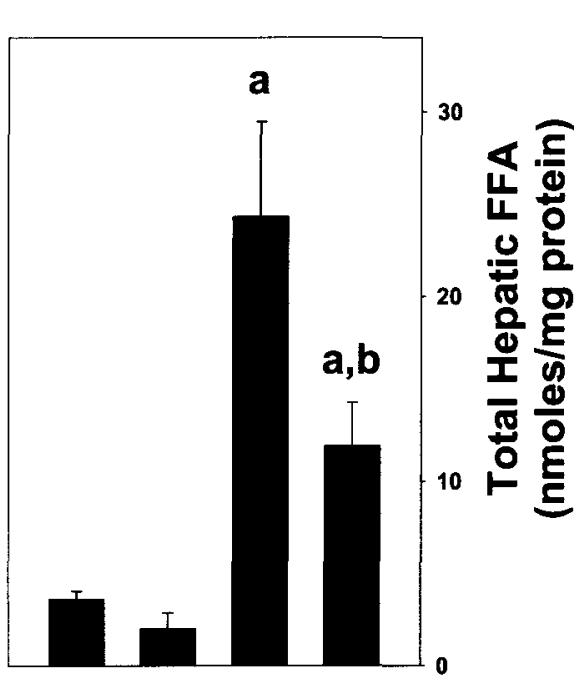

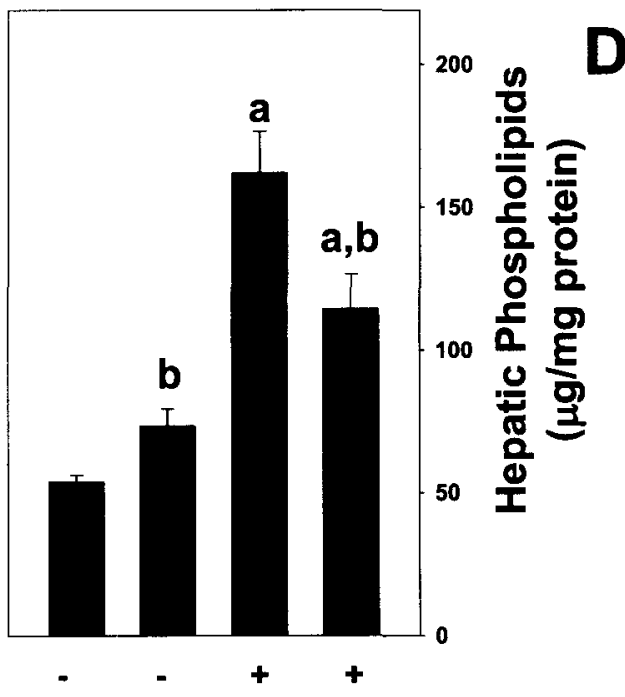

ASO

B

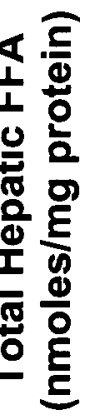

D 
Figure 4.5: Effect of chronic ethanol on specific free fatty acid species Representative gas-liquid chromatography profiles of fatty acid methyl esters are shown from liver extracts after direct transesterification. Labeled peaks by retention times (RT) have been identified to a known free fatty acid. Summary data is shown in tabular format for select species (lower panel). N/A refers to non-applicable. 


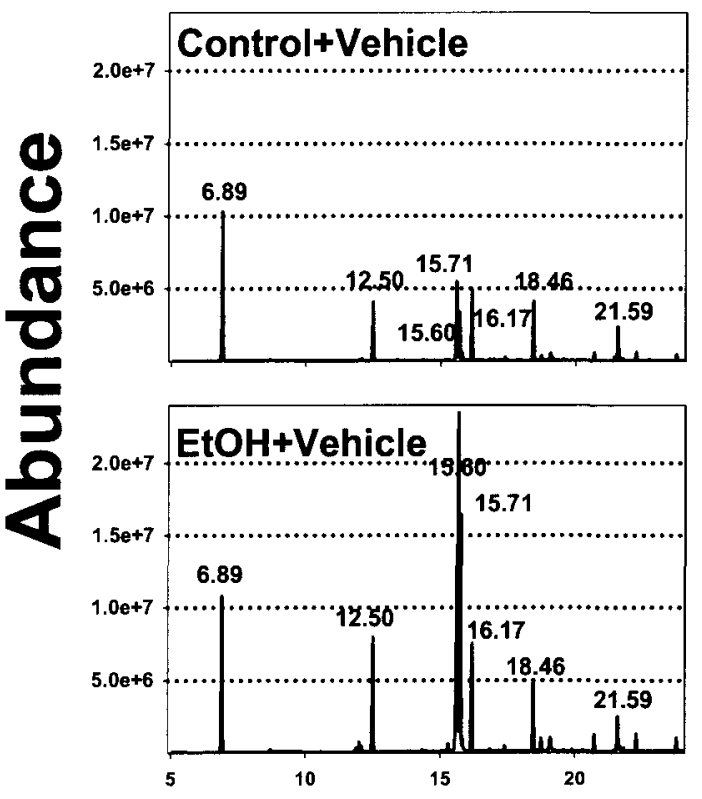

Retention Time
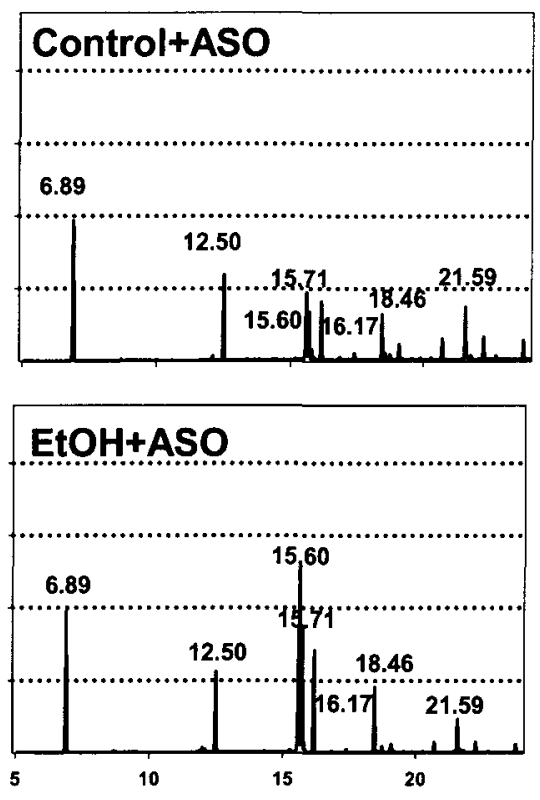

Retention Time

\begin{tabular}{|c|c|c|c|c|c|}
\hline \multirow[b]{2}{*}{ Fatty Acid Amount ( $\mu \mathrm{g} / \mathrm{mg}$ tissue) } & \multirow[b]{2}{*}{$\begin{array}{l}\text { Retention Time } \\
\text { (mins) }\end{array}$} & \multicolumn{2}{|c|}{ Control } & \multicolumn{2}{|c|}{ EtOH } \\
\hline & & +Vehicle & +ASO & +Vehicle & +ASO \\
\hline Internal Standard 13:0 & 6.89 & N/A & N/A & $\mathrm{N} / \mathrm{A}$ & N/A \\
\hline Palmitic 16:0 & 12.50 & $14 \pm 2$ & $20 \pm 5$ & $51 \pm 8^{a}$ & $27 \pm 3^{a . b}$ \\
\hline Linoleic 18:2 (n-6) & 15.60 & $14 \pm 3$ & $15 \pm 3$ & $213 \pm 47^{a}$ & $117 \pm 20^{8}$ \\
\hline Oleic 18:1 (n-9) & 15.71 & $9 \pm 1$ & $9 \pm 5$ & $108 \pm 26^{a}$ & $45 \pm 3^{a, b}$ \\
\hline Stearic 18:0 & 16.17 & $12 \pm 2$ & $12 \pm 1$ & $38 \pm 9 a$ & $28 \pm 6^{a}$ \\
\hline Arachidonic 20:4 (n-6) & 18.46 & $11 \pm 3$ & $8 \pm 1$ & $27 \pm 5^{a}$ & $18 \pm 2^{a}$ \\
\hline Docosohexacanoic 22:6 $(n-3)$ & 21.59 & $6 \pm 1$ & $10 \pm 0.2$ & $14 \pm 3^{2}$ & $11 \pm 1^{a}$ \\
\hline
\end{tabular}


Figure 4.6: Effect of ethanol on expression of key genes

The effect of ethanol and ASO on the expression of fatty acid synthase (FAS; Panel A), tumor necrosis factor a (TNFa; Panel B), and plasminogen activator inhibitor-1 (PAI-1; Panel C) was determined by real-time rtPCR. 


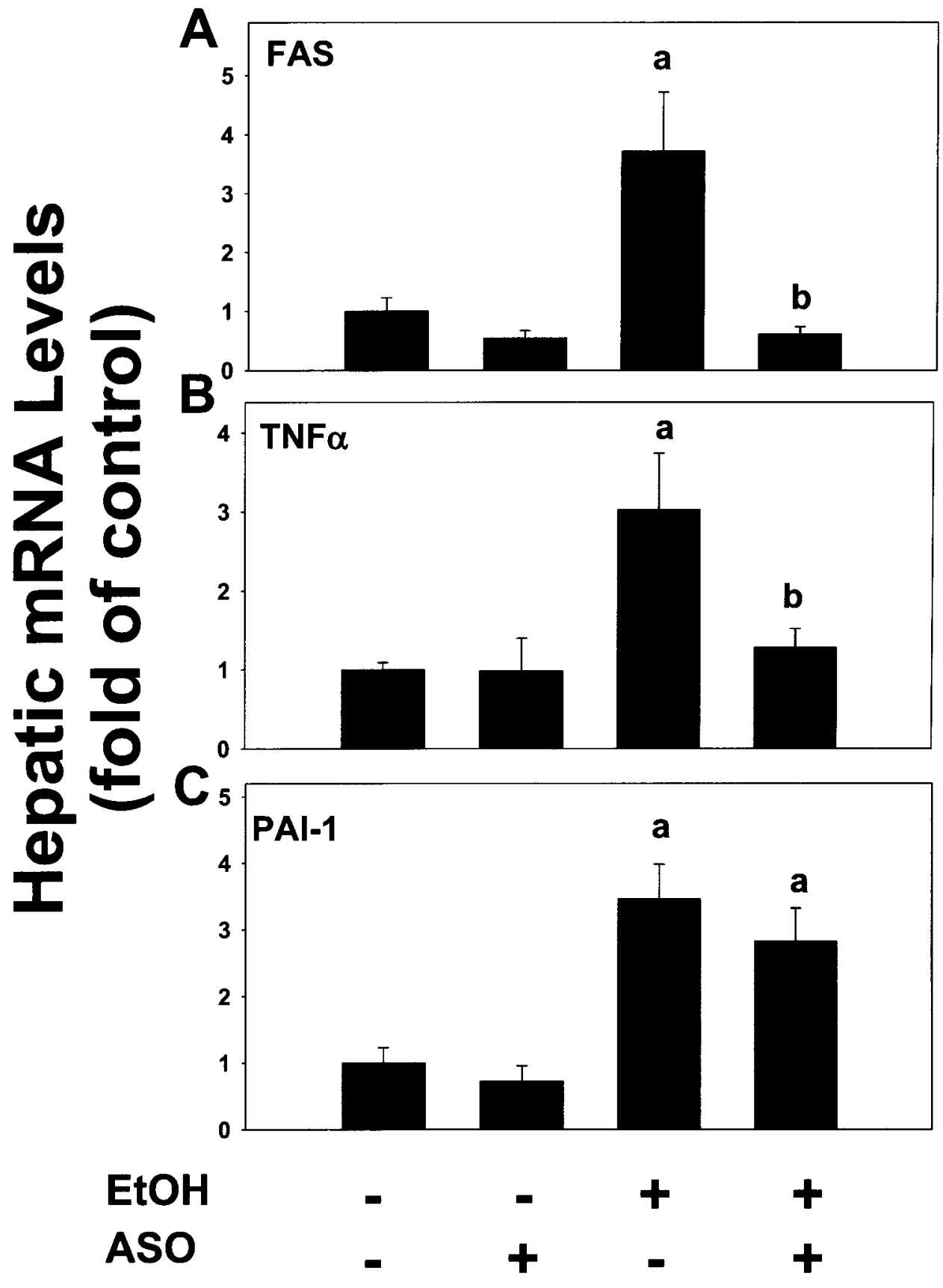


Figure 4.7: Effect of ethanol on fibrin deposition

Representative confocal photomicrographs $(400 \times)$ depicting immunofluorescent detection of hepatic fibrin (green) are shown. 


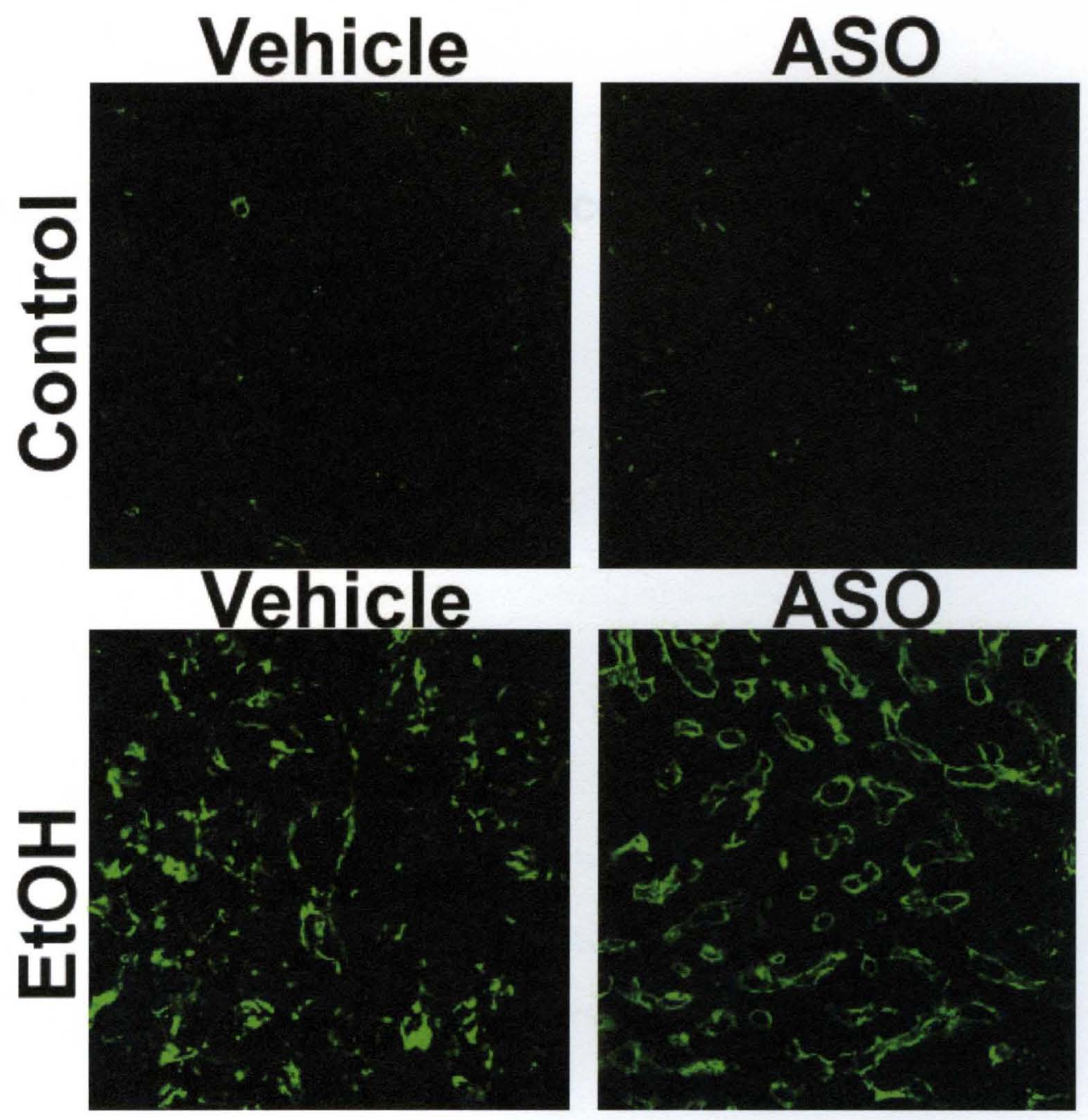


Chapter V

PKCE PLAYS A CRITICAL ROLE IN CCL 4 -INDUCED FIBROSIS 


\section{A. Introduction}

One of the common pathological changes in response to chronic liver damage is accumulation of extracellular matrices (ECM) leading to fibrosis. ${ }^{108}$ Fibrosis can eventually lead to cirrhosis; once cirrhosis ensues, the inflicted person may die without a liver transplant. ${ }^{52}$ In a previous study performed in humans, it was shown that liver fibrosis and cirrhosis can partially repair if the underlying cause is successfully treated (e.g. hepatitis virus C infection). ${ }^{43}$ However, there is no FDA approved therapy to stop the progression of fibrotic liver disease due to the incomplete understanding of the mechanisms underlying hepatic fibrosis.

In previous studies by this group, it was determined that $\mathrm{PKC} \varepsilon$ plays a causal role in both experimental acute and chronic ethanol-induced steatosis, most likely by disrupting hepatic lipid metabolism (Chapter III and IV). ${ }^{91}$ The next pathological step in ALD is steatohepatitis which is comprised of inflammation and necrosis. Studies performed by this group have shown that PKCE ASO treatment provided no protection against chronic ethanol-induced steatohepatitis due to the proinfammatory protein, $\mathrm{PAI}-1$ being independent of $\mathrm{PKC} \varepsilon$ activation (Chapter IV). Following steatohepatitis, the next pathological step in ALD is fibrosis, which is basically the scarring of the liver. Whereas data for the role of PKC $\varepsilon$ in hepatic fibrosis is lacking, past studies have shown that PKC $\varepsilon$ contributes to fibrosis in the heart via the upregulation of TGF $\beta-1$, leading to ECM secretion and the subsequent fibrosis. ${ }^{61}$ Although unknown, it could be possible 
that PKC $\varepsilon$ causes hepatic fibrosis via a similar mechanism as described in the heart.

Although evidence for a role of PKC $\varepsilon$ in hepatic fibrosis is lacking, it has been determined that PKC $\varepsilon$ is activated by compounds that lead to hepatic fibrosis. Specifically, a study performed in rats determined that $\mathrm{CCl}_{4}$ and thioacetamide, chemical agents known to cause hepatic fibrosis, significantly activate $\mathrm{PKC} \varepsilon$, and the activation of this kinase precedes the morphological changes (i.e. fibrosis). ${ }^{109}$ It may be possible that upon activation by one of these fibrosis causing chemicals, $\mathrm{PKC} \varepsilon$ could play a role in the conversion of the liver to a profibrotic state. ${ }^{109}$ Therefore, the purpose of this study was to test the hypothesis that PKC $\varepsilon$ plays a causal role in hepatic fibrosis owing to $\mathrm{CCl}_{4}$ administration. 
B. Materials and Methods

1. Animals and treatments

Mice were treated with $\mathrm{CCl}_{4}$ as described in Chapter II.

2. Immunoblotting

Western Blotting comparing the membrane and cytosol fractions was done as described in Chapter II.

\section{Histological Analysis}

See Chapter II for detailed method.

\section{Clinical Chemistry}

See detailed method in Chapter II.

5. RNA isolation and Real-Time PCR

See detailed method in Chapter II.

\section{Zymography}

The gelatinase activity of MMP-9 was measured by zymography as described in Chapter II 


\section{Results}

\section{Effect of chronic $\mathrm{CCl}_{4}$ on plasma and histological indices of liver damage and fibrosis}

Figure 5.1A depicts representative photomicrographs depicting liver pathology $(\mathrm{H}+\mathrm{E}$, Figure 5.1A, left column) and liver fibrosis (Sirius red Figure 5.1A, right column). Chronic exposure of $\mathrm{CCl}_{4}$ caused robust liver damage which was not attenuated by the PKC $\varepsilon$ ASO (Figure 5.1A, left column). The PKCE ASO also did not prevent the $\mathrm{CCl}_{4}$-induced increase in the plasma transaminases (AST and ALT) (Figure 5.1B, left column). Administration of the PKCE ASO to mice treated with olive oil had no effect on liver pathology or plasma transaminases.

Four weeks of $\mathrm{CCl}_{4}$ treatment also caused hepatic fibrosis as determined by Sirius red (Figure 5.1A, right column). Although there was no difference in the extent of the ECM deposition between vehicle and ASO-treated mice that received $\mathrm{CCl}_{4}$, the PKCE ASO decreased the septa width of the ECM fibers compared to vehicle-treated mice (Figure 5.1A, right column). This effect of the ASO significantly decreased $(\sim 50 \%)$ the Sirius red-positive area of the liver caused by $\mathrm{CCl}_{4}$ (Figure 5.1B, right column).

\section{Chronic $\mathrm{CCl}_{4}$ decreases $\mathrm{PKC} \varepsilon$ activation}

Figure 5.2 shows the effect of chronic $\mathrm{CCl}_{4}$ on the ratio of membrane to cytosol ratio of PKC $\varepsilon$ and mRNA levels of PKCE. As stated previously, a recent study completed by this group demonstrated that acute ethanol increases the ratio of membrane to cytosolic PKCE (Chapter III), ${ }^{91}$ which is indicative of 
increased activation. Therefore, the effect of chronic $\mathrm{CCl}_{4}$ on this index of PKCE activation was determined in Figure 5.2 (upper panel). Surprisingly, $\mathrm{CCl}_{4}$ exposure significantly decreased ( 2-fold) PKC $\varepsilon$ membrane localization compared to controls (Figure 5.2, lower left panel). As expected, administration of the PKCE ASO dramatically decreased protein levels in both compartments.

Figure 5.2 (lower right panel) shows the effect of $\mathrm{CCl}_{4}$ on mRNA levels of PKCE. $\mathrm{CCl}_{4}$ alone downregulated $\mathrm{PKC} \varepsilon$ mRNA expression compared to control mice that received vehicle. In line with the Western data, ASO treatment significantly decreased PKC $\varepsilon$ mRNA levels to about $20 \%$ of controls (Figure 5.3 , lower right panel).

\section{Effect of $\mathrm{CCl}_{4}$ on pro-fibrotic genes}

Increases in mRNA levels of TGF $\beta-1, \alpha S M A$, and collagen la1 are measures of stellate cell activation and ECM synthesis. Furthermore, it has been shown that experimental models that cause hepatic fibrosis, also upregulate PAI1. ${ }^{51}$ Therefore, the effect of $\mathrm{CCl}_{4}$ on the expression of these genes was determined by real-time rtPCR. $\mathrm{CCl}_{4}$ significantly increased the mRNA levels of all of these genes compared to control mice (Figure 5.3). Specifically, chronic exposure of $\mathrm{CCl}_{4}$ significantly upregulated TGF $\beta-1$ ( $\sim 1.5$ fold) compared to controls. The PKCE ASO partially blunted the increase in this gene in both $\mathrm{CCl}_{4}$ and olive oil-treated mice (Figure 5.3A). $\mathrm{CCl}_{4}$ also enhanced the expressions of aSMA and collagen la1; the PKC $\varepsilon$ ASO significantly blunted the increase in aSMA but not collagen la1 (Figure 5.3B and C). PAl-1 was also significantly 
upregulated by $\mathrm{CCl}_{4}$, the increase in mRNA levels of this gene by $\mathrm{CCl}_{4}$ was attenuated by the knockdown of PKCE (Figure 5.3D).

\section{4. $\mathrm{CCl}_{4}$ increases stellate cell activation and hepatic fibrin deposition}

In Figure 5.3, it was determined that the upregulation of aSMA expression by $\mathrm{CCl}_{4}$, an index of stellate cell activation, was blunted by ASO treatment (Figure 5.3B). To further establish the role of PKC $\varepsilon$ in activating stellate cells, immunohistochemical staining for aSMA was performed (Figure 5.4, left panel). Chronic $\mathrm{CCl}_{4}$ exposure caused a robust increase in aSMA staining which was partially blunted by the PKCE ASO treatment (Figure 5.4, left panel).

Whereas collagen I is the prominent ECM accumulated during fibrosis, there are many other types of ECM such as laminin, proteoglycan, and fibrin that also accumulate and lead to the pathological changes associated with fibrosis. ${ }^{45}$ In previous studies, plasmin has been shown to play a major role in the regulation of ECM accumulation by directly degrading types of ECM like laminin and fibrin. ${ }^{47-49}$ PAl-1 plays a major role in fibrinolysis by inhibiting the conversion of plasminogen to plasmin. ${ }^{20}$ In support of this, it was recently demonstrated that impaired fibrin degradation owing to PAl-1 contributes to hepatic inflammation. ${ }^{21}$, 96, 97 The effect of chronic $\mathrm{CCl}_{4}$ on hepatic fibrin deposition was therefore determined. Figure 5.4 (right panel) comprises representative confocal photomicrographs depicting immunofluorescent detection of fibrin deposition. Chronic $\mathrm{CCl}_{4}$ increased fibrin deposition in sinusoidal spaces of the liver lobule. 
PKC $\varepsilon$ ASO treatment partially blunted the increase in fibrin deposition caused by $\mathrm{CCl}_{4}$ (Figure 5.4, right panel).

\section{Effect of $\mathrm{CCl}_{4}$ on MMP-9 activity}

ECM deposition is regulated not only at the level of synthesis (e.g. stellate cell activation) but at the level of degradation as well by MMPs for example. In a previous study performed by this group, it was shown that PAl-1 knockout mice were protected from BDL-induced liver fibrosis, most likely owing to an increase in MMP-9 activity. ${ }^{51}$ Therefore, the effect of $\mathrm{CCl}_{4}$ on MMP-9 was determined (Figure 5.5). Chronic $\mathrm{CCl}_{4}$ significantly increased activation of MMP-9 ( 2.5-fold) compared to controls and this effect was not affected by PKCE ASO treatment (Figure 5.5).

\section{Discussion}

The major findings of this chapter demonstrate that PKC $\varepsilon$ mediates hepatic fibrosis in a mouse model of chronic $\mathrm{CCl}_{4}$ exposure. Specifically, it was determined that mice treated with an ASO to knockdown PKCE, had less ECM accumulation as determined by Sirius Red staining compared to vehicle-treated mice receiving $\mathrm{CCl}_{4}$. This ability of the PKC $\varepsilon$ ASO to partially block fibrosis correlated with a blunting of the upregulation of aSMA, an index of hepatic stellate cell activation, and of PAI-1, a major regulator of fibrinolysis.

Furthermore, this protective effect of the PKCE ASO seems to be mediated primarily at the level of fibrosis as the early onset of hepatic inflammation and liver damage caused by $\mathrm{CCl}_{4}$ was not abrogated by knocking down PKCE. 
As mentioned previously, previous studies have determined that PKCE contributes to cardiac fibrosis. ${ }^{61}$ Whereas no studies have investigated the role of PKC $\varepsilon$ in hepatic fibrosis, results have shown a correlation between PKC $\varepsilon$ activation and $\mathrm{CCl}_{4}$-induced liver fibrosis. ${ }^{109}$ From these results, it could be hypothesized that PKCE may induce changes (e.g. stellate cell activation, upregulation of profibrotic cytokines, etc.) in the liver that result in the development of fibrosis. The data presented in the current study support this hypothesis by demonstrating a causal role of PKC $\varepsilon$ in the formation of fibrosis owing to $\mathrm{CCl}_{4}$.

\section{How does PKC $\varepsilon$ cause fibrosis?}

One of the surprising results of this study is that four weeks of $\mathrm{CCl}_{4}$ exposure actually decreased the activation of PKCE (Figure 5.2). However, this effect of chronic $\mathrm{CCl}_{4}$ on $\mathrm{PKC} \varepsilon$ is not without precedence. Specifically, studies have shown that $\mathrm{CCl}_{4}$ causes a cyclic pattern in the activation of PKCs and that activation of PKC $\varepsilon$ precedes the onset of fibrosis followed by the deactivation of the kinase at the peak fibrotic/cirrhotic changes. ${ }^{109}$

The formation of fibrosis is generally thought to be due to the overproduction of ECM and/or impairment in the degradation of these proteins. One mechanism that can lead to an overproduction of ECM is the transformation of stellate cells to myofibroblasts which then produce and secrete collagen and other types of ECM. To determine if PKC $\varepsilon$ was mediating hepatic fibrosis at this level, the expression of aSMA, an index of stellate cell activation, was 
determined under these conditions (Figure 5.3B). As expected, chronic $\mathrm{CCl}_{4}$ significantly upregulated aSMA and this effect was partially blunted by the PKC $\varepsilon$ (Figure 5.3B). This blunting of aSMA by the PKC $\varepsilon$ ASO was also verified by histological assessment (Figure 5.4, left panel). Therefore, it is likely that the knockdown of $\mathrm{PKC} \varepsilon$ partially prevents fibrosis, in part by preventing the activation of stellate cells and their subsequent conversion to myofibroblasts.

Of the many profibrotic cytokines (e.g. VEGF, PDGF, etc.) that activate hepatic stellate cells, TGF $\beta-1$ represents the major causal player of stellate cell activation in the liver. ${ }^{42}$ In support of the role of TGF $\beta-1$ in activating stellate cells and causing fibrosis, many compounds that block fibrosis also blunt the upregulation of TGF $\beta-1 .{ }^{61}$ Under the current conditions, chronic $\mathrm{CCl}_{4}$ significantly increased mRNA levels of TGF $\beta-1$ and this effect was partially blunted by the PKCE ASO (Figure 5.3C). Therefore, the activation of hepatic stellate cells by PKC $\varepsilon$ is most likely mediated by TGF $\beta-1$. In support of this, a previous study determined that a PKC $\varepsilon$ blocker blunts cardiac fibrosis by inhibiting TGF $\beta-1$ and the subsequent ECM accumulation. ${ }^{61}$

Hepatic fibrosis is associated with an excess of ECM accumulation in the liver. Whereas the production of ECM by myofibroblasts is a major cause of fibrosis, it is not the sole mechanism of this pathology. Many studies have shown a strong correlation between impaired ECM degradation and liver fibrosis and that the balance between enzymes that degrade ECM (e.g. MMPs) and the inhibitors of these enzymes (e.g. TIMPs) is critical in the progression of fibrosis. ${ }^{45}$ A key process in the degradation of ECM is the activation of plasminogen to 
plasmin by tissue-type plasminogen activator (tPA) and urokinase-type plasminogen activator (UPA). The conversion of plasminogen to plasmin plays a major role in ECM metabolism as plasmin has been shown to directly degrade ECM proteins like fibrin and laminin and indirectly by activating MMPs. ${ }^{47-50}$ Thus, the regulation of the plasminogen activating system is critical in preventing hepatitis fibrosis.

One of the major regulators of the plasminogen activating system is PAl-1. Specifically, PAI- 1 inhibits the activity of UPA and tPA, thus eliminating the ECM degradation properties of plasmin. The casual role of PAI-1 in fibrosis is well known and further supported by the positive correlation between hepatic fibrosis and PAl-1 expression. ${ }^{110}$ Furthermore, studies by this group have shown that PAl-1 knockout mice are partially protected against fibrosis owing to bile duct ligation and this protective effect was likely mediated by an increase in MMP-9 and UPA/tPA activity. Given this profibrotic role of PAI-1 and the fact that PAl-1 has been shown to be regulated by PKCs, ${ }^{111}$ the expression of PAI-1 under these conditions was determined. As expected, four weeks of $\mathrm{CCl}_{4}$ significantly upregulated PAl-1 and this effect was partially blunted by knocking down PKC $\varepsilon$ (Figure 5.3D). Mentioned previously, the ECM that accumulates in fibrosis is comprised not only of collagen but other matrix proteins as well such as fibrin. By blocking the conversion of plasminogen to plasmin, PAI-1 prevents the degradation (i.e. fibrinolysis) of fibrin, causing its accumulation thus contributing to fibrosis. ${ }^{112}$ To determine if the protective effect of the PKCE ASO against fibrosis could be mediated by preventing the PAl-1-induced impairment of matrix 
degradation, the effect of $\mathrm{CCl}_{4}$ on fibrin accumulation was determined (Figure 5.4, right panel). $\mathrm{CCl}_{4}$ caused a robust accumulation of fibrin in the liver, which was partially blunted the PKCE ASO. These data therefore suggest that PKC $\varepsilon$ may contribute to fibrosis by upregulating PAI-1, which subsequently impairs matrix degradation processes such as fibrinolysis, leading to fibrosis.

\section{Does fibrin accumulation contribute to the complications associated with cirrhosis?}

Mentioned above, fibrosis is considered the last phase of alcoholic liver disease before the development of cirrhosis which will most likely lead to death without a liver transplant. ${ }^{52}$ However, mortality with a cirrhotic patient is not due to cirrhosis itself but to the secondary effects of the disease such as portal hypertension, ascites, esophageal varices for example. These potentially lethal side effects of cirrhosis may be due to liver failure itself or could be owing to other etiological factors. ${ }^{4}$ In previous studies, it was shown that accumulation of fibrin clots can lead to hemostasis, the conversion of blood from a fluid to a solid. ${ }^{113}$ Hemostasis can cause resistance to blood flow in the hepatic portal vein, causing portal hypertension which can then lead to other complications like ascite and/or espophageal varices. ${ }^{114}$ Mentioned in the Results section of this chapter, $\mathrm{CCl}_{4}$ caused a robust accumulation of fibrin in the liver (Figure 5.4). Whereas fibrin accumulation may be a pathological trademark of fibrosis, it may actually have a more clinical role in causing secondary effects of ALD that result in the death of inflicted patients. 
Figure 5.1: Effect of the PKC $\varepsilon$ ASO on $\mathrm{CCl}_{4}$-induced liver damage

Panel A, The effect of $\mathrm{CCl}_{4}$ on liver histology was assessed by hematoxylin and eosin $[(H+E$, left column, 100x) (inserts are 400x)] and Sirius red [(right panel, 100x) (inserts are 400x)]. Representative photomicrographs are shown. Panel B, plasma transaminases (left column) were determined as described in Chapter II. Intensity of Sirius red staining (right column) was assessed by image analysis. Quantitative data are reported as means $\pm \mathrm{SEM}, \mathrm{n}=4-6 .{ }^{a}, \mathrm{p}<0.05$ compared to absence of $\mathrm{CCl}_{4} .{ }^{\mathrm{b}}$, $p<0.05$ compared to the absence of ASO as determined by 2-way ANOVA. 

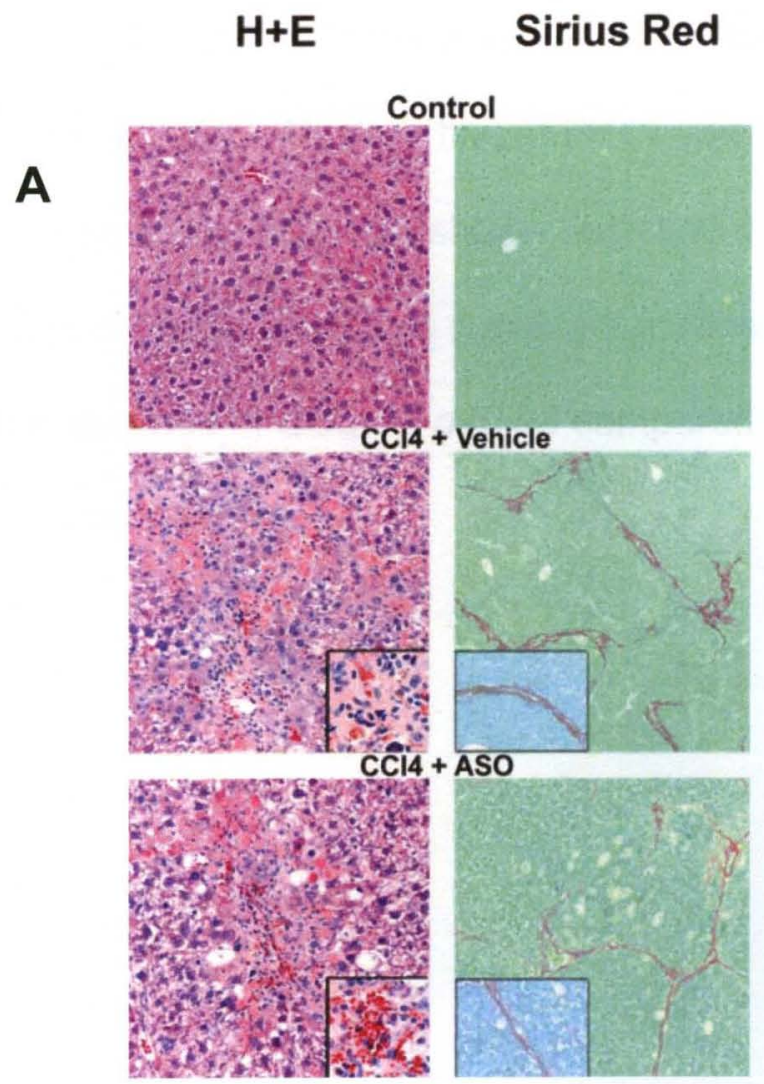

B

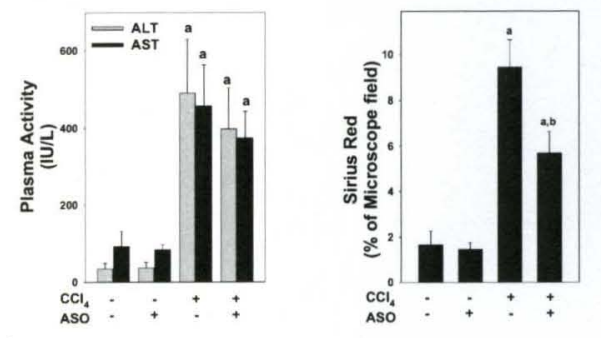


Figure 5.2: Effect of $\mathrm{CCl}_{4}$ on $\mathrm{PKC} \varepsilon$ activation

Real-time rtPCR was performed as described in Chapter II, and results were normalized to $\beta$-actin. Western blot of PKC $\varepsilon$ was performed as described in Chapter II. Representative blots are shown depicting the membrane and cytosolic fractions of PKC $\varepsilon$. The data represent means \pm SEM $(n=4-6) .{ }^{a}, p<0.05$ compared to the absence of $\mathrm{CCl}_{4}{ }^{\mathrm{b}}, \mathrm{p}<0.05$ compared to the absence of ASO as determined by 2-way ANOVA. 

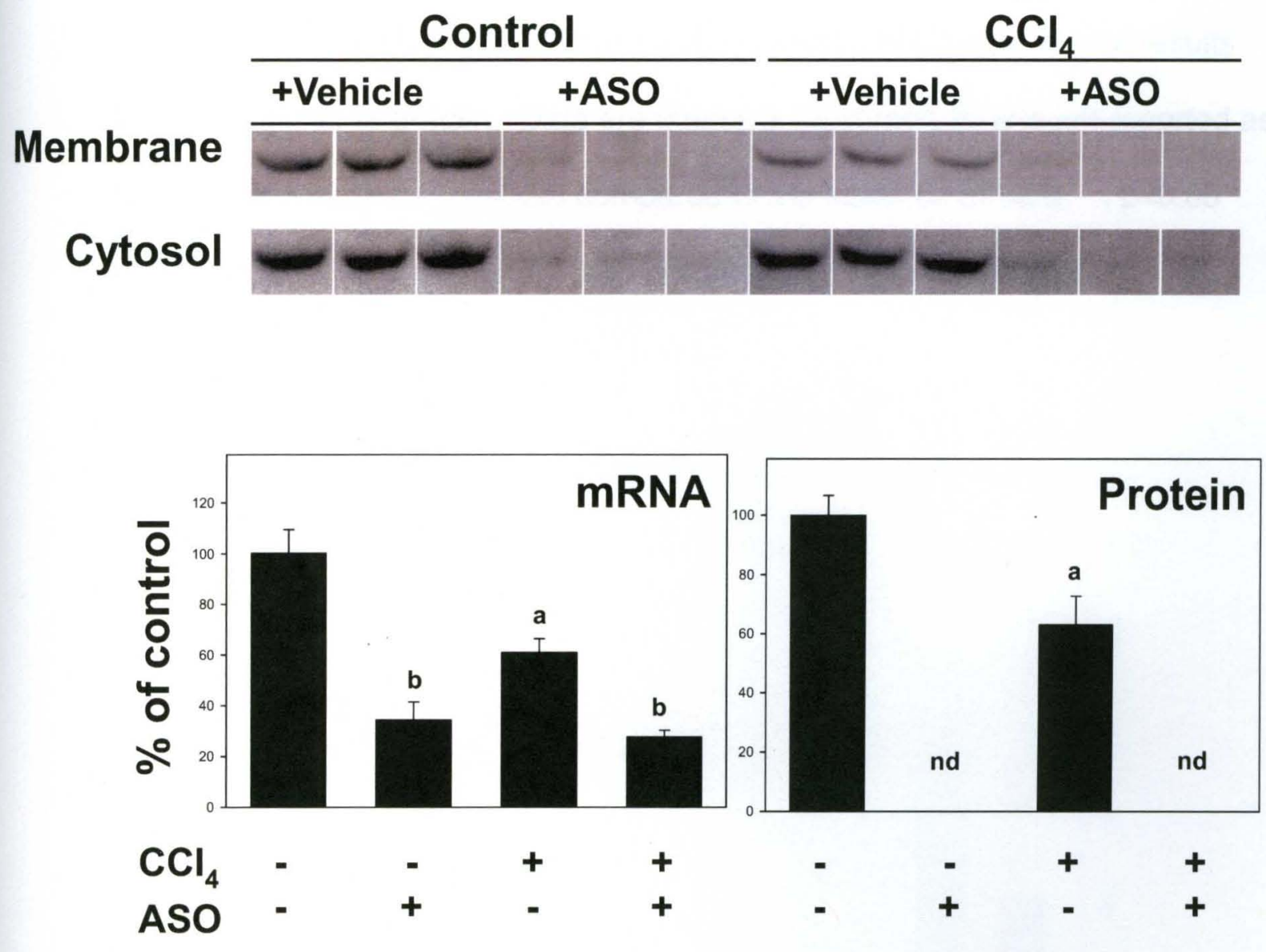
Figure 5.3: Effect of $\mathrm{CCl}_{4}$ on the expression of pro-fibrotic genes

Real-time rtPCR was performed as described in Chapter II, and results were normalized to $\beta$-actin. Data are means \pm SEM $(n=4-6)$ and are reported as fold of control values. ${ }^{a}, p<0.05$ compared to the absence of $\mathrm{CCl}_{4} .{ }^{b}, p<0.05$ compared to the absence of ASO as determined by 2-way ANOVA. 


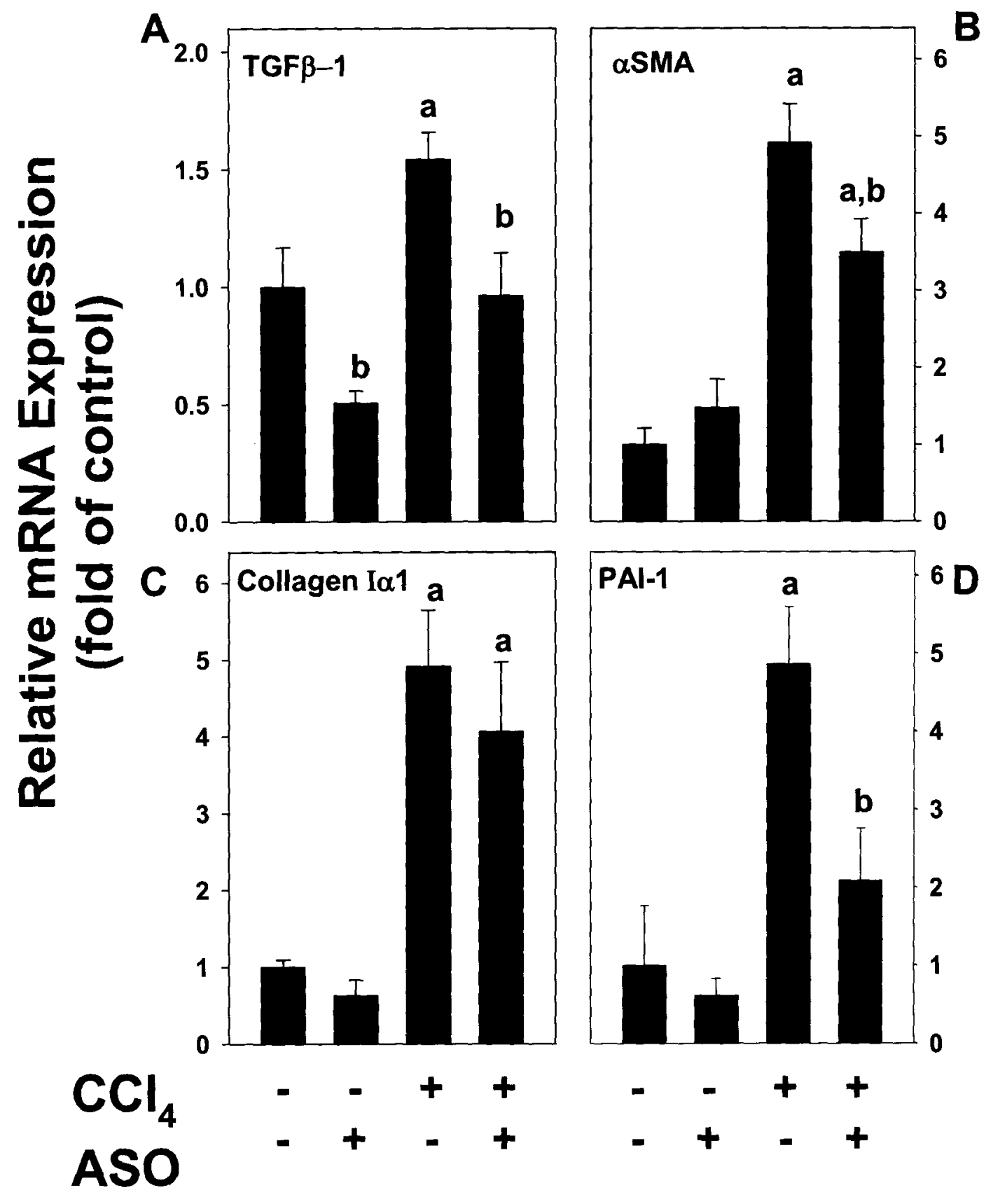


Figure 5.4: Effect of $\mathrm{CCl}_{4}$ on $\alpha \mathrm{SMA}$ and fibrin deposition

The effect of $\mathrm{CCl}_{4}$ on aSMA accumulation was assessed by immunohistochemical staining [(aSMA, left column, 100x) (inserts are 400x)]. Representative confocal photomicrographs $(400 \times)$ depicting immunofluorescent detection of hepatic fibrin (green) against a Hoechst counterstain (blue) are shown (left panel). 
$\alpha$ SMA

Fibrin

\section{Control}

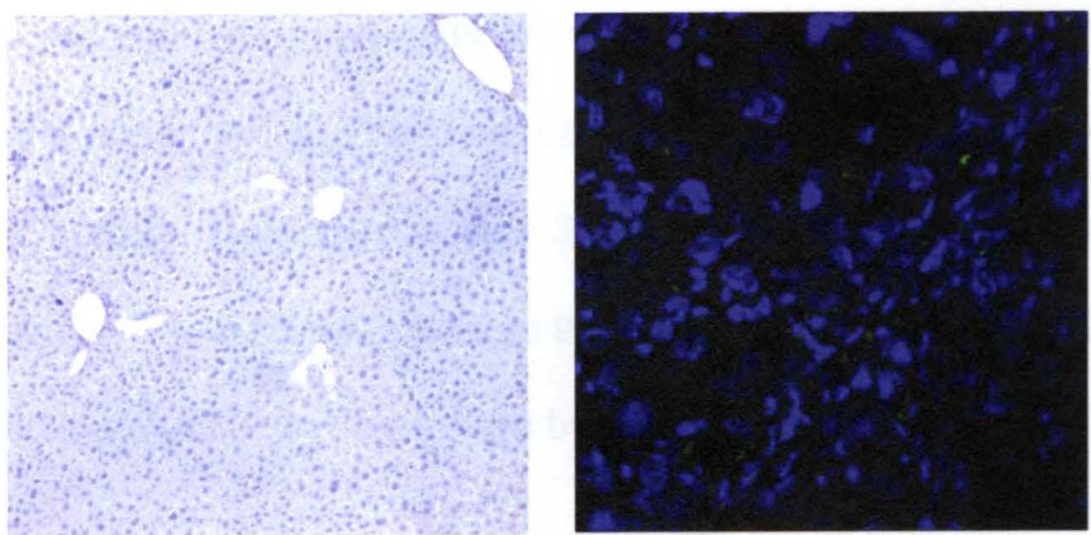

$\mathrm{CCl} 4$ + Vehicle

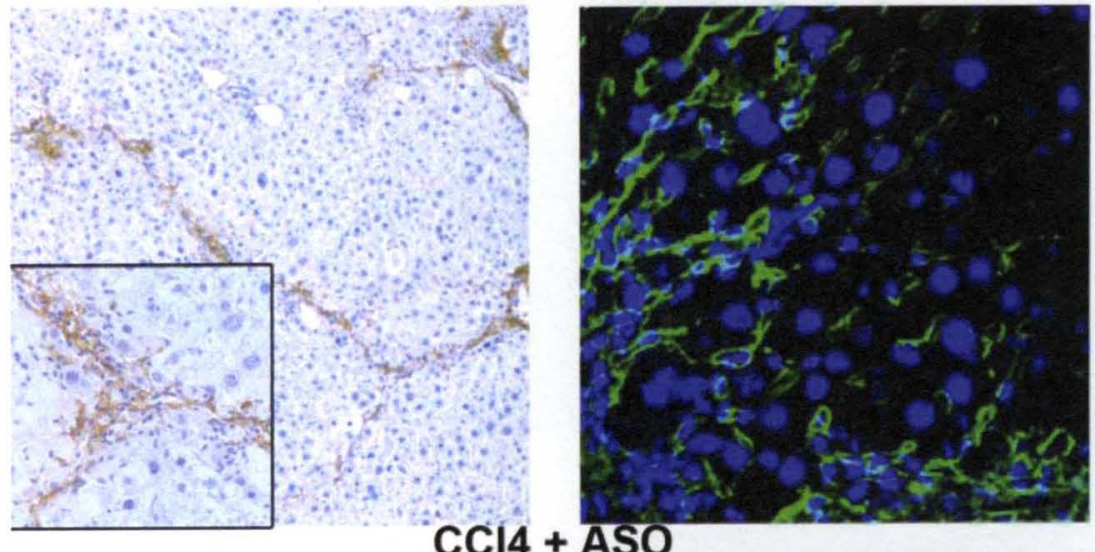

\section{$\mathrm{CCl} 4+\overline{\mathrm{ASO}}$}
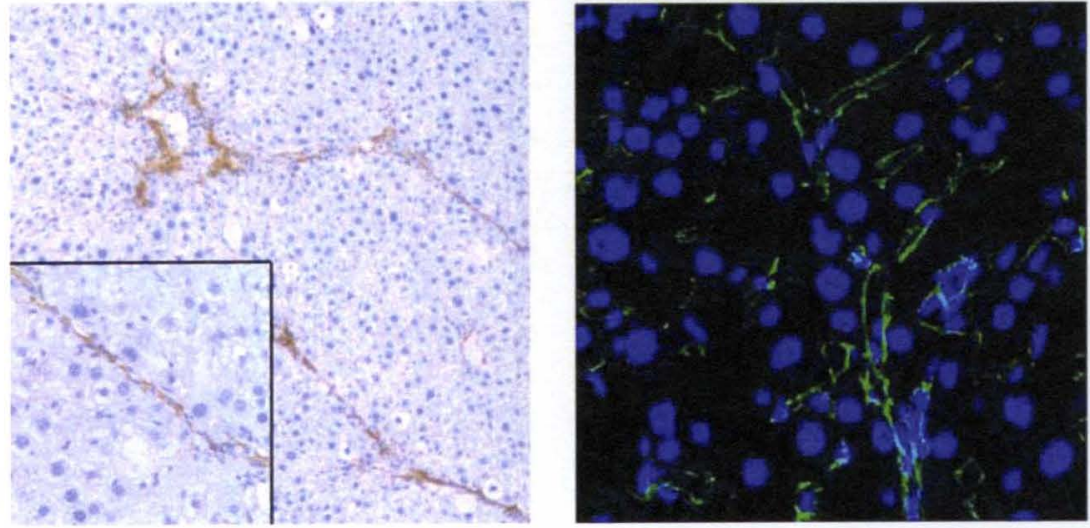
Figure 5.5: Effect $\mathrm{CCl}_{4}$ on MMP-9 activity

Representative zymographs demonstrating gelatin lysis by MMP-9 are shown in the upper panel. The lower panels show results of densitometric analysis of activity. Data are means $\pm \operatorname{SEM}(n=4-6)$ and are expressed as $\%$ of control values. ${ }^{a}, p<0.05$ compared to the absence of $\mathrm{CCl}_{4} .{ }^{b}, \mathrm{p}<0.05$ compared to the absence of ASO as determined by 2-way ANOVA. 

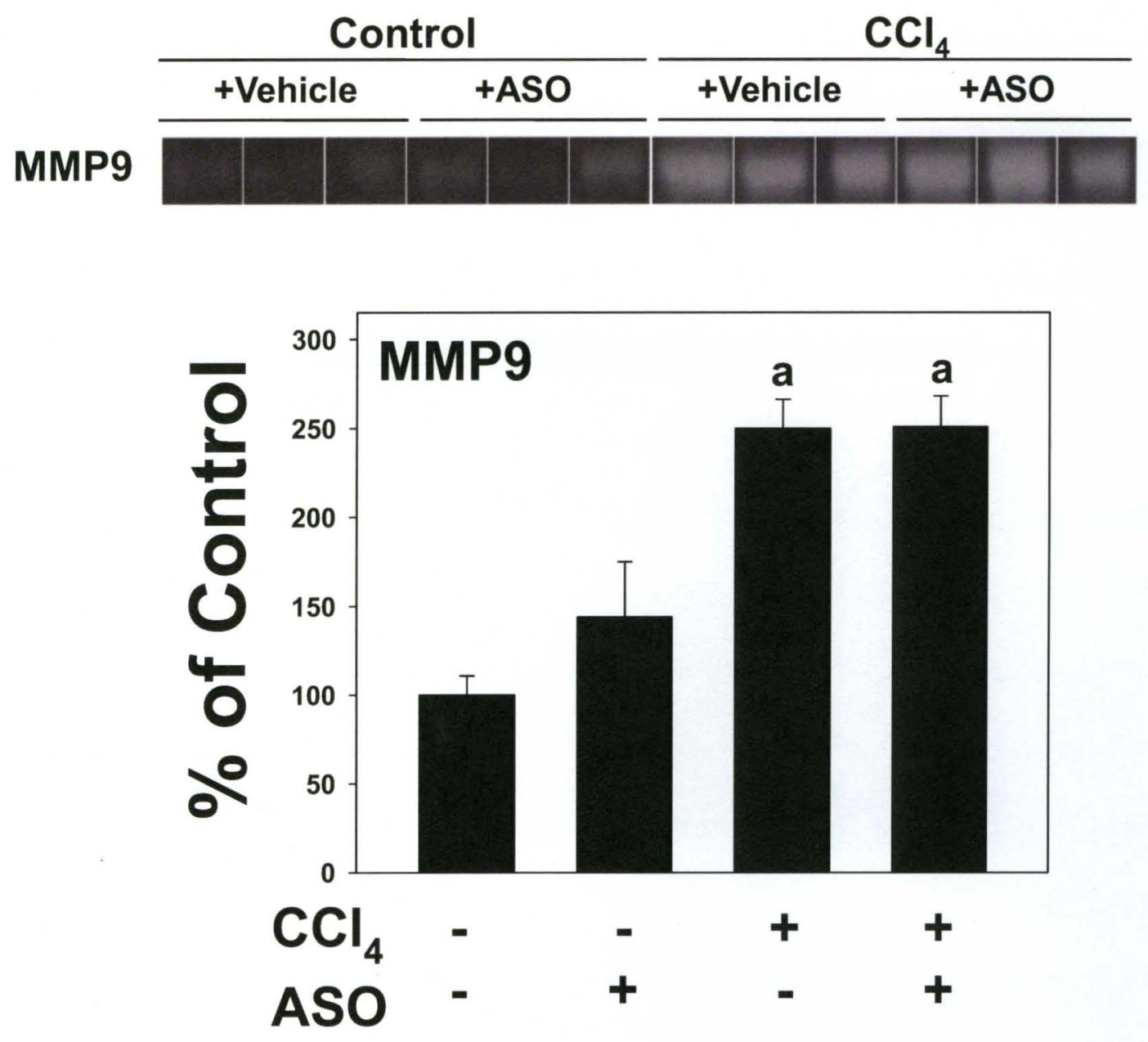


\section{CHAPTER VI}

SUMMARY AND GENERAL DISCUSSION 


\section{A. Major Findings of this Dissertation}

The experiments performed in the third chapter of this dissertation were designed to test the hypothesis that PKCE plays a causal role in acute ethanolinduced steatosis. The effects of acute ethanol on PKCE activation and indices of insulin signaling were determined, as well as the effect of inhibiting (i.e. knockout or knockdown) PKCE on ethanol-induced steatosis. Mentioned previously (Chapter I, Section E), the acute model of ethanol exposure employed here is a useful screening tool for molecular mechanisms of chronic ethanolinduced liver damage. Therefore, experiments described in Chapter IV build on results of the third chapter and examine the role of PKCE in steatohepatitis owing to chronic ethanol exposure. The effects of a PKCE ASO on histological indices of hepatoxicity owing to alcohol were determined. The regulation of the PKCE ASO on increases in mRNA levels of proinflammatory and lipid metabolism genes caused by ethanol was also determined. Chapter $V$ focuses on the role of $\mathrm{PKC} \varepsilon$ on $\mathrm{CCl}_{4}$-induced fibrosis, determining the effect of knocking down PKC $\varepsilon$ on the accumulation of ECM and the upregulation of profibrotic genes owing to $\mathrm{CCl}_{4}$. Detailed findings of each of these chapters are detailed below.

\section{PKC $\varepsilon$ plays a causal role in acute ethanol-induced steatosis}

As mentioned in Chapter III, hepatic insulin resistance is a known risk factor for hepatic steatosis. This causal role of insulin resistance in fatty liver is further supported by studies from this group showing that metformin, an insulin sensitizing drug, partially prevents fatty liver owing to acute ethanol. ${ }^{21}$

Furthermore, PKCE, a known inducer of insulin resistance, has been 
demonstrated to contribute to steatosis caused by a high fat diet in the absence of ethanol. ${ }^{86}$ However, the role of this kinase in steatosis caused by alcohol was unknown and was the main question of this Chapter III. Experiments were designed to determine if PKC $\mathrm{P}$ contributes to ethanol-induced steatosis and the mechanisms by which PKC $\varepsilon$ is causing steatosis.

First, a time course of the effect of ethanol on hepatic free fatty acids, DAG, and triglycerides was determined. As observed previously, ${ }^{21}$ triglycerides peaked $\sim 12 \mathrm{~h}$ after ethanol exposure and free fatty acids and DAG were maximum at $\sim 1 \mathrm{~h}$. Next, it was determined that the accumulation of hepatic

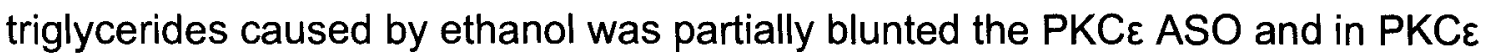
knockout mice. To verify that $\mathrm{PKC} \varepsilon$ was causing steatosis via insulin resistance, the effect of ethanol on insulin sensitive genes (GK and G6Pase) was determined and found to be modulated by ethanol in a manner indicative of insulin resistance, which was further substantiated by an increase in the ratio of plasma insulin to glucose caused by alcohol. Furthermore, the protection against fatty liver by the PKCE ASO correlated with a blunting of the increase in G6Pase caused by ethanol, suggesting that PKC $\varepsilon$ is indeed causing steatosis by inducing insulin resistance. A visual description of this mechanism can be seen in Figure 6.2.

The major findings of this chapter are that $\mathrm{PKC} \varepsilon$ contributes to ethanolinduced fatty liver. This chapter also sheds further light on the role of insulin resistance as a possible mechanism working in tandem with alcohol metabolism to cause steatosis after ethanol exposure. Finally, this chapter reveals a novel 
mechanism by which redox inhibition of $\beta$-oxidation of fatty acids owing to ethanol, is leading to increased DAG production and PKC $\varepsilon$ activation. PKC $\varepsilon$ then causes ethanol-induced steatosis by impairing insulin signaling. These findings and their signifance are further detailed in section B of this chapter.

\section{PKCE plays a critical role in chronic ethanol-induced steatosis but not in inflammation or necrosis}

One of the major findings of this dissertation is that PKC $\varepsilon$ plays a causal role in acute ethanol-induced steatosis (Chapter III). As stated previously (Chapter I, section E), the acute model of ethanol exposure is a useful screening tool for mechanisms involved in later stages of ALD and therapies that protect against experimental acute ethanol-induced liver damage have also been shown

to attenuate hepatic damage owing to chronic insults. ${ }^{115}$ Therefore, the goal of this chapter was to determine the role of PKCE in liver injury caused by chronic administration of ethanol. As expected, four weeks of intragrastric alcohol led to robust hepatoxicity as determined by histological analyses. The PKCE ASO was able to partially prevent fatty liver but had no protective effect against inflammation or necrosis. These data suggest that the pathologies of steatosis and steatohepatitis may be mechanistically unrelated.

One of the major themes of liver research is the 'two-hit' hypothesis, which implies that preventing steatosis should blunt more advanced liver damage (e.g., inflammation and necrosis). ${ }^{27,98}$ In this chapter, the PKC $\varepsilon$ ASO blunted steatosis but conferred no protection against hepatic inflammation or necrosis. Therefore, 
the mechanism(s) responsible for this "disconnect" between steatosis and inflammation were investigated. Summarily, it was determined that chronic ethanol upregulated the expression of FAS, a major inducer of lipid synthesis, which was partially blunted by knocking down PKC $\varepsilon$ suggesting that PKC $\varepsilon$ may cause steatosis via increasing FAS mRNA levels. The proinflammatory gene PAI-1 was also upregulated by chronic ethanol and this effect was not abrogated by the PKCE ASO. This PKCE-independent regulation of PAI-1 may explain why the PKC $\varepsilon$ ASO has no effect on inflammation. Mentioned above, PAI-1 has been shown to cause inflammation in various studies. ${ }^{21,51,97,105}$ This proinflammatory role of PAI-1 is hypothesized to be due to PAI-1 impairing fibrinolysis, as fibrin clots have been shown to be permissive to chemotaxis and to activation of monocytes and leukocytes. ${ }^{96,106,107}$ Under these conditions, chronic ethanol caused a robust accumulation of fibrin, which was not attenuated by the PKC $\varepsilon$ ASO, suggesting that inflammation under these conditions can most likely be attributed to the impairment of fibrinolysis by PAI-1, which is independent of PKC $\varepsilon$ activation (see scheme of hypothesized mechanism in Figure 6.3).

The major finding of this chapter is that the prevention of steatosis does not necessarily correlate with protection against inflammation. However, this finding is not unique as other studies have demonstrated similar results. For example, Yamaguchi et al. ${ }^{101}$ determined that the inhibition of diacylglycerol acyltransferase 2 (DGAT2) prevented steatosis, but not inflammation and liver damage. These data suggests that the validity of the two-hit hypothesis may depend on the role of the respective gene that is being targeted to prevent ALD. 
The deletion of a gene that only plays a part in the steatotic component of ALD, may not protect against the further stages (i.e. inflammation, fibrosis etc.).

Furthermore, Chapter IV gives further support to the steatotic role of PKC $\varepsilon$ and to PAI-1 being proinflammatory. Finally, a therapy may only be effective in treating ALD if it targets mediators of inflammation like PAI-1.

\section{PKC $\varepsilon$ causes hepatic fibrosis}

The finding that PKC $\varepsilon$ did not contribute to inflammation (Chapter IV) was a surprising, suggesting that this kinase may not play a role in later stages (e.g. steatohepatitis, fibrosis, etc) of ALD. However, previous studies have shown that PKC $\varepsilon$ contributes to fibrosis in other organs (heart, lung etc.). ${ }^{61,116}$ Furthermore, results have shown that $\mathrm{PKC} \varepsilon$ is activated in a rat model of $\mathrm{CCl}_{4}$-induced liver fibrosis. ${ }^{109}$ Therefore, the main objective of Chapter $V$ was to test the role of PKC $\varepsilon$ in hepatic fibrosis owing to chronic administration of $\mathrm{CCl}_{4}$. In short, $\mathrm{CCl}_{4}$ caused a robust accumulation of ECM in the liver which was partially attenuated by the knockdown of PKCE.

It was previously determined in rats that the activation of PKC $\varepsilon$ by $\mathrm{CCl}_{4}$ precedes the onset of hepatic fibrosis, and it was therefore hypothesized that PKC $\varepsilon$ may play a role in the development of this pathology. ${ }^{109}$ However, this hypothesis had not been directly tested. Results from Chapter V of this dissertation directly support this hypothesis. The ability of the PKCE ASO to prevent fibrosis correlated, with attenuated upregulation of profibrotic genes induced by $\mathrm{CCl}_{4}$ exposure. The increase in stellate cell activation, as determined 
by aSMA expression, was also blunted by knocking down PKCE, suggesting that this kinase plays a causal role in the transdifferentiation of quiescent stellate cells to myofibroblast-like cells. Furthemore, the PKCE ASO abrogated the rise in mRNA levels of TGF $\beta-1$, a known inducer of hepatic stellate activation. ${ }^{42}$ Therefore, it is likely that TGF $\beta-1$ serves as the catalyst for stellate activation owing to PKC $\varepsilon$ under these conditions. Finally, the ability of the ASO to block PAI-1 induction suggests that PKC $\varepsilon$ contributes to fibrosis, in part, by indirectly impairing the plasminogen activation system, leading to a decreased degradation of ECM. Figure 6.4 contains a detailed schematic regarding the role of PKC $\varepsilon$ in $\mathrm{CCl}_{4}$-induced fibrosis.

The onset of fibrosis can divided into two broad categories: initiation and progression. The iniation phase consists of cellular events that allow quiescent stellate cells to be more readily activated by growth factors (e.g. PDGF, VEGF, TGF $\beta-1$ etc). This senisitization of stellate cells is accompanied by an increase in growth factor signaling like TGF $\beta-1$ for example. The progression stage, also known as perpetuation, is highlighted by the activation of stellate cells (via growth factors), conversion of these cells to myofibrobast-like state, ECM secretion from stellate cells, and impaired matrix degration. ${ }^{42}$

The most significant finding of this chapter is that PKCE appears to be causing hepatic fibrosis both at the level of initiation and progression. This causal role of PKCE in hepatic fibrosis correlates with other studies that determined a similar role of PKC $\varepsilon$ in other organs. ${ }^{61,116}$ In Chapter V, PKC $\varepsilon$ upregulated TGF $\beta-1$ (i.e. initiation phase) which then activates stellate cells (i.e. 
progression stage). Under these conditions, PKC further contributed to fibrosis by decreasing the plasminogen activation system by upregulating PAl-1, leading to impaired matrix degradation (i.e. progression stage). Therefore, it could be suggested that PKC $\varepsilon$ is causing fibrosis at the initiation level (TGF $\beta-1$

upregulation) as well as the progression phase by activating stellate cells via TGF $\beta-1$ and by impairing the degradation of ECM that are secreted by stellate cells upon their activation.

\section{B Significance of this Study}

As mentioned throughout this dissertation, ALD is a major disease with no FDA approved therapy for treatment. This lack of treatment is in part, due to an incomplete understanding of the mechanisms behind the pathologies associated with ALD. This dissertation provides detailed mechanisms of the involvement or lack thereof in different pathologies (steatotitis, inflammation, and fibrosis). Therefore, the finding that PKC $\varepsilon$ contributes to ALD is crucial in that it provides further mechanistic insight into ALD and reveals a new possible therapeutic target in ALD treatment.

The role of PKCE in ALD, specifically in steatosis, may answer questions in the liver research field that have been unknown for over 30 years. Specifically, as described in Chapter I, a long standing hypothesis of ALD is the increase in alcohol metabolism directly contributes to liver injury caused by alcohol administration. ${ }^{85}$ However, therapies (e.g. inhibiton of iNOS, NADPH oxidase, etc) that block alcohol-induced steatosis are ineffective in preventing the rise in 
alcohol metabolism, implying that some other factor(s) are working in tandem with alcohol metabolism to induce steatosis. ${ }^{13,14}$ One possible mechanism that could be collarobating with alcohol metbalism to cause steatosis is insulin resistance due to the ability of metformin, an insulin sensitizing agent, to prevent ethanol-induced steatosis. ${ }^{21}$ Interstingly, genes that are known to cause fatty liver owing to ethanol exposure, such as iNOS and NADPH oxidase, while having no role in increasing alcohol metabolism have been shown to cause impaired muscular insulin signaling. ${ }^{117,118}$ Furthermore, protection against steatosis by the PKCE ASO correlated with a blocking of insulin resistance. These data along with other studies showing that some genes (e.g. iNOS,NADPH oxidase, etc) play a role in both steatosis and insulin resistance, suggests that insulin resistance, due to PKCE activation under these condtions, and alcohol metabolism may be working together to cause steatosis. Therefore, the identification of PKCE as a causal player in ethanol-induced steatosis and hepatic insulin resistance may fill voids in our knowledge of ALD mechanisms that have been present for over three decades.

ALD and Type II diabetes are closely related diseases in that they have pathological and mechanistic traits in common. One of the major characteristics of Type II diabetes is insulin resistance, which is known to contribute to ALD. ${ }^{18}$ Furthermore, Type II diabetes and ALD share some pathological similarities, such as steatosis and steatohepatitis. Also, people with type II diabetes have a higher risk of developing ALD than people without diabetes. ${ }^{119,} 120$ Liver disease is also one of the leading causes of death in patients inflicted with type II 
diabetes. ${ }^{121}$ However, the link between the two diseases (ALD and type II diabetes) is not a novel idea. For example, metfomin, a therapy used quite commonly in type II diabetes, was previously tested in patients with ALD. ${ }^{122,123}$ Whereas metformin was beneficial in a mouse model of steatohepatitis, ${ }^{21}$ the use of metformin in patients with ALD had serious drawbacks as ethanol consumption was shown to exacerbate the risk of lactic acidosis by metformin, which suggests that metformin may not be an optimal drug to treat ALD. ${ }^{122,123}$ In Chapter III of this dissertation, it was determined that PKC $\varepsilon$ contributes to insulin resistance and steatosis caused by acute ethanol exposure. It may be therefore possible that PKC $\mathrm{E}$ plays a similar role in the steatotic component of Type II diabetes. Therefore, the therapeutic targeting of this kinase may confer beneficial effects against both diseases hopefully without the negative side effects observed with metformin for alcoholics.

\section{Strengths and Weaknesses of this Dissertation}

\section{Strengths}

There are many strengths to this dissertation. First, it identifies a new player $(\mathrm{PKC} \varepsilon)$ in alcoholic liver disease and details mechanisms by which this kinase participates in various stages of liver disease. Second, there has been much debate about the contribution of insulin resistance in causing steatosis. This dissertation further supports this link by showing that PKC $\varepsilon$ causes ethanolinduced steatosis potentially by inducing insulin resistance. Lastly, this work further solidifies the role of PAI-1 in ALD and suggests that a proper therapy for 
treating ALD may only be effective if it is successful in preventing the later more severe stages (e.g. steatohepatitis, fibrosis, etc).

A specific strength of this dissertation is the use of an ASO to determine the role of PKCE in liver damage. Whereas knockout mice are a useful tool, the lifelong deletion of a gene in the development stage of a mouse could result in nonspecific effects like the induction of compensatory mechanisms, thus emphasizing the need to pharmacologically (e.g ASO, peptide inhibitor, etc.) inhibit a target of interest. ${ }^{124}$ Conversely, ASOs are highly specific to the liver and do not result in a lifelong deletion of a gene that could cause compensatory physiology. ${ }^{67}$

A preliminary study determined that $\mathrm{PKC} \varepsilon$ knockout mice were partially protected against acute ethanol-induced steatosis. To determine if these results were due to a compensatory mechanism owing to the lifelong deletion of PKCE, an ASO specific to PKCE was used to validate these results. In correlation with the data using the knockout mice, $\mathrm{PKC} \varepsilon$ ASO-treated mice were protected to a similar degree against ethanol-caused fatty. Therefore, using both methods (knockout and ASO) provides strong weight-of-evidence that PKC $\varepsilon$ contributes to steatosis owing to acute ethanol.

Another strength of this work is the use of whole animals (i.e. mice) to investigate mechanisms of ALD. The entirety of this research performed was completed using in vivo animal models. ALD is a chronic disease involving multiple organs and various cell types (see Figure 6.1 for illustration ${ }^{125}$ ). 
Therefore, whereas cell culture experiments are useful, whole body experiments (e.g. in vivo models) are more suitable to fully understand the effects of multiple organs and cell types on ALD, allowing for the results of these studies to be better translated to the human disease.

One type of in vivo model of ALD is the Tsukamoto and French intragastric chronic ethanol model. Compared to other models (e.g. ad libitum feeding) of chronic ethanol, this model bypasses the natural aversion of mice to alcohol by intragastric feeding and therefore results in much higher concentrations of alcohol, comparable to what is observed in the human disease. The high ethanol levels achieved in the Tsukamoto and French model result in many of the pathologies observed in human alcoholic liver disease like steatosis, inflammation, pericentral necrosis, and fibrosis. Therefore, the employment of this model allows for the progression of liver damage owing to ethanol to be investigated in a clinically-relevant rodent model.

\section{Weaknesses}

The main focus of this dissertation was the investigation of PKC $\varepsilon$ in ALD, mainly due to its role in hepatic insulin resistance and the contribution to nonalcoholic fatty liver. However, as stated in Chapter 1 (section E), there are many other isoforms of PKC that potentially can play similar roles (i.e. insulin resistance, collagen production, etc.) as PKCE. One of the limitations in researching individual PKCs is the lack of specific inhibitors. It may very well be possible that other types of PKC are working in tandem with PKCE to cause 
ethanol-induced steatosis for example. This could explain why the PKCE ASO is only able to partially blunt fatty liver caused by alcohol exposure (see Chapter 3 , Figure 6). Therefore, it could be very beneficial to study different PKCs beside $\varepsilon$ in mechanisms of ALD. It was fortunate for this study that a PKCE ASO was readily available. If $A S O$ s are designed for other $\mathrm{PKC}$ isozymes, it would be interesting to determine the role of these other isotypes in models (e.g. acute ethanol, chronic ethanol, etc.) of liver damage employed here.

A second weakness of this dissertation is the use of a chronic model (i.e. Tsukamoto and French model) to investigate the role of PKC $\varepsilon$ in hepatic inflammation. Whereas the chronic intragastric model of ethanol exposure has its advantages (see Chapter 1, section E for further detail), it is not without drawbacks. Specifically, this chronic model of ethanol exposure, due to mechanisms unknown, does not cause fibrosis in rodents. Also, a requirement of this model is forced feeding (e.g. intragastric feeding tube) due to a rodents' aversion to alcohol; a situation that does not apply to humans. Furthermore, Tsukamoto and French ethanol model delivers a nutritional complete diet to mice. It is likely that alcoholics consume diets that are of lesser quality and not adequate nutritionally. This difference in diets between mice fed ethanol intragastrically and human alcoholics coupled with the forced feeding of ethanol to mice, highlight the inadequacies of the Tsukamoto and French model to perfectly model human liver disease owing to alcohol. Finally, the intragastric model of ethanol is a chronic experimental model. When employing a chronic model of liver damage, it is often difficult to discern between effects and 
proximate causes in chronic models of liver disease, suggesting that to fully determine the role of target in hepatic inflammation, an acute model of inflammation might be useful.

There are acute models of inflammation such as an LPS sensitization model that cause similar pathology (e.g steatosis, inflammation and necrosis) as observed with the Tsukamoto and French intragastric ethanol model but the mechanisms behind liver injury owing to acute LPS exposure are less mechanistically complex than those of chronic ethanol. Therefore, it may be useful to determine the role of PKC $\varepsilon$ in hepatic inflammation owing to acute models of hepatoxicity like LPS or bile duct ligation for example.

Chapter $V$ determined that $P K C \varepsilon$ plays a critical role in hepatic fibrosis owing to chronic $\mathrm{CCl}_{4}$. The advantages of this model have been highlighted previously Chapter 1 (section E). The major drawback of this model is that it is irrelevant to human fibrosis. People do not consume $\mathrm{CCl}_{4}$, nor can they survive transaminase values $>8000 \mathrm{IU} / \mathrm{L}$ as witnessed in rodents chronically exposed to $\mathrm{CCl}_{4}$. Until recently, there have been no optimal rodent paradigms to model fibrosis in humans. Nevertheless as the PKC $\varepsilon$ ASO was able to partially blunt fibrosis caused chronic $\mathrm{CCl}_{4}$, which is considered to be a very severe model of fibrosis, it is likely that the ASO will confer a similar protective effect against a less robust model (e.g. angiotensin II) of fibrosis. Such a weight-of-evidence approach would be useful. 


\section{Future Directions}

\section{Do other isoforms of PKC contribute to ALD?}

Future directions described here are to address issues mentioned in Weakness (Chapter 6, section C2). The purpose of these experiments is to build on the ideology of this dissertation and these future projects are not required to complete this dissertation. There are many isoforms of PKC that like PKCE, play a role in many processes hypothesized to be involved in ALD. For example, previous studies have shown that PKCa mediates collagen synthesis leading to lung fibrosis. ${ }^{126}$ Whereas the investigation of individual PKC isozymes has been difficult due to non-selective inhibitors, small peptide inhibitors and ASOs are becoming more readily available to use in experimental settings. A recent study employed the use of an ASO, known as aprinocarsen, targeted against PKC $\alpha$ to determine the role of this PKC in tumorigenesis. ${ }^{127}$ Mentioned previously, PKC $\alpha$ is known to coordinate collagen synthesis in the lung; it may also play a similar role in the liver leading to hepatic fibrosis. Therefore, a future study could investigate the role of $\mathrm{PKCa}$ in $\mathrm{CCl}_{4}$-induced fibrosis by employing aprinocarsen.

\section{Does PKC $\varepsilon$ play a role in angiotensin II-induced fibrosis?}

Recent unpublished work by Dr. Julianne Beier, a member of Dr. Arteel's lab, has resulted in the development of a new experimental model of hepatic fibrosis. Mice received angiotensin II for four weeks via an osmotic pump, resulting in "chicken-wire" fibrosis with little or no liver damage. This model is considered to be more relevant to human liver disease than pre-existing models (e.g. bile duct ligation, $\mathrm{CCl}_{4}$ ), as it causes mild fibrosis and relatively little liver 
injury. Results from that study demonstrated that the fibrosis under those conditions is most likely due to an increase in stellate cell activation and an upgregulation of PAl-1, a similar mechanism by which PKCE causes $\mathrm{CCl}_{4}$ induced fibrosis. Therefore, it may be beneficial to determine if the PKC $\varepsilon$ plays a critical role in angiotensin II-induced fibrosis.

\section{Does PKC $\varepsilon$ play a critical role in LPS-induced hepatic inflammation?}

The release of proinflammatory mediators from macrophages, especially Kupffer cells, is hypothesized to be a major mechanism involved in ethanolinduced inflammation. In Chapter 1 (section D), it was stated that PKC $\varepsilon$ primes macrophages to release proinflammatory cytokines due to LPS administration. ${ }^{60}$ Given this role of PKCE, it was unexpected that the PKCE ASO was unable to prevent inflammation caused by chronic ethanol exposure (CHAPTER IV). However as mentioned in section $\mathrm{C} 2$ of this chapter, whereas the chronic model of intragastric ethanol exposure is very relevant clinically, it is very biochemically complex suggesting there may be a need to investigate the role of PKC $\varepsilon$ in an acute model of inflammation.

A previous study by this group determined that fibrin accumulation contributes to inflammation in a model of ethanol sensitization to LPS-induced liver damage. ${ }^{97}$ Under those conditions, it was proposed that pre-exposure to ethanol primes Kupffer cells to release TNFa caused by LPS. TNFa then activates PAI-1 via ERK1/2; PAI-1 then inhibits the plasminogen activating system leading to fibrin accumulation and the subsequent inflammation. In Chapter IV, results demonstrated that the PKC $\varepsilon$ ASO, while able to attenuate the 
upregulation of TNFa, was not able to prevent the increase in mRNA levels of PAl-1, suggesting that under those conditions PAI-1 is TNFa independent. In the study by Beier et al, ${ }^{97}$ TNFa indirectly upregulated PAI-1 which then causes fibrin accumulation and hepatic inflammation. As TNFa seems to be regulated by $\mathrm{PKC} \varepsilon$ (Figure 4.6A), the PKC $\varepsilon$ ASO may confer protection against inflammation caused by ethanol/LPS by preventing the increase in TNFa mRNA levels and the subsequent upregulation of PAI-1. Future experiments could be completed to investigate this possible role of PKCE in hepatic inflammation owing to a 'two-hit' model of ethanol and LPS.

\section{Are steatosis and inflammation mechanistically linked?}

One of the prevailing hypotheses in experimental liver research is the 'two-hit' hypothesis, which implies that preventing the early stages of liver damage (i.e. steatosis) will result in the protection against later stages of ALD, thus suggesting that fatty liver is critical to the development of ALD.9, 128 Therefore, it was very surprising that the prevention of steatosis by the PKC $\varepsilon$ ASO did not correlate with protection against steatohepatitis (Chapter IV). These data therefore suggest that steatosis and inflammation owing to ethanol may not necessarily share a common mechanism. Described in more detail in Chapter IV (section E), such results showing the disconnect between steatosis and inflammation are not without precedence..$^{97,101,103}$ A better understanding of this possible mechanistic detachment between fatty liver and inflammation is crucial in finding a viable therapy to treat ALD. 
One possible explanation for the disconnect between steatosis and inflammation could be that a fatty liver is not a proximal cause of the sensitization of the liver to further insults that result in steatohepatitis but rather the development of fatty liver and inflammation may occur in parallel. Therapies may be blocking mechanisms, which results in protection against both early and late stages of liver damage. Therefore, it is plausible that in the chronic ethanol model, PKC $\varepsilon$ plays a causal role in the development of fatty liver, but not in sensitizing the liver to a second hit. Future experiments must be completed in order to better understand the 'two-hit' hypothesis to better understand its applicability to ALD.

One of the findings of Chapter IV is that the PKC $\varepsilon$ ASO does not prevent hepatic inflammation due to fibrin accumulation via PAl-1 being independent of PKCE. Further studies by this group have also demonstrated that the inhibition of PAI-1 prevents LPS-induced hepatic inflammation, in the absence of steatosis, by blocking fibrin accumulation. ${ }^{97}$ Therefore, it could be possible that fibrin accumulation is a mechanism that occurs in parallel with steatosis to sensitize the liver to further damage as fibrin matrices are permissive to chemotaxis and activation of monocytes and leukocytes. ${ }^{106,107}$ This possible role of fibrin in sensitization could also explain other studies where a disconnect between fatty liver and inflammation has occurred. For example, the knockdown of DGAT2 prevented steatotis but worsened inflammation in a methionine-choline deficient mouse model. ${ }^{101}$ The inability of DGAT2 to block inflammation coincided with elevalated hepatic free fatty acids. Importantly, free fatty acids have been shown 
to prevent plasmin activation, leading to fibrin accumulation. ${ }^{129}$ Therefore, the hepatic inflammation not blocked by DGAT2 could be owing to inhibition of fibrinolysis due to elevated fatty acids under those conditions. Therefore, it may be possible that therapies that block both steatosis and inflammation are doing so by attenuating fibrin accumulation and steatosis simultaneously. Further studies should be designed to test this hypothesis that the development of steatosis and fibrin-induced hepatic sensitization are occurring in parallel. 
Figure 6.1: The involvement of other organs and cell types in causing ALD.

This scheme illustrates the involvement of a multitude of different cell types and organs in the development of ALD. This figure was modified from Froh et al. ${ }^{125}$ 


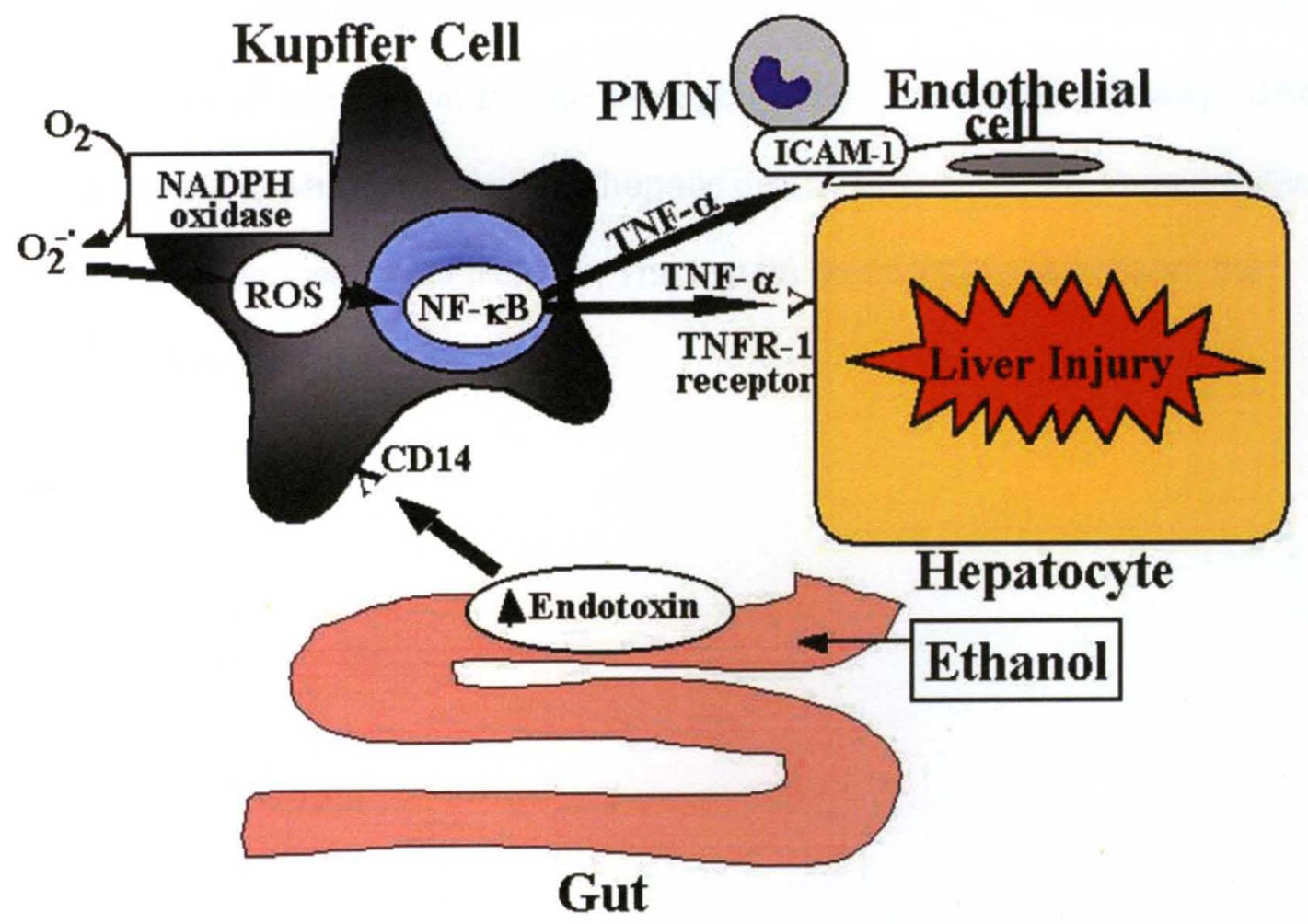


Figure 6.2: Working hypothesis by which PKC $\varepsilon$ causes ethanol-induced steaosis

The increase in the pyridine nucleotide redox state caused by ethanol metabolism inhibits the $\beta$-oxidation of free-fatty acids (FFA). This increase in FFA leads to an increase in the flux through the DAG synthesis pathway. DAG activates PKCE, which then causes hepatic insulin resistance, by impairing the tyrosine phosphorylation of IRS1/2. The insulin resistance exacerbates the hepatic steatosis caused by ethanol. 


\section{Working Hypothesis}

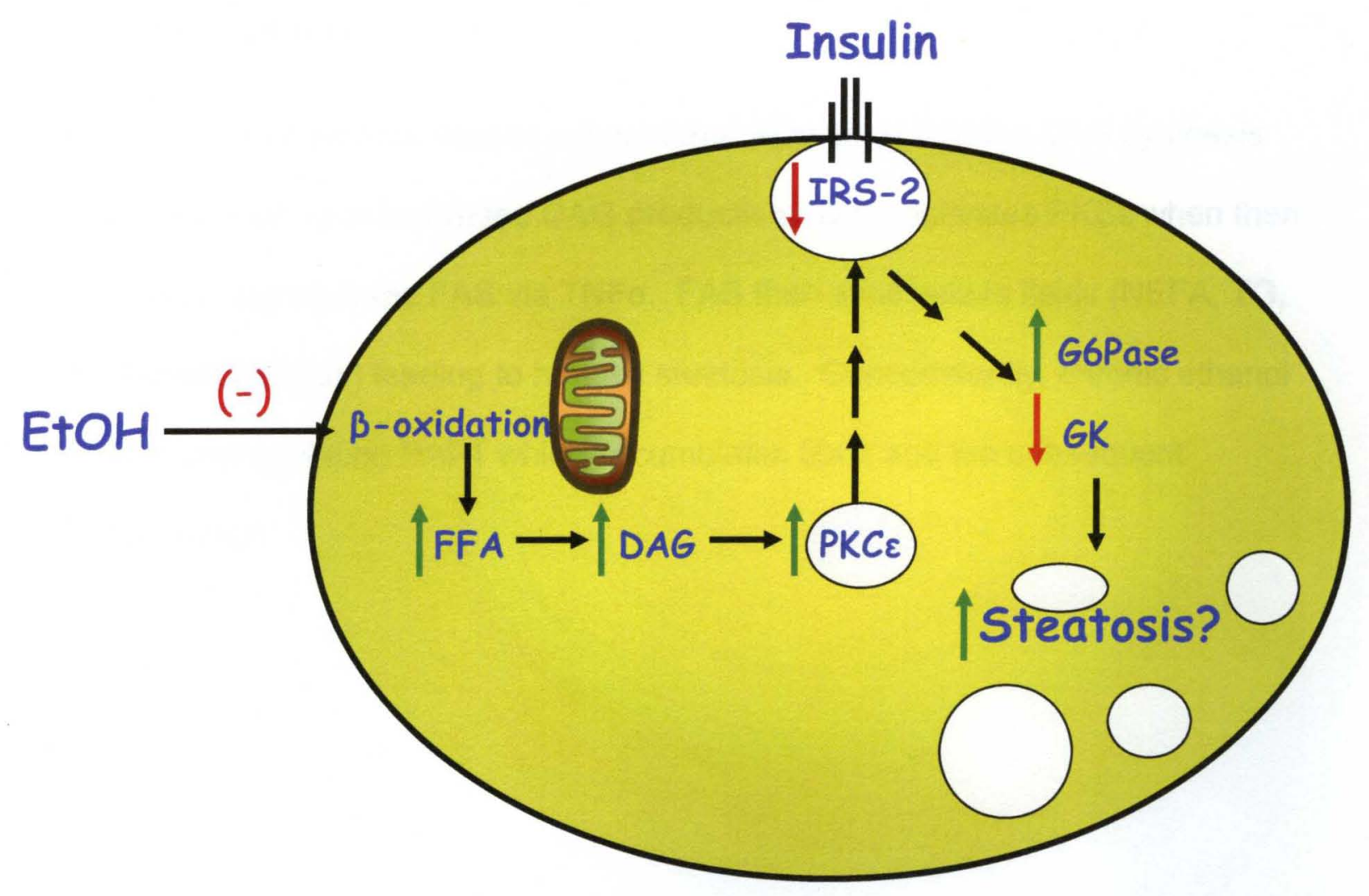


Figure 6.3: The working hypothesis by which PKCE plays a critical role in hepatic steatosis but not inflammation or necrosis owing to chronic ethanol exposure

Chronic ethanol causes a flux of free fatty acids into the DAG synthesis pathway, leading to increased DAG production. DAG activates $P K C \varepsilon$ when then indirectly upgregulates FAS via TNFa. FAS then synthesizes lipids (NEFA, TG, and phospholipids) leading to hepatic steatosis. Concomitantly, chronic ethanol is also upgregulating PAl-1 which accumulates fibrin and the subsequent inflammation. 


\section{Working Hypothesis}

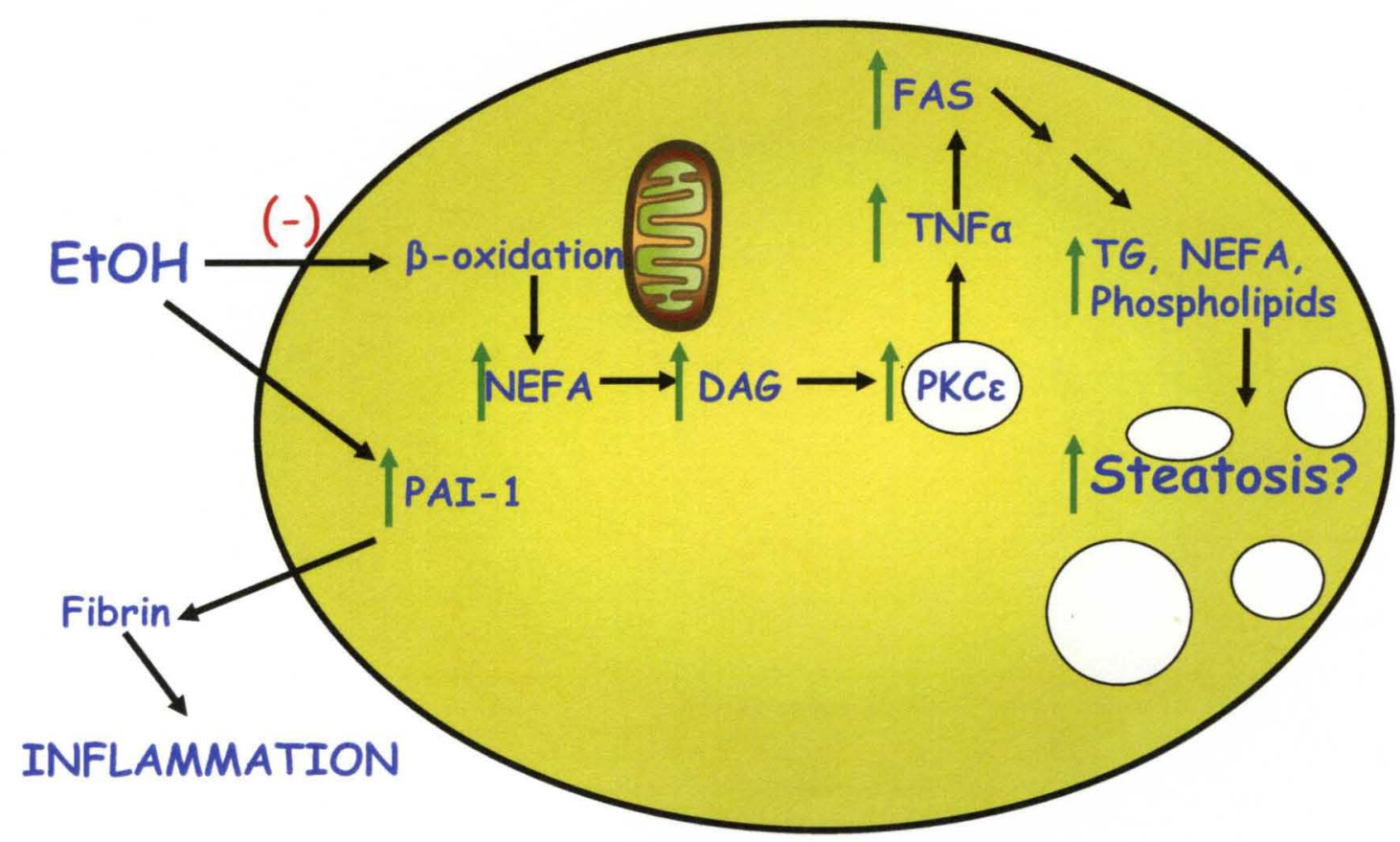


Figure 6.4: The proposed mechanism by which $\mathrm{PKC} \varepsilon$ causes $\mathrm{CCl}_{4}$-induced hepatic fibrosis

$\mathrm{CCl}_{4}$ causes fibrosis by first activating PKCE. PKCE subsequently upregulates the expression TGF $\beta 1$, the major fibrogenic cytokine in the liver. TGF $\beta 1$ then activates hepatic stellate cells, which then increases fibrogenesis and impairs fibrinolysis (via PAI-1). 


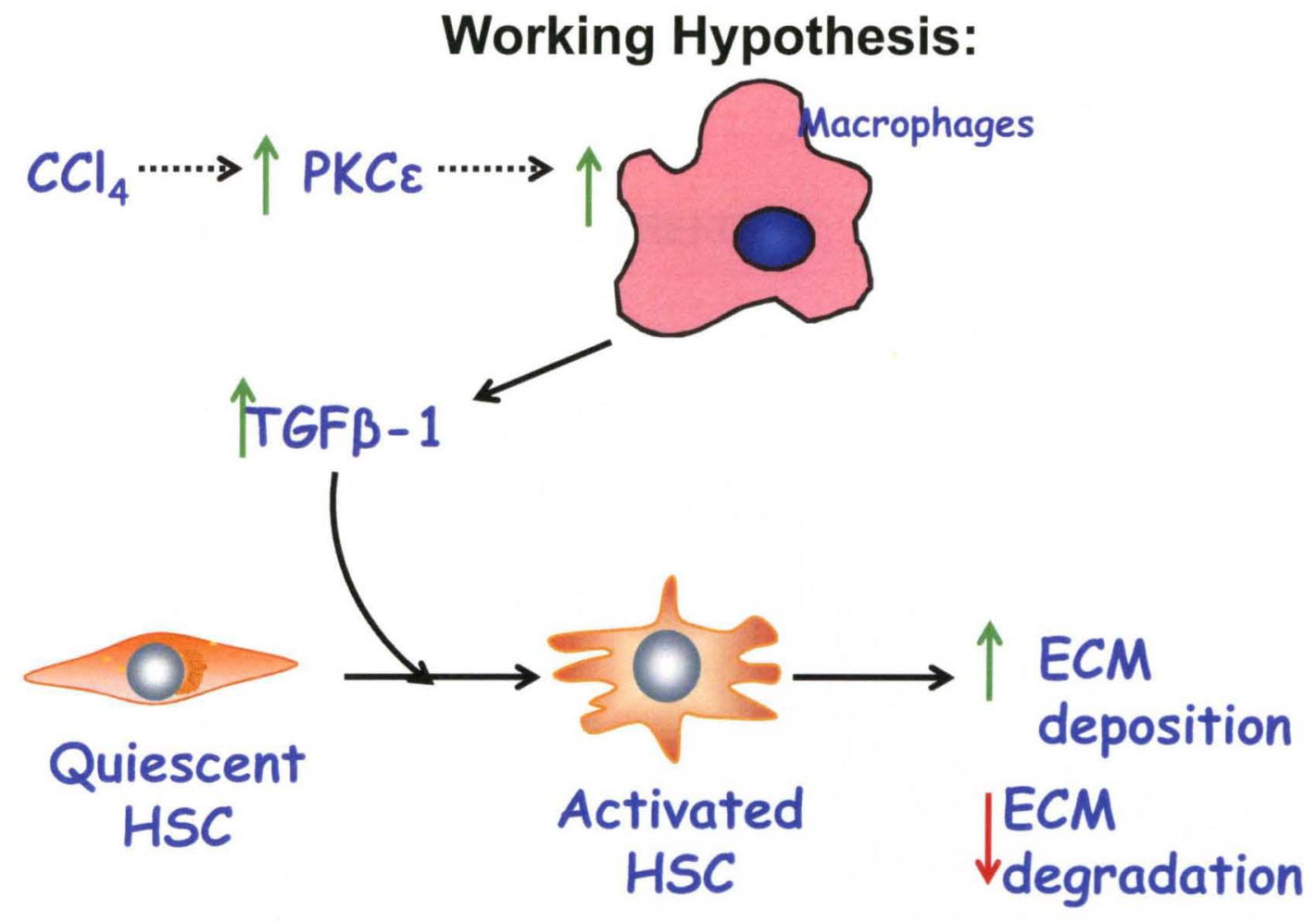


REFERENCES 
1. Grant BF, Dufour MC, Harford TC. Epidemiology of alcoholic liver disease. Semin Liver Dis 1988;8:12-25.

2. Diehl AM. Alcoholic Liver Disease. Med Clin North Am 1989;73:815-830.

3. NIAAA/NIDA. The economic costs of alcohol and drug abuse in the United States: 1992. NIAAA/NIDA News Release 1998.

4. Bergheim I, McClain CJ, Arteel GE. Treatment of alcoholic liver disease. Dig Dis 2005;23:275-284.

5. Merkel C, Marchesini G, Fabbri A, Bianco S, Bianchi G, Enzo E, Sacerdoti $D$, Zoli M, Gatta A. The course of galactose elimination capacity in patients with alcoholic cirrhosis: possible use as a surrogate marker for death. Hepatology 1996;24:820-823.

6. Desmet VJ. Alcoholic liver disease. Histological features and evolution. Acta Med Scand Suppl 1985;703:111-26.:111-126.

7. MacSween RN, Burt AD. Histologic spectrum of alcoholic liver disease. Semin Liver Dis 1986;6:221-232.

8. Ishak KG, Zimmerman HJ, Ray MB. Alcoholic liver disease: pathologic, pathogenetic and clinical aspects. Alcohol Clin Exp Res 1991;15:45-66.

9. Day CP, James OF. Hepatic steatosis: innocent bystander or guilty party? Hepatology 1998;27:1463-1466.

10. Sorensen TI, Orholm M, Bentsen KD, Hoybye G, Eghoje K, Christoffersen $P$. Prospective evaluation of alcohol abuse and alcoholic liver injury in men as predictors of development of cirrhosis. Lancet 1984;2:241-244.

11. Teli MR, Day CP, Burt AD, Bennett MK, James OF. Determinants of progression to cirrhosis or fibrosis in pure alcoholic fatty liver. Lancet 1995;346:987-990.

12. Ontko JA. Effects of ethanol on the metabolism of free fatty acids in isolated liver cells. J Lipid Res 1973;14:78-86.

13. Kono H, Rusyn I, Yin M, Gabele E, Yamashina S, Dikalova A, Kadiiska MB, Connor HD, Mason RP, Segal BH, Bradford BU, Holland SM, Thurman RG. NADPH oxidase-derived free radicals are key oxidants in alcohol-induced liver disease. J Clin Invest 2000;106:867-872.

14. McKim SE, Gabele E, Isayama F, Lambert JC, Tucker LM, Wheeler MD, Connor HD, Mason RP, Doll MA, Hein DW, Arteel GE. Inducible nitric oxide synthase is required in alcohol-induced liver injury: studies with knockout mice. Gastroenterology 2003;125:1834-1844. 
15. Yin M, Bradford BU, Wheeler MD, Uesugi T, Froh M, Goyert SM, Thurman RG. Reduced early alcohol-induced liver injury in cd14-deficient mice. J Immunol 2001;166:4737-4742.

16. Uesugi T, Froh M, Arteel GE, Bradford BU, Thurman RG. Toll-like receptor 4 is involved in the mechanism of early alcohol- induced liver injury in mice. Hepatology 2001;34:101-108.

17. Uesugi T, Froh M, Arteel GE, Bradford BU, Wheeler MD, Gabele E, Isayama $F$, Thurman RG. Role of lipopolysaccharide-binding protein in early alcohol-induced liver injury in mice. J Immunol 2002;168:2963-2969.

18. Petersen KF, Shulman GI. Etiology of insulin resistance. Am J Med 2006;119:S10-S16.

19. Onishi $Y$, Honda $M$, Ogihara $T$, Sakoda $H$, Anai M, Fujishiro $M$, Ono H, Shojima N, Fukushima Y, Inukai K, Katagiri H, Kikuchi M, Oka Y, Asano T. Ethanol feeding induces insulin resistance with enhanced PI 3-kinase activation. Biochem Biophys Res Commun 2003;303:788-794.

20. Day CP. Genes or environment to determine alcoholic liver disease and non-alcoholic fatty liver disease. Liver Int 2006;26:1021-1028.

21. Bergheim I, Guo L, Davis MA, Lambert JC, Beier JI, Duveau I, Luyendyk JP, Roth RA, Arteel GE. Metformin prevents alcohol-induced liver injury in the mouse: Critical role of plasminogen activator inhibitor-1. Gastroenterology 2006;130:2099-2112.

22. Hill DB, Kugelmas M. Alcoholic liver disease. Treatment strategies for the potentially reversible stages. Postgrad Med 1998;103:261-8, 273.

23. Ramaiah S, Rivera C, Arteel G. Early-phase alcoholic liver disease: an update on animal models, pathology, and pathogenesis. Int J Toxicol 2004;23:217-231.

24. Diehl AM. Liver disease in alcohol abusers: clinical perspective. Alcohol 2002;27:7-11.

25. Galambos JT. Natural history of alcoholic hepatitis. 3. Histological changes. Gastroenterology 1972;63:1026-1035.

26. Colell A, Garcia-Ruiz C, Miranda M, Ardite E, Mari M, Morales A, Corrales F, Kaplowitz N, Fernandez-Checa JC. Selective glutathione depletion of mitochondria by ethanol sensitizes hepatocytes to tumor necrosis factor. Gastroenterology 1998;115:1541-1551. 
27. Yang SQ, Lin HZ, Lane MD, Clemens $M$, Diehl AM. Obesity increases sensitivity to endotoxin liver injury: implications for the pathogenesis of steatohepatitis. Proc Natl Acad Sci U S A 1997;94:2557-2562.

28. Teli MR, Day CP, Burt AD, Bennett MK, James OF. Determinants of progression to cirrhosis or fibrosis in pure alcoholic fatty liver. Lancet 1995;346:987-990.

29. Everett L, Galli A, Crabb D. The role of hepatic peroxisome proliferatoractivated receptors (PPARs) in health and disease. Liver 2000;20:191199.

30. Fischer M, You M, Matsumoto M, Crabb DW. Peroxisome proliferatoractivated receptor alpha (PPARalpha) agonist treatment reverses PPARalpha dysfunction and abnormalities in hepatic lipid metabolism in ethanol-fed mice. J Biol Chem 2003;278:27997-28004.

31. Galli A, Pinaire J, Fischer M, Dorris R, Crabb DW. The transcriptional and DNA binding activity of peroxisome proliferator-activated receptor alpha is inhibited by ethanol metabolism. A novel mechanism for the development of ethanol-induced fatty liver. J Biol Chem 2001;276:68-75.

32. Pastorino JG, Hoek JB. Ethanol potentiates tumor necrosis factor-alpha cytotoxicity in hepatoma cells and primary rat hepatocytes by promoting induction of the mitochondrial permeability transition. Hepatology 2000;31:1141-1152.

33. Liu H, Jones BE, Bradham C, Czaja MJ. Increased cytochrome P-450 2E1 expression sensitizes hepatocytes to c-Jun-mediated cell death from TNFalpha. Am J Physiol Gastrointest Liver Physiol 2002;282:G257-G266.

34. Deaciuc IV, Fortunato F, D'Souza NB, Hill DB, Schmidt J, Lee EY, McClain CJ. Modulation of caspase-3 activity and Fas ligand mRNA expression in rat liver cells in vivo by alcohol and lipopolysaccharide. Alcohol Clin Exp Res 1999;23:349-356.

35. McClain $\mathrm{CJ}$, Cohen DA. Increased tumor necrosis factor production by monocytes in alcoholic hepatitis. Hepatology 1989;9:349-351.

36. Hill DB, Marsano L, Cohen D, Allen J, Shedlofsky S, McClain CJ. Increased plasma interleukin-6 concentrations in alcoholic hepatitis. J Lab Clin Med 1992;119:547-552.

37. Hill DB, Marsano LS, McClain CJ. Increased plasma interleukin-8 concentrations in alcoholic hepatitis. Hepatology 1993;18:576-580. 
38. Devalaraja MN, McClain CJ, Barve S, Vaddi K, Hill DB. Increased monocyte MCP-1 production in acute alcoholic hepatitis. Cytokine 1999;11:875-881.

39. McClain CJ, Hill DB, Song Z, Deaciuc I, Barve S. Monocyte activation in alcoholic liver disease. Alcohol 2002;27:53-61.

40. Koop DR, Klopfenstein B, limuro Y, Thurman RG. Gadolinium chloride blocks alcohol-dependent liver toxicity in rats treated chronically with intragastric alcohol despite the induction of CYP2E1. Mol Pharmacol 1997;51:944-950.

41. Yin M, Wheeler MD, Kono H, Bradford BU, Gallucci RM, Luster MI, Thurman RG. Essential role of tumor necrosis factor a in alcohol-induced liver injury. Gastroenterology 1999;117:942-952.

42. Friedman SL. Mechanisms of hepatic fibrogenesis. Gastroenterology 2008;134:1655-1669.

43. Poynard T, McHutchison J, Manns M, Trepo C, Lindsay K, Goodman Z, Ling $\mathrm{MH}$, Albrecht $\mathrm{J}$. Impact of pegylated interferon alfa- $2 \mathrm{~b}$ and ribavirin on liver fibrosis in patients with chronic hepatitis C. Gastroenterology 2002;122:1303-1313.

44. Jochum W, Passegue E, Wagner EF. AP-1 in mouse development and tumorigenesis. Oncogene 2001;20:2401-2412.

45. Arthur MJ. Fibrogenesis II. Metalloproteinases and their inhibitors in liver fibrosis. Am J Physiol Gastrointest Liver Physiol 2000;279:G245-G249.

46. Parsons CJ, Bradford BU, Pan CQ, Cheung E, Schauer M, Knorr A, Krebs B, Kraft S, Zahn S, Brocks B, Feirt N, Mei B, Cho MS, Ramamoorthi R, Roldan G, Ng P, Lum P, Hirth-Dietrich C, Tomkinson A, Brenner DA. Antifibrotic effects of a tissue inhibitor of metalloproteinase-1 antibody on established liver fibrosis in rats. Hepatology 2004;40:1106-1115.

47. Liotta LA, Goldfarb RH, Brundage R, Siegal GP, Terranova V, Garbisa S. Effect of plasminogen activator (urokinase), plasmin, and thrombin on glycoprotein and collagenous components of basement membrane. Cancer Res 1981;41:4629-4636.

48. Mackay AR, Corbitt RH, Hartzler JL, Thorgeirsson UP. Basement membrane type IV collagen degradation: evidence for the involvement of a proteolytic cascade independent of metalloproteinases. Cancer Res 1990;50:5997-6001.

49. Mochan E, Keler T. Plasmin degradation of cartilage proteoglycan. Biochim Biophys Acta 1984;800:312-315. 
50. Ramos-DeSimone N, Hahn-Dantona E, Sipley J, Nagase H, French DL, Quigley JP. Activation of matrix metalloproteinase-9 (MMP-9) via a converging plasmin/stromelysin-1 cascade enhances tumor cell invasion. J Biol Chem 1999;274:13066-13076.

51. Bergheim I, Guo L, Davis MA, Duveau I, Arteel GE. Critical role of plasminogen activator inhibitor-1 in cholestatic liver injury and fibrosis. $J$ Pharmacol Exp Ther 2006;316:592-600.

52. Kim WR, Brown RS, Jr., Terrault NA, El Serag H. Burden of liver disease in the United States: summary of a workshop. Hepatology 2002;36:227242.

53. La Vecchia C, Negri E, D'Avanzo B, Boyle P, Franceschi S. Medical history and primary liver cancer. Cancer Res 1990;50:6274-6277.

54. Gogel BM, Goldstein RM, Kuhn JA, McCarty TM, Donahoe A, Glastad K. Diagnostic evaluation of hepatocellular carcinoma in a cirrhotic liver. Oncology (Williston Park) 2000;14:15-20.

55. Mellor $\mathrm{H}$, Parker PJ. The extended protein kinase $\mathrm{C}$ superfamily. Biochem J 1998;332:281-292.

56. Nishizuka $Y$. Protein kinase $\mathrm{C}$ and lipid signaling for sustained cellular responses. FASEB J 1995;9:484-496.

57. Kikkawa U, Ogita K, Go M, Nomura H, Kitano T, Hashimoto T, Ase K, Sekiguchi K, Koumoto J, Nishizuka Y, . Protein kinase C in transmembrane signaling. Adv Second Messenger Phosphoprotein Res 1988;21:67-74.:67-74.

58. Sampson SR, Cooper DR. Specific protein kinase C isoforms as transducers and modulators of insulin signaling. Mol Genet Metab 2006;89:32-47.

59. Akita Y. Protein kinase C-epsilon (PKC-epsilon): its unique structure and function. J Biochem 2002;132:847-852.

60. Castrillo A, Pennington DJ, Otto F, Parker PJ, Owen MJ, Bosca L. Protein kinase Cepsilon is required for macrophage activation and defense against bacterial infection. J Exp Med 2001;194:1231-1242.

61. Inagaki K, Koyanagi T, Berry NC, Sun L, Mochly-Rosen D. Pharmacological inhibition of epsilon-protein kinase $C$ attenuates cardiac fibrosis and dysfunction in hypertension-induced heart failure. Hypertension 2008;51:1565-1569. 
62. Thurman RG, Bradford BU, limuro $Y$, Knecht KT, Arteel GE, Yin M, Connor HD, Wall C, Raleigh JA, Frankenberg Mv, Adachi Y, Forman DT, Brenner D, Kadiiska M, Mason RP. The role of gut-derived bacterial toxins and free radicals in alcohol- induced liver injury. J Gastroenterol Hepatol 1998;13 Suppl:S39-50:S39-50.

63. Tsukamoto H, French SW, Benson N, Delgado G, Rao GA, Larkin EC, Largman $\mathrm{C}$. Severe and progressive steatosis and focal necrosis in rat liver induced by continuous intragastric infusion of ethanol and low fat diet. Hepatology 1985;5:224-232.

64. Lieber CS, DeCarli LM. Liquid diet technique of ethanol administration: 1989 update. Alcohol Alcohol 1989;24:197-211.

65. Safadi R, Ohta M, Alvarez CE, Fiel MI, Bansal M, Mehal WZ, Friedman $\mathrm{SL}$. Immune stimulation of hepatic fibrogenesis by CD8 cells and attenuation by transgenic interleukin-10 from hepatocytes. Gastroenterology 2004;127:870-882.

66. Khasar SG, Lin YH, Martin A, Dadgar J, McMahon T, Wang D, Hundle B, Aley KO, Isenberg W, McCarter G, Green PG, Hodge CW, Levine JD, Messing RO. A novel nociceptor signaling pathway revealed in protein kinase C epsilon mutant mice. Neuron 1999;24:253-260.

67. Samuel VT, Liu ZX, Wang A, Beddow SA, Geisler JG, Kahn M, Zhang XM, Monia BP, Bhanot S, Shulman GI. Inhibition of protein kinase Cepsilon prevents hepatic insulin resistance in nonalcoholic fatty liver disease. J Clin Invest 2007;117:739-745.

68. Balafanova Z, Bolli R, Zhang J, Zheng Y, Pass JM, Bhatnagar A, Tang XL, Wang O, Cardwell E, Ping P. Nitric oxide (NO) induces nitration of protein kinase Cepsilon (PKCepsilon), facilitating PKCepsilon translocation via enhanced PKCepsilon -RACK2 interactions: a novel mechanism of notriggered activation of PKCepsilon. J Biol Chem 2002;277:15021-15027.

69. Bligh EG, Dyer WJ. A rapid method of total lipid extraction and purification. Can J Biochem Physiol 1959;37:911-917.

70. Callender HL, Forrester JS, Ivanova P, Preininger A, Milne S, Brown HA. Quantification of diacylglycerol species from cellular extracts by electrospray ionization mass spectrometry using a linear regression algorithm. Anal Chem 2007;79:263-272.

71. Guo L, Richardson KS, Tucker LM, Doll MA, Hein DW, Arteel GE. Role of the renin-angiotensin system in hepatic ischemia reperfusion injury in rats. Hepatology 2004;40:583-589. 
72. Kaidanovich-Beilin O, Eldar-Finkelman $\mathrm{H}$. Long-term treatment with novel glycogen synthase kinase-3 inhibitor improves glucose homeostasis in ob/ob mice: molecular characterization in liver and muscle. J Pharmacol Exp Ther 2006;316:17-24.

73. Rossetti L, Chen W, Hu M, Hawkins M, Barzilai N, Efrat S. Abnormal regulation of HGP by hyperglycemia in mice with a disrupted glucokinase allele. Am J Physiol 1997;273:E743-E750.

74. Thompson JA, Reitz RC. Effects of ethanol ingestion and dietary fat levels on mitochondrial lipids in male and female rats. Lipid 1978;13:540-550.

75. Morimoto $M$, Zern MA, Hagbjork AL, Ingelman-Sundberg M, French SW. Fish oil, alcohol, and liver pathology: role of cytochrome P4502E1. Proc Soc Exp Biol Med 1994;207:197-205.

76. Babcock DF, First NL, Lardy HA. Action of ionophore A23187 at the cellular level. J Biol Chem 1976;251:3881-3886.

77. Gujral JS, Liu J, Farhood A, Hinson JA, Jaeschke H. Functional importance of ICAM-1 in the mechanism of neutrophil-induced liver injury in bile duct-ligated mice. Am J Physiol Gastrointest Liver Physiol 2004;286:G499-G507.

78. Lopez-De Leon A, Rojkind M. A simple micromethod for collagen and total protein determination in formalin-fixed paraffin-embedded sections. $J$ Histochem Cytochem 1985;33:737-743.

79. Arteel GE, limuro Y, Yin M, Raleigh JA, Thurman RG. Chronic enteral ethanol treatment causes hypoxia in rat liver tissue in vivo. Hepatology 1997;25:920-926.

80. Lepage G, Roy CC. Direct transesterification of all classes of lipids in a one-step reaction. J Lipid Res 1986;27:114-120.

81. Adachi Y, Bradford BU, Gao W, Bojes HK, Thurman RG. Inactivation of Kupffer cells prevents early alcohol-induced liver injury. Hepatology 1994;20:453-460.

82. Bergmeyer HU. Methods of enzymatic analysis. New York: Academic Press, 1988.

83. Jiang $Y$, Liu J, Waalkes $M$, Kang YJ. Changes in the gene expression associated with carbon tetrachloride-induced liver fibrosis persist after cessation of dosing in mice. Toxicol Sci 2004;79:404-410. 
84. Sorensen TI, Orholm M, Bentsen KD, Hoybye G, Eghoje K, Christoffersen $P$. Prospective evaluation of alcohol abuse and alcoholic liver injury in men as predictors of development of cirrhosis. Lancet 1984;2:241-244.

85. Tremolieres J, Lowy R, Griffaton G. Metabolic effects of ethanol. Proc Nutr Soc 1972;31:107-115.

86. Samuel VT, Liu ZX, Qu X, Elder BD, Bilz S, Befroy D, Romanelli AJ, Shulman GI. Mechanism of hepatic insulin resistance in non-alcoholic fatty liver disease. J Biol Chem 2004;279:32345-32353.

87. Gregori C, Guillet-Deniau I, Girard J, Decaux JF, Pichard AL. Insulin regulation of glucokinase gene expression: evidence against a role for sterol regulatory element binding protein 1 in primary hepatocytes. FEBS Lett 2006;580:410-414.

88. Kuo M, Zilberfarb V, Gangneux N, Christeff N, Issad T. O-glycosylation of FoxO1 increases its transcriptional activity towards the glucose 6phosphatase gene. FEBS Lett 2008;582:829-834.

89. Williamson JR, Scholz R, Browning ET, Thurman RG, Fukami MH. Metabolic effects of ethanol in perfused rat liver. J Biol Chem 1969;244:5044-5054.

90. Rawat AK, Lundquist FN. Influence of thyroxine on the metabolism of ethanol and glycerol in rat liver slices. Eur J Biochem 1968;5:13-17.

91. Kaiser JP, Beier JI, Zhang J, David HJ, von Montfort C, Guo L, Zheng Y, Monia BP, Bhatnagar A, Arteel GE. PKCepsilon plays a causal role in acute ethanol-induced steatosis. Arch Biochem Biophys 2009;482:104111.

92. Aksoy E, Goldman M, Willems F. Protein kinase $C$ epsilon: a new target to control inflammation and immune-mediated disorders. Int J Biochem Cell Biol 2004;36:183-188.

93. Listenberger LL, Han X, Lewis SE, Cases S, Farese RV, Jr., Ory DS, Schaffer JE. Triglyceride accumulation protects against fatty acid-induced lipotoxicity. Proc Natl Acad Sci U S A 2003;100:3077-3082.

94. Muramatsu M, Kuriyama K, Yuki T, Ohkuma S. Hepatic lipogenesis and mobilization of peripheral fats in the formation of alcoholic fatty liver. Jpn J Pharmacol 1981;31:931-940.

95. Grunfeld C, Verdier JA, Neese R, Moser AH, Feingold KR. Mechanisms by which tumor necrosis factor stimulates hepatic fatty acid synthesis in vivo. J Lipid Res 1988;29:1327-1335. 
96. Luyendyk JP, Maddox JF, Green CD, Ganey PE, Roth RA. Role of hepatic fibrin in idiosyncrasy-like liver injury from lipopolysaccharide-ranitidine coexposure in rats. Hepatology 2004;40:1342-1351.

97. Beier JI, Luyendyk JP, Guo L, von Montfort C, Staunton DE, Arteel GE. Fibrin accumulation plays a critical role in the sensitization to lipopolysaccharide-induced liver injury caused by ethanol in mice. Hepatology 2009; in press.

98. Day CP, James OF. Steatohepatitis: a tale of two "hits"? Gastroenterology 1998;114:842-845.

99. Comalada M, Xaus J, Valledor AF, Lopez-Lopez C, Pennington DJ, Celada A. PKC epsilon is involved in JNK activation that mediates LPSinduced TNF-alpha, which induces apoptosis in macrophages. Am J Physiol Cell Physiol 2003;285:C1235-C1245.

100. Arteel GE. Oxidants and antioxidants in alcohol-induced liver disease. Gastroenterology 2003;124:778-790.

101. Yamaguchi K, Yang L, McCall S, Huang J, Yu XX, Pandey SK, Bhanot S, Monia BP, Li YX, Diehl AM. Inhibiting triglyceride synthesis improves hepatic steatosis but exacerbates liver damage and fibrosis in obese mice with nonalcoholic steatohepatitis. Hepatology 2007;45:1366-1374.

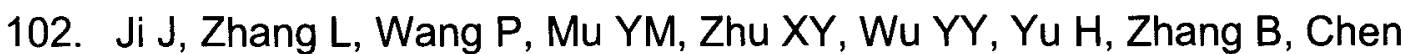
$S M$, Sun $X Z$. Saturated free fatty acid, palmitic acid, induces apoptosis in fetal hepatocytes in culture. Exp Toxicol Pathol 2005;56:369-376.

103. Wouters K, van Gorp PJ, Bieghs V, Gijbels MJ, Duimel H, Lutjohann D, Kerksiek A, van Kruchten R, Maeda N, Staels B, van Bilsen M, ShiriSverdlov R, Hofker MH. Dietary cholesterol, rather than liver steatosis, leads to hepatic inflammation in hyperlipidemic mouse models of nonalcoholic steatohepatitis. Hepatology 2008;48:474-486.

104. Fernandez A, Colell A, Garcia-Ruiz C, Fernandez-Checa JC. Cholesterol and sphingolipids in alcohol-induced liver injury. J Gastroenterol Hepatol 2008;23 Suppl 1:S9-15.:S9-15.

105. Shaw PJ, Fullerton AM, Scott MA, Ganey PE, Roth RA. The role of the hemostatic system in murine liver injury induced by coexposure to lipopolysaccharide and trovafloxacin, a drug with idiosyncratic liability. Toxicol Appl Pharmacol 2009;236:293-300.

106. Holdsworth SR, Thomson NM, Glasgow EF, Atkins RC. The effect of defibrination on macrophage participation in rabbit nephrotoxic nephritis: studies using glomerular culture and electronmicroscopy. Clin Exp Immunol 1979;37:38-43. 
107. Loike JD, el Khoury J, Cao L, Richards CP, Rascoff H, Mandeville JT, Maxfield FR, Silverstein SC. Fibrin regulates neutrophil migration in response to interleukin 8 , leukotriene $\mathrm{B} 4$, tumor necrosis factor, and formyl-methionyl-leucyl-phenylalanine. J Exp Med 1995;181:1763-1772.

108. Lotersztajn S, Julien B, Teixeira-Clerc F, Grenard P, Mallat A. Hepatic fibrosis: molecular mechanisms and drug targets. Annu Rev Pharmacol Toxicol 2005;45:605-28.:605-628.

109. Jeong DH, Lee SJ, Lee JH, Bae IH, Jeong KS, Jang JJ, Lim IK, Kim MR, Lee MJ, Lee YS. Subcellular redistribution of protein kinase $C$ isozymes is associated with rat liver cirrhotic changes induced by carbon tetrachloride or thioacetamide. J Gastroenterol Hepatol 2001;16:34-40.

110. Zhang LP, Takahara T, Yata Y, Furui K, Jin B, Kawada N, Watanabe A. Increased expression of plasminogen activator and plasminogen activator inhibitor during liver fibrogenesis of rats: role of stellate cells. J Hepatol 1999;31:703-711.

111. McCarty MF. De novo synthesis of diacylglycerol in endothelium may mediate the association between PAI-1 and the insulin resistance syndrome. Med Hypotheses 2005;64:388-393.

112. Kruithof EK. Plasminogen activator inhibitors--a review. Enzyme 1988;40:113-121.

113. Hewett JA, Roth RA. The coagulation system, but not circulating fibrinogen, contributes to liver injury in rats exposed to lipopolysaccharide from gram-negative bacteria. The Journal of Pharmacological and Experimental Therapeutics 1995;272:53-62.

114. Cichoz-Lach H, Celinski K, Slomka M, Kasztelan-Szczerbinska B. Pathophysiology of portal hypertension. J Physiol Pharmacol 2008;59 Suppl 2:231-8.:231-238.

115. Enomoto N, Ikejima K, Yamashina S, Enomoto A, Nishiura T, Nishimura T, Brenner DA, Schemmer P, Bradford BU, Rivera CA, Zhong Z, Thurman RG. Kupffer cell-derived prostaglandin $E(2)$ is involved in alcohol-induced fat accumulation in rat liver. Am J Physiol Gastrointest Liver Physiol 2000;279:G100-G106.

116. Bogatkevich GS, Tourkina E, Silver RM, Ludwicka-Bradley A. Thrombin differentiates normal lung fibroblasts to a myofibroblast phenotype via the proteolytically activated receptor-1 and a protein kinase C-dependent pathway. J Biol Chem 2001;276:45184-45192. 
117. Fujimoto M, Shimizu N, Kunii K, Martyn JA, Ueki K, Kaneki M. A role for iNOS in fasting hyperglycemia and impaired insulin signaling in the liver of obese diabetic mice. Diabetes 2005;54:1340-1348.

118. Wei Y, Whaley-Connell AT, Chen K, Habibi J, Uptergrove GM, Clark SE, Stump CS, Ferrario CM, Sowers JR. NADPH oxidase contributes to vascular inflammation, insulin resistance, and remodeling in the transgenic (mRen2) rat. Hypertension 2007;50:384-391.

119. Gupte P, Amarapurkar D, Agal S, Baijal R, Kulshrestha P, Pramanik S, Patel N, Madan A, Amarapurkar A, Hafeezunnisa. Non-alcoholic steatohepatitis in type 2 diabetes mellitus. J Gastroenterol Hepatol 2004;19:854-858.

120. Zein NN, Abdulkarim AS, Wiesner RH, Egan KS, Persing DH. Prevalence of diabetes mellitus in patients with end-stage liver cirrhosis due to hepatitis C, alcohol, or cholestatic disease. J Hepatol 2000;32:209-217.

121. Tolman KG, Fonseca V, Dalpiaz A, Tan MH. Spectrum of liver disease in type 2 diabetes and management of patients with diabetes and liver disease. Diabetes Care 2007;30:734-743.

122. Schaffalitzky de Muckadell OB, Mortensen $H$, Lyngsoe J. Metabolic effects of glucocorticoid and ethanol administration in phenformin- and metformintreated obese diabetics. Acta Med Scand 1979;206:269-273.

123. Dubas TC, Johnson WJ. Metformin-induced lactic acidosis: potentiation by ethanol. Res Commun Chem Pathol Pharmacol 1981;33:21-31.

124. Fausto $N$. Lessons from genetically engineered animal models. $V$. Knocking out genes to study liver regeneration: present and future. Am J Physiol 1999;277:G917-G921.

125. Froh M, Wheeler MD, Smutney O, Zhong Z, Bradford BU, Thurman RG. New method of delivering gene-altered Kupffer cells to rat liver: studies in an ischemia-reperfusion model. Gastroenterology 2003;124:172-183.

126. Luzina IG, Highsmith K, Pochetuhen K, Nacu N, Rao JN, Atamas SP. PKCalpha mediates CCL18-stimulated collagen production in pulmonary fibroblasts. Am J Respir Cell Mol Biol 2006;35:298-305.

127. Hanauske AR, Sundell $K$, Lahn $M$. The role of protein kinase $C$-alpha (PKC-alpha) in cancer and its modulation by the novel PKC-alpha-specific inhibitor aprinocarsen. Curr Pharm Des 2004;10:1923-1936.

128. Yang S, Lin H, Diehl AM. Fatty liver vulnerability to endotoxin-induced damage despite NF-kappaB induction and inhibited caspase 3 activation. Am J Physiol Gastrointest Liver Physiol 2001;281:G382-G392. 
129. Rabai G, Varadi B, Longstaff C, Sotonyi P, Kristof V, Timar F, Machovich $\mathrm{R}$, Kolev K. Fibrinolysis in a lipid environment: modulation through release of free fatty acids. J Thromb Haemost 2007;5:1265-1273. 
ABBREVIATIONS

aSMA

ALD

ALT

ASO

AST

CAE

$\mathrm{CCl}_{4}$

DAG

DGAT2

$\mathrm{EtOH}$

FAS

FFA

GK

G6Pase

$\mathrm{H}+\mathrm{E}$

IRS1/2

MMP-9

NAFLD

NEFA alpha smooth muscle actin

alcoholic liver disease

alanine aminotransferase

antisense oligonucleotide

aspartate aminotransferase

chloroacetate esterase

carbon tetrachloride

diacylglycerols

diacylglycerol acyltransferase 2

ethanol

fatty acid synthase

free fatty acids

glucokinase

glucose-6-phosphatase

hematoxylin and eosin

insulin receptor substrate $1 / 2$

metallomatrix proteinase 9

non alcoholic fatty liver disease

non esterified fatty acids 
PAl-1

PKC $\varepsilon$

TGF $\beta-1$

TNFa plasminogen activator inhibitor 1

protein kinase c-epsilon

transforming growth factor beta 1

tumor necrosis factor alpha 


\section{CURICCULUM VITAE}

\section{PERSONAL}

J. Phillip Kaiser

Born February 11, 1981; Louisville, Kentucky

Work Address:

Department of Pharmacology and Toxicology

University of Louisville Health Sciences Center

Louisville, KY 40292

Phone (502) 852-5157

Fax (502) 852-3242

Email 1pkais01@gwise.louisville.edu

\section{EDUCATION}

1998-1999 Bellarmine University, Louisville, KY

Completed Two Semesters during high school GPA: 3.0 
1999-2000 Jefferson Community College, Louisville, KY General Academics

GPA: 3.6

2000-2004 Texas A\&M University, Galveston, TX

B.S., Marine Science

GPA: 2.99

2004-2005 University of Louisville, Louisville, KY

General Academics

Post baccalaureate

GPA: 3.12

2005 -2007 University of Louisville School of Medicine,

Louisville, KY

M.S., Pharmacology and Toxicology

GPA: 3.24

2007-2009 University of Louisville School of Medicine

Louisville, KY

Ph.D., Pharmacology and Toxicology

\section{PROFESSIONAL EXPERIENCE}

2003-2004 Undergraduate independent researcher, Texas A\&M 
2005-present Graduate research assistant, University of Louisville

\section{HONORS}

1999 Jefferson Community College Scholarship,

1999, 2000 Dean's List, Jefferson Community College,

2001, 2002 National College Science Award,

2004 Dean's List, Texas A\&M,

2007 Presidential Poster of Distinction, AASLD,

2007 Ruth L. Kirschtein institutional predoctoral fellowship (T32),

2007 Ruth L. Kirschtein individual predoctoral fellowship (F31),

2009 Data selected to appear on cover of Archives of Biochemistry and Biophysics

2009 K.C. Huang Outstanding Graduate Student Award, University of Louisville School of Medicine

\section{PROFESSIONAL SOCIETIES}

2000-presentPhi Theta Kappa

2005-present Ohio Valley Chapter of the Society of Toxicology (OVSOT)

2007-present American Association for the Study of Liver Diseases (AASLD)

2007-2008 Graduate Student Council (University of Louisville)

2007-2008 Pharmacology/Toxicology Graduate Committee (University of Louisville)

2009-presentPharmacology/Toxicology Events Committee (University of Louisville) 
2009-presentUniversity of Louisville Alcohol Research Center

\section{BIBLIOGRAPHY}

1. Arteel GE, Guo L, Schlierf TJ, Beier JI, Kaiser JP, Chen TS, Liu M, Conklin DP, Miller HL, von Montfort C and States JC. (2008): Subhepatotoxic exposure to arsenic enhances lipopolysaccharideinduced liver injury in mice. Toxicology and Applied Pharmacology, 226:128-39.

2. von Montfort C, Beier JI, Guo L, Kaiser JP and Arteel GE. (2008): Preexposure to epinephrine enhances the inflammatory response to LPS and leads to liver damage in mice. American Journal of Physiology-GI and Liver Physiology, 294(5):G1227-34.

3. Beier JI, Guo L, von Montfort C, Kaiser JP, Joshi-Barve S and Arteel GE. (2008): Resistin enhances liver damage by lipopolysaccharide in mice. Journal of Pharmacology and Experimental Therapeutics Jun;325(3):801-8.

4. Kaiser JP, Beier JI, Zhang J, Hoetker JD, von Montfort C, Guo L, Zheng Y, Monia BP, Bhatnagar A, and Arteel GE. (2008): PKC $\varepsilon$ plays a causal role in acute ethanol-induced steatosis. Archives of Biochemistry and Biophysics, 482(1-2):104-11.

5. Kaiser JP, Luping Guo, Beier JI, Zhang J, Lesgards JF, Hoetker JD, Monia BP, Bhatnagar A, and Arteel GE. (2009): PKC $\varepsilon$ contributes to chronic ethanol-induced steatosis in mice but not inflammation and necrosis. Hepatology (submitted).

\section{PUBLISHED ABSTRACTS}

1. Kaiser JP, von Montfort C, Beier JI, Guo L, Zheng Y, Bhatnagar A, and Arteel GE (2007): PKCE plays a causal role in ethanol-induced steatosis. Hepatology 46:325A

2. Arteel GE, Miller HL, Chen TS, Guo L, Schlierf TJ, Beier JI, Kaiser JP, and States JC (2007): Arsenic at subhepatotoxic doses synergistically enhances lipopolysaccharide-induced liver injury in mice. Hepatology 46:463A

3. Kaiser JP, Beier JI, von Montfort C, Monia BP, and Arteel GE (2008): $\mathrm{PKC} \varepsilon$ plays a critical role in $\mathrm{CCl}_{4}$-induced hepatic fibrosis in mice. Hepatology 48:913A 


\section{UNPUBLISHED ABSTRACTS}

1. Kaiser JP, Davis MA, and Arteel GE (2006): Metformin prevents the downregulation of GK caused by ethanol; critical involvement in steatosis? Research! Louisville.

2. Kaiser JP, von Montfort C, Beier JI, Guo L, Zheng Y, Bhatnagar A, Arteel GE (2007): PKCE plays a causal role in ethanol-induced steatosis. Research! Louisville.

3. Arteel GE, Miller HL, Chen TS, Guo L, Schlierf TS, Beier JI, Kaiser JP, States JC (2007): Arsenic at subhepatotoxic doses synergistically enhances LPS-induced liver injury. Research! Louisville.

4. Kaiser JP, von Montfort C, Beier JI, Guo L, Zheng Y, Bhatnagar A, Arteel GE (2007): PKCE plays a causal role in ethanol-induced steatosis. James Graham Brown Cancer Center Retreat.

5. Arteel GE, Miller HL, Chen TS, Guo L, Schlierf TS, Beier JI, Kaiser JP, States JC (2007): Arsenic at subhepatotoxic doses synergistically enhances LPS-induced liver injury. James Graham Brown Cancer Center Retreat.

6. Kaiser JP, Beier JI, Guo L, von Montfort C, Monia BP, and Arteel GE (2008): PKCE plays a critical role in $\mathrm{CCl}_{4}$-induced hepatic fibrosis in mice. Research! Louisville.

7. Kaiser JP, Beier JI, Guo L, von Montfort C, Monia BP, and Arteel GE (2008): PKC $\varepsilon$ plays a critical role in $\mathrm{CCl}_{4}$-induced hepatic fibrosis in mice. James Graham Brown Cancer Center Retreat.

\section{PRESENTATIONS}

1. Research Seminar, 03/06, "The effects of acute ethanol exposure on hepatic glucose regulatory genes" University of Louisville, Seminar in Pharmacology and Toxicology, Louisville, KY. 
2. Poster Presentation, 10/06, "Metformin prevents the downregulation of GK caused by ethanol; critical involvement in steatosis?" University of Louisville, Research! Louisville, Louisville, KY.

3. Research Seminar, 05/07, "The role of PKC $\varepsilon$ in alcoholic liver disease" University of Louisville, Cytokines, Inflammation and Chemoprevention Group, Louisville, KY.

4. Oral master's exam, 05/07, "The role of PKCE in alcoholic liver disease" University of Louisville, Seminar in Pharmacology and Toxicology, Louisville, KY.

5. Poster Presentation, 10/07, "PKCE plays a causal role in ethanolinduced steatosis" University of Louisville, Research! Louisville, Louisville, KY.

6. Poster Presentation, 11/07, "PKCE plays a causal role in ethanolinduced steatosis" AASLD, Boston, MA.

7. Poster Presentation, 12/07, "PKCE plays a causal role in ethanolinduced steatosis" James Graham Brown Cancer Center Retreat, Louisville, KY.

8. Poster Presentation, $10 / 08$, "PKC $\varepsilon$ plays a critical role in $\mathrm{CCl}_{4}$-induced hepatic fibrosis in mice" Research! Louisville, Louisville, KY.

9. Poster Presentation, 10/08, "PKC $\varepsilon$ plays a critical role in $\mathrm{CCl}_{4}$-induced hepatic fibrosis in mice" James Graham Brown Cancer Center Retreat, Louisville, $\mathrm{KY}$.

10. Poster Presentation, 11/08, "PKC $\varepsilon$ plays a critical role in $\mathrm{CCl}_{4}$-induced hepatic fibrosis in mice" AASLD, San Francisco, CA.

11. Researcher Seminar, 04/09 "The role of PKCE in alcoholic liver disease" University of Louisville, University of Louisville Alcohol Research Center, Louisville, KY.

12. Researcher Seminar, 04/09 "The role of PKCE in alcoholic liver disease" Loyola University Medical Center Alcohol Research Program, Maywood, IL.

13. Researcher Seminar, 04/09 "The role of PKCE in alcoholic liver disease" Institute for Biochemistry and Molecular Biology I, Düsseldorf, Germany.

\section{FELLOWSHIPS}


Title: The role of PKCE in alcoholic liver disease; Agency: NIH (NIEHS); Type: Kirschtein institutional fellowship; Period: 09/01/2007-11/30/2007. Overall goals: Determine the role of $\mathrm{PKC} \varepsilon$ in the early stages of alcoholic liver disease. Responsibilities: $\mathrm{PI}$.

Title: The role of PKCE in alcoholic liver disease; Agency: NIH (NIAAA); Type: Kirschtein individual fellowship; Period: 01/01/2008-01/01/2010. Overall goals: Determine the role of $P K C \varepsilon$ in the early stages of alcoholic liver disease. Responsibilities: PI. 